Aus der Klinik für Hämatologie und Medizinische Onkologie (Prof. Dr. med. L. Trümper) der Medizinischen Fakultät der Universität Göttingen

\title{
Der natürliche Wnt-Antagonist SFRP4 in der Wachstumsregulation von diffusen großzelligen B-Zell-Lymphomen
}

\author{
INAUGURAL-DISSERTATION \\ zur Erlangung des Doktorgrades \\ der Medizinischen Fakultät der \\ Georg-August-Universität Göttingen
}

vorgelegt von

Anna Karen Cicholas

aus

Detmold

Göttingen 2015 
Dekan:

Prof. Dr. rer. nat. H. K. Kroemer

I. Berichterstatter: $\quad$ Prof. Dr. med. G. G. Wulf

II. Berichterstatter/in: $\quad$ Prof. Dr. rer. nat. H. D. Bastians

III. Berichterstatter/in:

Tag der mündlichen Prüfung: 27. April 2016 


\section{Inhaltsverzeichnis}

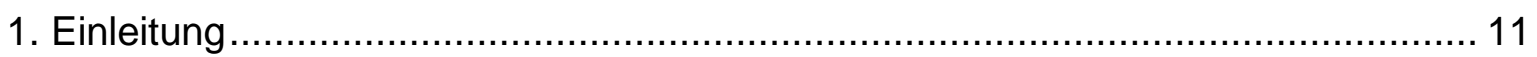

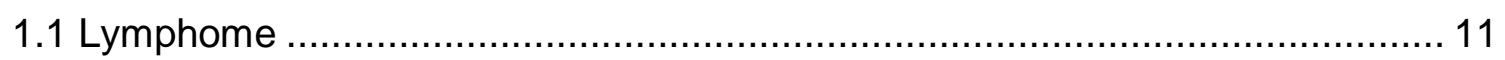

1.1.1 Diffuse großzellige B-Zell-Lymphome ….............................................. 11

1.1.2 Die Side Population in Lymphomen …………………....................... 13

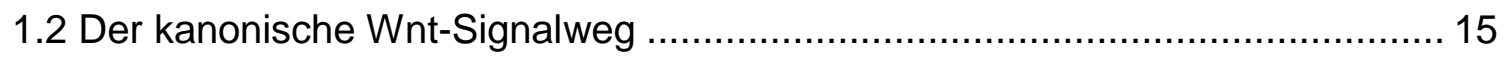

1.2.1 Die Bedeutung des kanonischen Wnt-Signalwegs für Malignome und Lymphozytenentwicklung ....................................................................... 17

1.2.2 Secreted frizzled-related protein 4 (SFRP4) ........................................ 18

1.3 Epigenetische Faktoren in der Tumorbiologie ............................................ 19

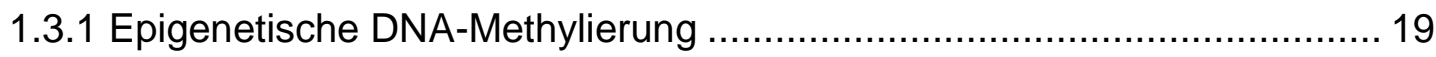

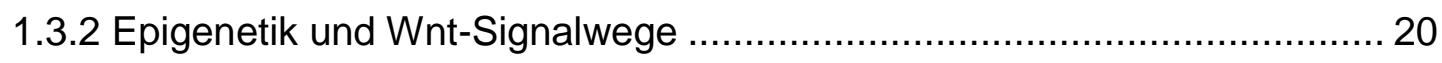

1.3.3 Modifikation der DNA-Methylierung mittels 5-Azacytidine …................... 21

1.4 Exosomen und Mikrovesikel zur interzellulären Kommunikation ...................... 22

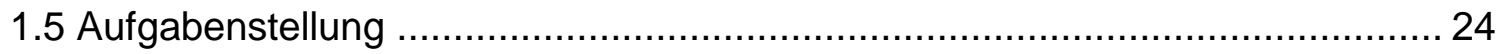

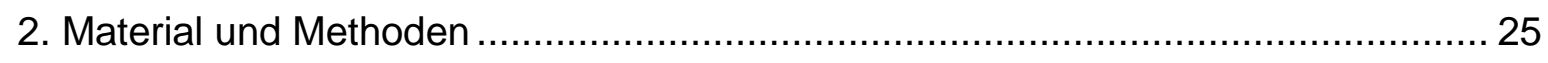

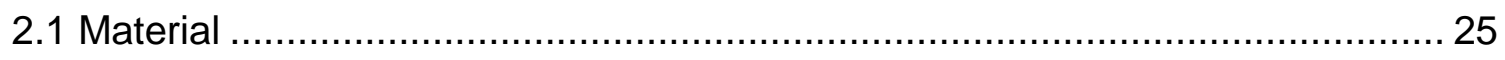

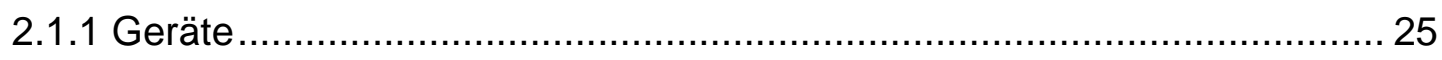

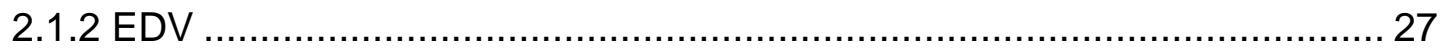

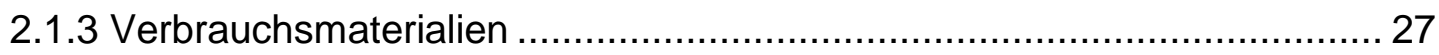

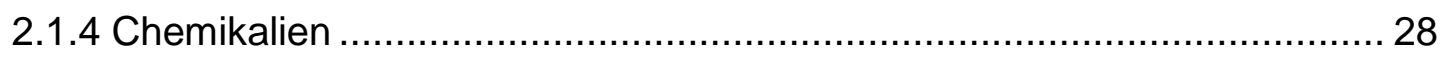

2.1.5 Gebräuchliche Puffer, Lösungen und Zellkulturmedien .......................... 30

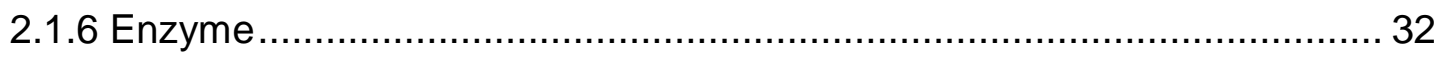

2.1.7 Kits zur Bearbeitung von RNA, DNA und Proteinen ................................. 32

2.1.8 Rekombinante Proteine, Proteaseinhibitoren und Proteinstandards ........ 33

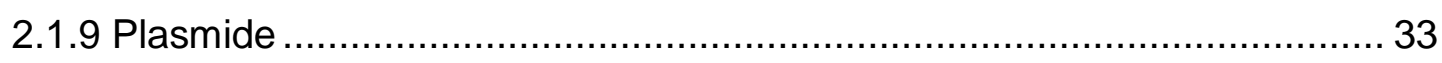

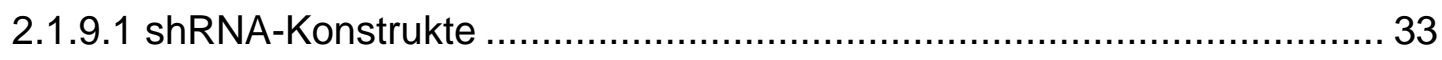




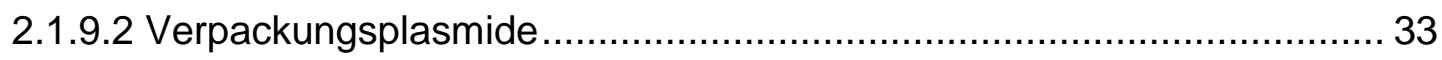

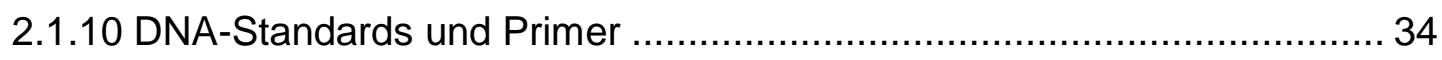

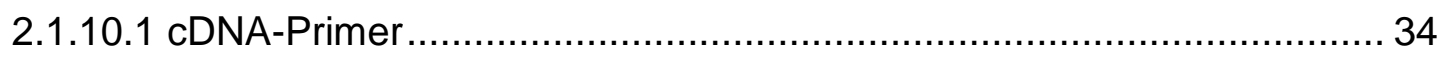

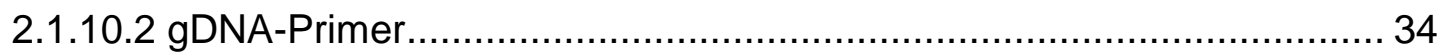

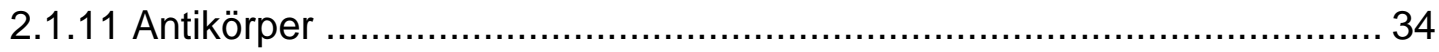

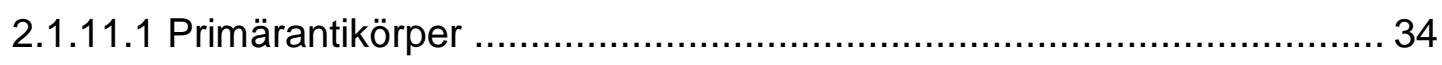

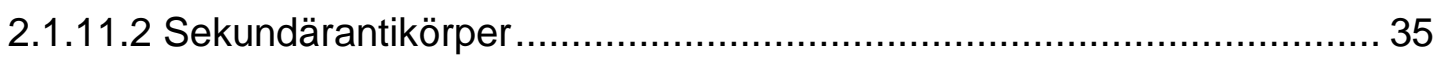

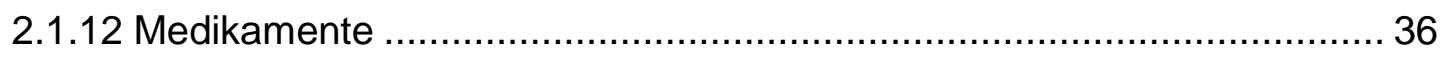

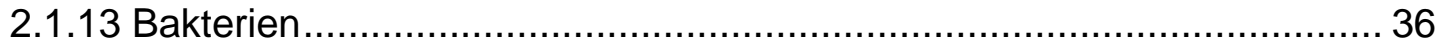

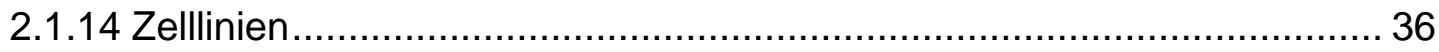

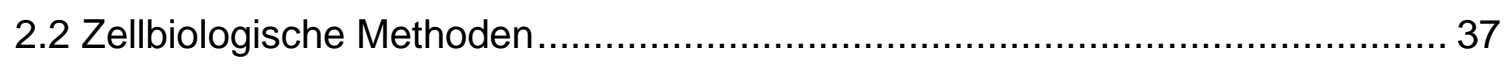

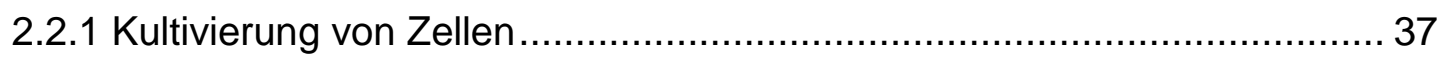

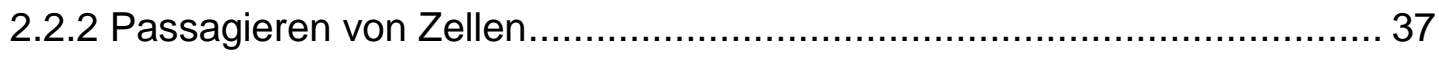

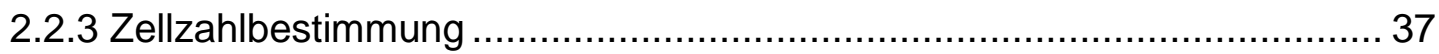

2.2.4 Bestimmung der Expansionskapazität ..................................................... 37

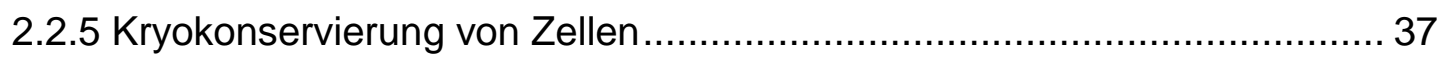

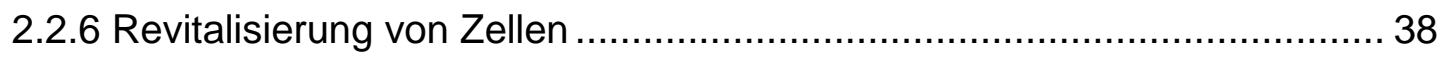

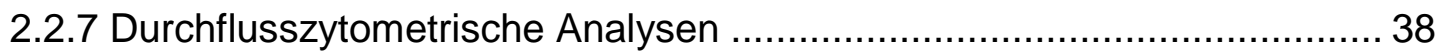

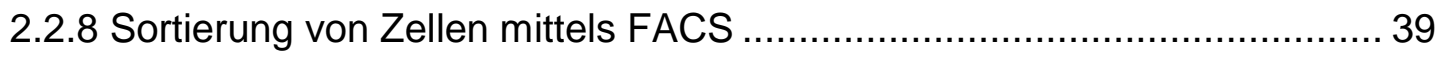

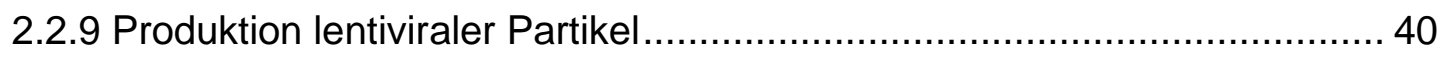

2.2.10 Lentivirale Transduktion der Zielzellen .................................................... 40

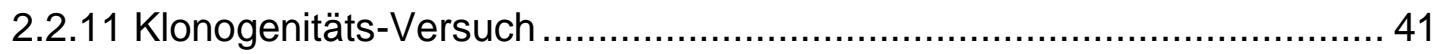

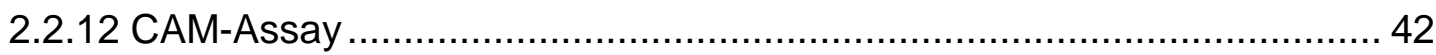

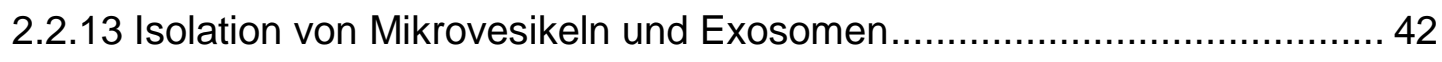

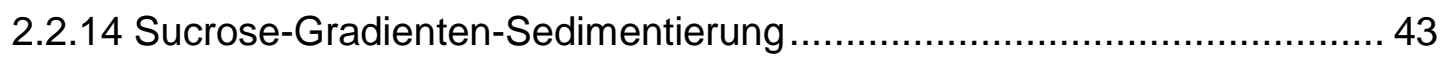

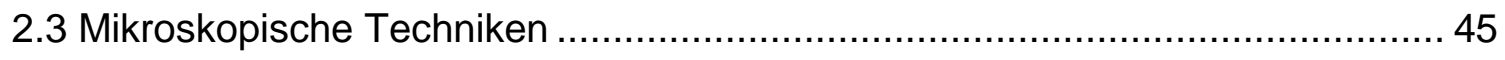

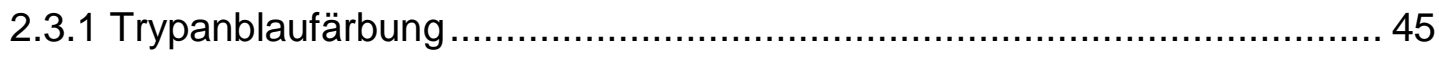

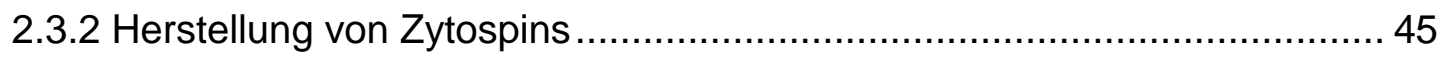

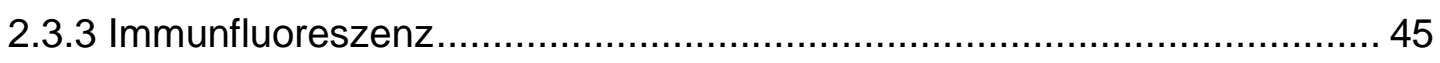




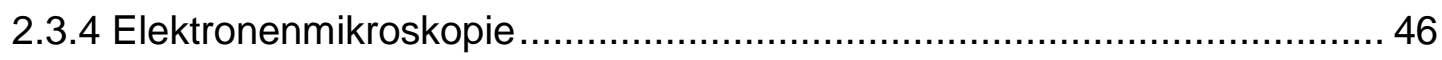

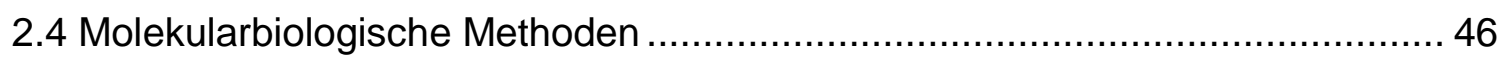

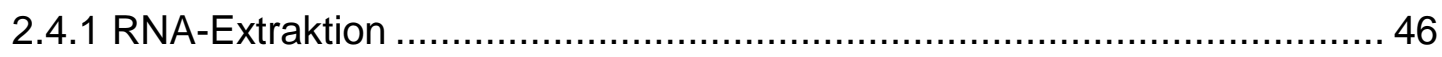

2.4.2 Reverse Transkription (cDNA-Synthese) …………................................ 47

2.4.3 Quantitative Realtime-PCR .............................................................. 48

2.4.4 Immunpräzipitation methylierter DNA ...................................................... 49

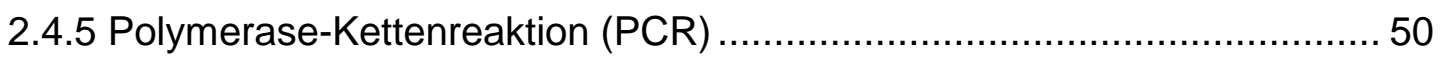

2.4.6 Auftrennen von DNA in Agarosegelen ............................................... 51

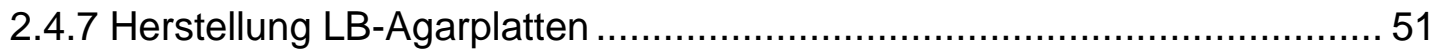

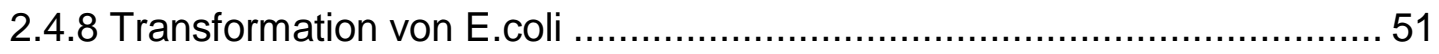

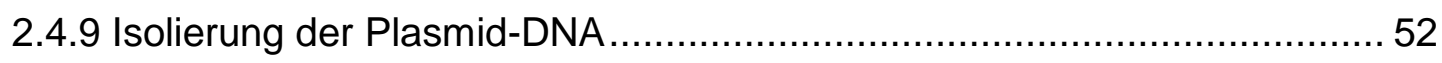

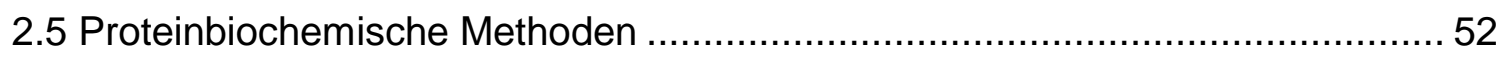

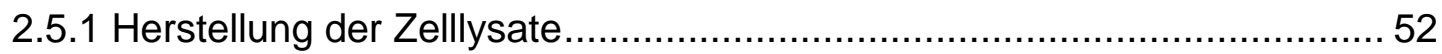

2.5.2 Bestimmung der Proteinkonzentration ................................................ 52

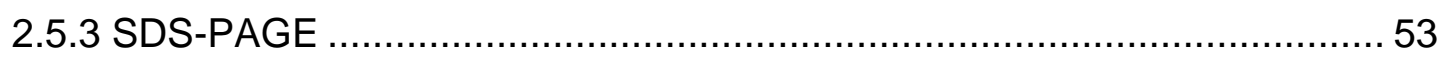

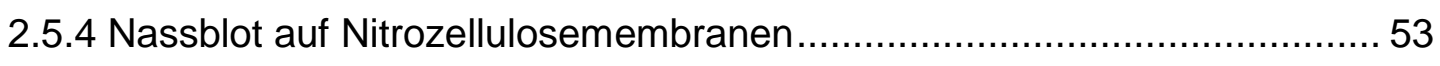

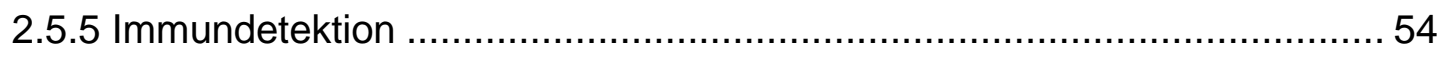

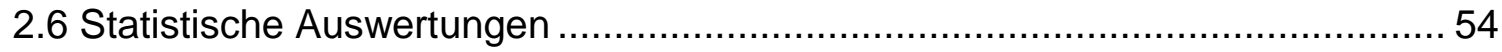

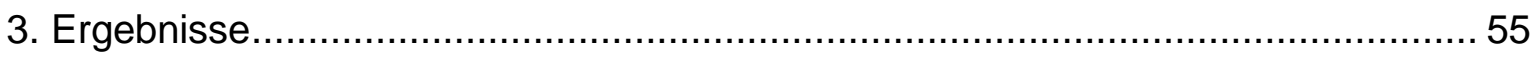

3.1 Vorkommen von SFRP4 in bovinem Serum ................................................ 55

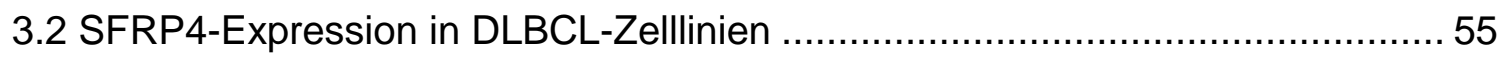

3.3 Differentielle Expression von SFRP4 in Side Population- und non-Side

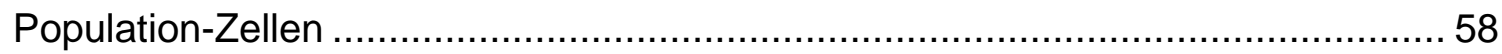

3.4 Funktionelle Analysen zur Wachstumsregulation von DLBCL-Zellen durch SFRP4 60

3.4.1 Funktionelle Untersuchungen mit rekombinantem humanen SFRP4 ....... 60

3.4.1.1 Expansionskapazität unter Behandlung mit rekombinantem humanen SFRP4 60

3.4.1.2 Wirkung von rekombinantem humanen SFRP4 auf zelluläres $\beta$-Catenin 
3.4.1.3 Expansionskapazität bei Co-Stimulation mit rhWnt3a und rhSFRP4.... 63 3.4.1.4 Beeinflussung der Side Population durch rekombinantes humanes SFRP4

3.4.2 Funktionelle Untersuchungen an SFRP4-expressionsreduzierten Zellen 65

3.4.2.1 Expansionskapazität von SFRP4-expressionsreduzierten Zellen 66

3.4.2.2 Effekt der SFRP4-Expressionsreduktion auf zelluläres $\beta$-Catenin. 66

3.4.2.3 Zellzyklus und Viabilität der Expressionsreduktion von SFRP4 in OCl-Ly1

3.4.2.4 Klonogenität der SFRP4-Expressionsreduktion und Antikörperbehandelter Zellen 68

3.4.2.5 Die Ausbildung einer Side Population unter SFRP4Expressionsreduktion.

3.4.2.6 In ovo-Passage von OCl-Ly1-Zellen nach SFRP4-Expressionsreduktion 70

3.4.2.7 Expansionskapazität von OCI-Ly3-Zellen unter Expressionsreduktion von Wnt3a. 71

3.5 Epigenetische Regulation der Expression von SFRP4 in DLBCL 72

3.5.1 Expansionskapazität und Klonogenität von DLBCL-Zellen unter 5-Azacytidine 74

3.5.2 Wirkung von 5-Azacytidine auf den kanonischen Wnt-Signalweg bei DLBCL-Zellen 76

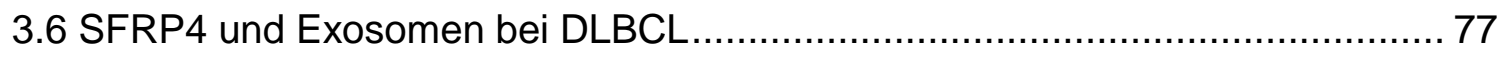

3.6.1 Wnt3a an der Oberfläche von Exosomen....................................... 77

3.6.2 Vorkommen von SFRP4 und Wnt3a in Mikrovesikel- und

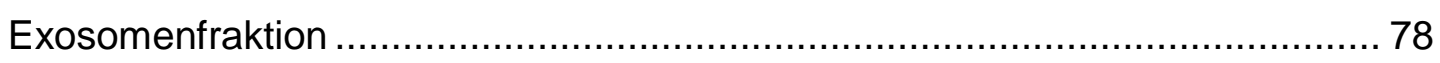

3.6.3 Stimulation mit Exosomen vergrößert Side Population .......................... 80

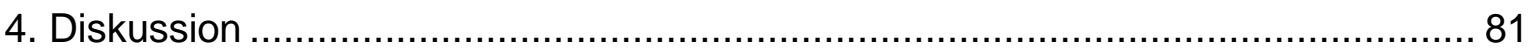

4.1 Vorkommen von SFRP4 in diffusen großzelligen B-Zell-Lymphomen .............. 81

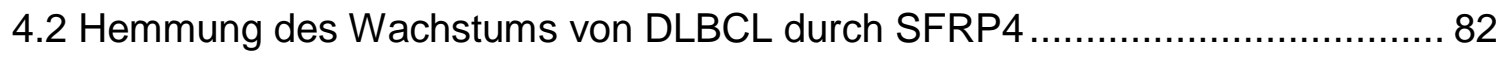

4.2.1 Hemmung der Expansionskapazität durch SFRP4 ........................... 82

4.2.2 Reduzierte Klonogenität durch SFRP4 …...................................... 82 
4.2.3 Beeinflussung des zellulären $\beta$-Catenins durch SFRP4

4.2.4 Veränderung der Proliferationseigenschaften durch Expressionsreduktion von SFRP4 84

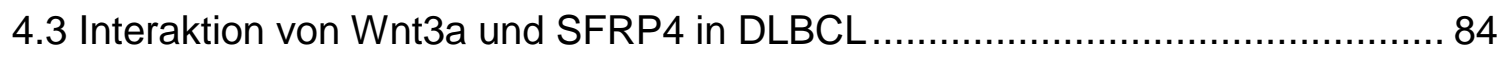

4.4 Die SFRP4-abhängige Regulation der Side Population in DLBCL .................. 86

4.4.1 Die exogene und endogene SFRP4-abhängige Beeinflussbarkeit des SPPhänotyps. 86

4.4.2 Die differentielle Expression und Promotormethylierung von SFRP4 in Side Population und non-Side Population 87

4.5 Einsatz des demethylierenden Medikamentes 5-Azacytidine bei DLBCL 88

4.6 Interzelluläre Kommunikation zwischen DLBCL-Zellen mittels SFRP4, Wnt3a und Exosomen..... 89

5. Zusammenfassung 91

6. Literaturverzeichnis 93 


\section{Abkürzungsverzeichnis}

$A B C$

ABC-DLBCL

AK

AML

APC

AUT

Bcl-6

bp

BSA

CAM

CD

CFU

$\mathrm{CH}$

$\mathrm{CHOP}$

CK1a

CLL

ctrl

d

DLBCL

DMEM

DMSO

DNA

DNMT

dNTP

DSMZ

DTT

FACS

FCS

fwd

GAPDH

GB
ATP-binding-cassette

activated B-cell like; Subtyp der DLBCL, der aus aktivierten post-Keimzentrums-B-Zellen hervorgeht

Antikörper

akute myeloische Leukämie

adenomatous-polyposis-coli-Protein

Österreich

B-cell lymphoma 6-Protein

Basenpaare

bovines Serumalbumin

Chorion-Allantois-Membran

Oberflächenmarker (cluster of differentiation)

colony forming units, siehe auch unter KBE

Schweiz

Chemotherapie-Schema bestehend aus Cyclophosphamid, Hydroxydaunorubicin (Doxorubicin), Vincristin (Oncovin $\AA$ ) und Predniso(lo)n

Casein-Kinase $1 \alpha$

chronische lymphatische Leukämie

control (Kontrolle)

$\operatorname{Tag}(\mathrm{e})$

Diffuse großzellige B-Zell-Lymphome (diffuse large B-cell lymphoma)

Dulbecco's Modified Eagle Medium

Dimethylsulfoxid

deoxyribonucleic acid (Desoxyribonukleinsäure)

DNA-Methyltransferase

Desoxyribonukleosidtriphosphat

Deutsche Sammlung von Mikroorganismen und Zellkulturen

Dithiothreitol

fluorescence-activated cell sorting; Gerät zur Zellsortierung mittels Durchflusszytometrie

fetales Kälberserum

vorwärts (forward)

Glycerinaldehyd-3-phosphat-Dehydrogenase

Großbritannien 
GCB-DLBCL

GER

GSK-3 $\beta$

$\mathrm{h}$

$\mathrm{HL}$

IMDM

$\mathrm{kb}$

KBE

LB

LEF

MDR

MDS

MeDIP

$\mathrm{MeOH}$

NFKB

mRNA

MTA

MVB

MYC

$\mathrm{NHL}$

$\mathrm{NL}$

nonSP

OCl-Ly1 scr

OCl-Ly1 shSFRP4

OCl-Ly3 scr

OCl-Ly3 shWnt3a

PAGE

PBS

PFA

PCR

PI germinal center B-cell like; Subtyp der DLBCL, der aus Keimzentrums-B-Zellen hervorgeht

Deutschland

Glykogensynthase-Kinase $3 \beta$

Stunde(n)

Hodgkin-Lymphome

Iscove's Modified Dulbecco's Medium

1000 Basenpaare

Koloniebildende Einheiten (colony forming units)

lysogeny broth

lymphocyte enhancer factor

Multidrogenresistenz

myelodysplastisches Syndrom

methylated DNA immunoprecipitation

Methanol

nuclear factor 'kappa-light-chain-enhancer' of activated Bcells

messenger RNA

Medizinisch-technische/r Assistent/in

multivesikuläre Körperchen

Myelocytomatose-Onkogen

Non-Hodgkin-Lymphome

Niederlande

non-Side Population

Bezeichnung für mittels lentiviraler Transduktion eines shRNA-Konstruktes erstellte OCI-Ly1-Zellen, die der Kontrolle dienen und keine veränderte Expression aufweisen sollen

Bezeichnung für mittels lentiviraler Transduktion eines shRNA-Konstruktes erstellte OCI-Ly1-Zellen, die eine reduzierte SFRP4-Expression aufweisen sollen

Bezeichnung für mittels lentiviraler Transduktion eines shRNA-Konstruktes erstellte OCl-Ly3-Zellen, die der Kontrolle dienen und keine veränderte Expression aufweisen sollen

Bezeichnung für mittels lentiviraler Transduktion eines shRNA-Konstruktes erstellte OCI-Ly3-Zellen, die eine reduzierte Wnt3a-Expression aufweisen sollen

Polyacrylamid-Gelelektrophorese

Phosphat-gepufferte Salzlösung (phosphate buffered saline)

Paraformaldehyd

Polymerase-Kettenreaktion

Propidiumiodid 


$\begin{array}{ll}\text { qRT-PCR } & \text { quantitative Realtime-PCR } \\ \text { rev } & \text { rückwärts (reverse) } \\ \text { rhSFRP4 } & \text { rekombinantes humanes SFRP4 } \\ \text { rhWnt3a } & \text { rekombinantes humanes Wnt3a } \\ \text { RISC } & \text { RNA-induzierter Silencing-Komplex } \\ \text { RNA } & \text { ribonucleic acid (Ribonukleinsäure) } \\ \text { rpm } & \text { Umdrehungen pro Minute (rounds per minute) } \\ \text { RPMI } & \text { Roswell Park Memorial Institute Medium } \\ \text { scr } & \text { scramble (zerstückelt, durcheinander gebracht) } \\ \text { SDS } & \text { sodium dodecyl sulfate } \\ \text { SE } & \text { Schweden } \\ \text { SFRP4 } & \text { secreted frizzled-related protein 4 } \\ \text { sh } & \text { small hairpin, im Zusammenhang mit Ribonukleinsäure, } \\ & \text { die eine Haarnadelstruktur bildet, verwendet } \\ \text { SP } & \text { Side Population } \\ \text { TBE } & \text { Tris-Borat-EDTA-Puffer } \\ \text { TBS } & \text { Tris-gepufferte Salzlösung (tris-buffered saline) } \\ \text { TBST } & \text { Tris-gepufferte Salzlösung mit Tween 20 } \\ \text { TCF } & \text { T-Zell-Faktor } \\ \text { TE-Puffer } & \text { Tris-EDTA-Puffer } \\ \text { Tris } & \text { Tris(hydroxymethyl)-aminomethan } \\ \text { v/v } & \text { Volumen pro Volumen } \\ \text { w/v } & \text { Masse pro Volumen } \\ & \end{array}$




\section{Einleitung}

\subsection{Lymphome}

Lymphome stellen eine heterogene Gruppe von Malignomen lymphatischen Ursprungs dar. Grundsätzlich unterschieden werden Non-Hodgkin-Lymphome (NHL) und Hodgkin-Lymphome (HL). Während sich $\mathrm{HL}$ charakteristischerweise durch Sternberg-Reed-Zellen auszeichnen, kommen diese bei NHL nicht vor. Der Großteil der NHL geht aus B-Lymphozyten hervor (80\%), während nur eine Minderheit von 20 \% T-lymphozytären Ursprungs ist (Taylor et al. 2013).

B-Zell-Lymphome entstehen, wenn die normale Regulation ihrer Zelldifferenzierung verloren geht und es zur Akkumulation von B-Zellen kommt, die in einem bestimmten Stadium ihrer Entwicklung arretieren. Lymphome können so anhand der Ähnlichkeit der entstandenen Tumorzellen zu dem entsprechenden normalen Entwicklungsstadium eingeteilt werden.

Die sehr heterogene Gruppe der Non-Hodgkin-Lymphome, die sich in Verlauf und Prognose erheblich unterscheiden, können nach ihrem klinischen Verlauf weiter unterteilt werden in indolente, langsam wachsende $\mathrm{NHL}$ und aggressive, schnell wachsende NHL. Die diffusen großzelligen B-Zell-Lymphome (engl.: diffuse large Bcell lymphoma (DLBCL)), die in dieser Arbeit untersucht wurden, gehören zu den aggressiven NHL (Baumgarten et al. 2013).

\subsubsection{Diffuse großzellige B-Zell-Lymphome}

Bei den diffusen großzelligen B-Zell-Lymphomen handelt es sich mit 30 - $40 \%$ um die häufigste Entität der Non-Hodgkin-Lymphome. Sie zeichnen sich durch einen aggressiven Krankheitsverlauf aus und verlaufen unbehandelt rasch tödlich. Das mittlere Erkrankungsalter liegt bei 70 Jahren (Smith et al. 2011). Das erste Zeichen der Erkrankung ist typischerweise eine Lymphadenopathie, in einem Teil der Fälle verbunden mit Fieber, Gewichtsverlust und nächtlichem Schwitzen (Freedman und Aster 2012). Neben primär nodalen werden auch primär extranodale Manifestationsformen beobachtet (Jehan et al. 2008).

Diffuse großzellige B-Zell-Lymphome entstehen meistens de novo durch maligne Transformation einer normalen B-Zelle und nur relativ selten sekundär aus einer indolenten malignen B-Zellerkrankung wie der CLL oder dem follikulären Lymphom (Horning und Rosenberg 1984; Nakamura und Abe 2003). Zur Lymphomgenese 
können sowohl Immunsuppression als auch chronische Entzündungen, wie sie bei Autoimmunerkrankungen vorkommen (Ponce et al. 2013), sowie verschiedene virale Infektionen wie HIV (Kaplan 2012), EBV (Ok et al. 2013) und Hepatitis C (PevelingOberhag et al. 2013) beitragen.

Diese heterogene Lymphom-Entität kann anhand ihres Genexpressionsmusters in molekulare Subtypen unterteilt werden, wie die ABC-DLBCL und die GCB-DLBCL (Alizadeh et al. 2000). Während GCB-DLBCL von den Keimzentrums-B-Zellen abstammen und eine vermehrte Expression von Bcl-6, einem Marker für Keimzentrums-B-Zellen (Staudt et al. 1999), zeigen, haben die ABC-DLBCL ihren Ursprung aus aktivierten post-Keimzentrums-B-Zellen und sind durch Aktivierung des NFkB-Signalwegs (Bavi et al. 2011) sowie des B-Zellrezeptorsignalwegs charakterisiert (Davis et al. 2010). Diese Einteilung besitzt prognostische Bedeutung, da für Patienten mit einem GCB-DLBCL bei gleichartiger Therapie signifikant bessere Überlebenswahrscheinlichkeiten bestehen (Alizadeh et al. 2000).

Neben der Genexpression der Tumorzellen erlangt die Mikroumgebung zunehmende Bedeutung. Als prognostisch günstig erwies sich eine intensive immunologische Reaktion durch infiltrierende Makrophagen und T-Lymphozyten sowie Genexpressionsmerkmale, assoziiert mit ausgeprägter extrazellulärer Matrix mit deutlich vorhandenen Ablagerungen und einer geringen Blutgefäßdichte (Lenz et al. 2008; Linderoth et al. 2008).

In DLBCL finden sich charakteristische Chromosomenaberrationen und Genmutationen (Dave et al. 2002). Ca. 30 \% der DLBCL zeigen eine Translokation von Bcl-6, einem Transkriptionsrepressor, der die B-Zell-Reaktion moduliert. Bcl-6 ist hochspezifisch für B-Zellen im Keimzentrum und kommt hier sowohl in gesunden als auch in neoplastischen Zellen vor (Staudt et al. 1999). Mutationen des Bcl-6- und MYC-Gens sind mit schlechterem Therapieansprechen und einer ungünstigeren Prognose assoziiert. Dabei sind kombinierte Veränderungen besonders schwerwiegend (Akyurek et al. 2012; Green et al. 2012). Das weit verbreitete Vorkommen von Chromosomenaberrationen bei DLBCL wird durch chromosomale Instabilität begünstigt, welche bei vielen humanen Tumoren vorkommt. Eine ausgeprägte chromosomale Instabilität bei DLBCL ist wie die Bcl-6- und MYCTranslokationen mit einer schlechteren Prognose und schlechterem Therapieansprechen assoziiert (Bakhoum et al. 2011).

Das diffuse großzellige B-Zell-Lymphom verläuft unbehandelt durch die hohe Zellproliferationsrate rasch tödlich, ist aber prinzipiell durch intensive 
Chemotherapieregime heilbar (Deutsche Gesellschaft für Hämatologie und Medizinische Onkologie e.V. 2012). Die in kurativer Absicht verabreichte Standardtherapie ist heutzutage eine Kombinationschemotherapie, die aus Cyclophosphamid, Hydroxydaunorubicin (Doxorubicin), Vincristin (Oncovin), Predniso(lo)n und Rituximab besteht (R-CHOP). Bei Rituximab handelt es sich um einen monoklonalen Antikörper, der gegen CD20, ein in fast allen Stadien der BZellentwicklung auf B-Lymphozyten vorkommendes Antigen, gerichtet ist. Seit Einführung von Rituximab in der Therapie der DLBCL verbesserte sich die Prognose der Betroffenen signifikant, so dass heute das 5 Jahre-progressionsfreie Überleben, je nach Stadium der Erkrankung bei Diagnose, zwischen 50 - 80 \% liegt (Martelli et al. 2013).

Trotz der neuen Erkenntnisse ist ein besseres Verständnis der heterogenen Biologie der DLBCL, die in unterschiedlichem Therapieansprechen, Verlauf und Prognose deutlich wird, notwendig. Weitere Erkenntnisse über die onkogenen Signalwege können zur Entwicklung individueller Therapieregime beitragen.

\subsubsection{Die Side Population in Lymphomen}

Malignome bestehen aus Zellpopulationen, die sich durch verschiedene Oberflächenmarker sowie ihre funktionellen Eigenschaften unterscheiden (Marusyk und Polyak 2010). Die Side Population (SP) beschreibt eine kleine Subpopulation von Zellen, die basierend auf ihrer Fähigkeit, den Farbstoff Hoechst 33342 in den Extrazellulärraum zu exportieren, identifiziert wurde (Teshima et al. 2013).

Die Side Population, die ursprünglich als Phänotyp hämatopoetischer Stammzellen der Maus beschrieben wurde, wurde inzwischen in verschiedenen soliden und hämatologischen Malignomen nachgewiesen (Goodell et al. 1997; Wulf et al. 2001; Hirschmann-Jax et al. 2005). Es zeigte sich, dass die Zellen der Side Population neben dem Farbstoff Hoechst 33342 auch andere Xenobiotika wie Chemotherapeutika exportieren können und dementsprechend Resistenzen gegenüber bestimmten Zytostatika aufweisen können. Bedingt ist die hohe Exportfähigkeit durch die Expression von Membrantransportern der ABC-TransporterFamilie wie z.B. ABCG2, MDR1 und ABCA3 (Teshima et al. 2013).

Die Bedeutung der SP-Zellen liegt in ihrer ausgeprägten Tumorigenität. Einzelne chemoresistente SP-Zellen können expandieren und so zu einer Therapieresistenz und/oder einem Rezidiv führen (Hirschmann-Jax et al. 2005). Daher ist es von 
besonderer Wichtigkeit, die biologischen Hintergründe der Regulierung der SP-Zellen besser zu verstehen, um mögliche Therapien zu etablieren und die SP-Zellen zu eradizieren.

Es werden verschiedene Mechanismen für die Ausbildung von Tumorstammzellen diskutiert. In manchen Modellen wird die Akquisition genetischer Mutationen als Ursache für die Heterogenität beschrieben, während andere Autoren über nichtgenomische Veränderungen wie epigenetische Modifikation durch exogene Signale berichten (Brock et al. 2009). Tendenziell eher für nicht-genomische Veränderungen spricht die Transienz des Tumorstammzell-Phänotyps, was bedeutet, dass aus Tumorstammzellen Nicht-Stammzellen hervorgehen können und umgekehrt (Chaffer et al. 2011).

Tumorstammzellen wurden insbesondere in Geweben mit aktivem, definierten Stammzellpool untersucht, aus dem Tumorzellen hervorgehen können (Dick und Lapidot 2005; Botchkina 2012). Kürzlich zeigte unsere Arbeitsgruppe, dass auch DLBCL, die aus Keimzentrums-B-Zellen oder post-Keimzentrumszellen entstehen und somit aus reifen B-Zellen hervorgehen, die keinem Stammzellpool angehören, eine Side Population besitzen (Koch et al. 2014). Die Side Population erreichte dabei einen Anteil zwischen $0,05 \%$ und $4 \%$ der Gesamtpopulation, wobei der Anteil jeweils charakteristisch für eine bestimmte DLBCL-Zelllinie war.

Auf der Suche nach Unterscheidungsmerkmalen zwischen Side Population- und nonSide Population-Zellen wurden typische differente Oberflächenmerkmale, wie sie für andere Malignome zur Differenzierung von Tumorstammzellen genutzt werden, nicht gefunden. Die kombinierte Microarray-basierte Analyse von Genexpression und Genmethylierung der Side Population im Vergleich zur non-Side Population der DLBCL-Zelllinie OCI-Ly3 zeigte hingegen Differenzen zwischen den Subpopulationen (Koch et al. 2014, Abbildung 1). 
Scatterplot Differential Expression vs. MethylationStatus

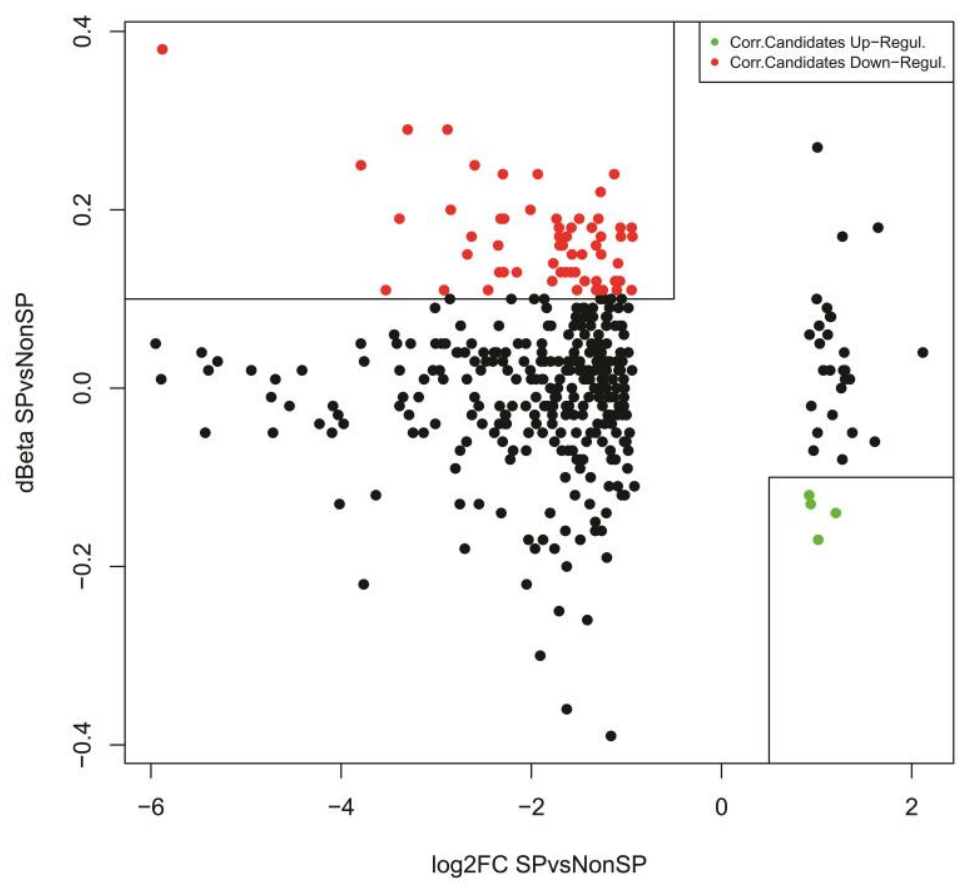

Abbildung 1 Scatterplot, basierend auf kombinierter Genexpressions- und Genmethylierungsanalyse von Side Population- und non-Side Population-Zellen der DLBCL-Zelllinie OCI-Ly3 (Koch et al. 2014)

Nach Microarray-basierter Analyse von Genexpressions- und Genmethylierungsmustern in Side Populationund non-Side Population-Zellen der DLBCL-Zelllinie OCI-Ly3 wurde eine vergleichende Auswertung der einzelnen Gene durchgeführt und die Unterschiede zwischen den SP- und nonSP-Zellen im Scatterplot abgebildet. Während dBeta SPvsNonSP (Ordinate) die Differenzen in der Genmethylierung abbildet, stellt log2FC SPvsNonSP (Abszisse) die Unterschiede in der Genexpression dar. Bei den grün markierten Genen handelt es sich um in der Side Population von OCl-Ly3 besonders hoch exprimierte und gering methylierte Gene im Vergleich zur non-Side Population. Bei den rot markierten Genen hingegen handelt es sich um in der Side Population von OCl-Ly3 im Vergleich zur non-Side Population besonders niedrig exprimierte und stark methylierte Gene. log2FC SPvsNonSP (SFRP4)= -2,88; dBeta SPvsNonSP (SFRP4)= 0,29.

SFRP4 gehörte dabei zu den Genen mit starken Differenzen zwischen Side Population und non-Side Population. Für SFRP4 betrug log2FC SPvsNonSP -2,88 und dBeta SPvsNonSP 0,29. Diese signifikanten Unterschiede waren Hinweis dafür, dass SFRP4 in der Side Population von OCl-Ly3 im Vergleich zur non-Side Population niedrig exprimiert und im Promotor stark methyliert ist.

\subsection{Der kanonische Wnt-Signalweg}

Bei den Wnt-Signalwegen handelt es sich um hoch konservierte Signaltransduktionskaskaden, die wichtige Funktionen bei der Zellproliferation, Zellmigration, Zelldifferenzierung sowie der embryonalen Entwicklung ausüben. Unterschieden werden zwei Signalweg-Kategorien: kanonisch und nicht-kanonisch. Die nicht-kanonischen Wnt-Signalwege operieren $\beta$-Catenin-unabhängig, während beim kanonischen Wnt-Signalweg $\beta$-Catenin der Schlüsselfaktor ist. Aktiviert werden die Signalwege durch Bindung von Wnt-Liganden an Frizzled-Rezeptoren, so dass die 
extrazellulären Signale über eine Aktivierung des Proteins Dishevelled nach intrazellulär weitergeleitet werden (Sheldahl et al. 2003).

Bei den nicht-kanonischen Wnt-Signalwegen wird ein Signalweg, der die planare Zellpolarität reguliert (PCP-Signalweg) - wobei die Aktivierung von Rho-GTPasen und Jun-N-terminalen Kinasen eine Rolle spielt - vom Wnt/Ca ${ }^{2+}$-Signalweg unterschieden, welcher die Freisetzung von Calcium aus dem endoplasmatischen Retikulum kontrolliert (Niehrs 2012; Kim et al. 2013).

Der kanonische Wnt-Signalweg beeinflusst mittels $\beta$-Catenin die Genexpression. Bei Inaktivität des kanonischen Wnt-Signalwegs durch fehlende Wnt-Liganden ist $\beta$ Catenin an den Destruktionskomplex, bestehend aus adenomatous-polyposis-coli-

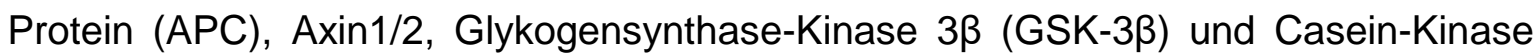
$1 \alpha(C K 1 \alpha)$, gebunden. Dieser Komplex führt zur Phosphorylierung von $\beta$-Catenin an einem Serinrest, so dass $\beta$-Catenin anschließend dem proteasomalen Abbau zugeführt wird. Sobald ein Wnt-Ligand an einen Frizzled-Rezeptor sowie den zugehörigen Korezeptor lipoprotein-related-Protein (LRP) 5 oder 6 bindet, wird die Funktion des Destruktionskomplexes aufgehoben (Pinson et al. 2000; He et al. 2004).

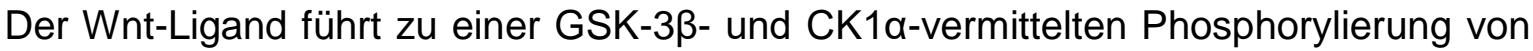
LRP5 oder LRP6, so dass Axin an den zytoplasmatischen Anteil von LRP 5/6 bindet. Diese Bindung löst die Dephosphorylierung von Axin mit resultierender Instabilität sowie Abnahme von Axin aus, und $\beta$-Catenin dissoziiert Dishevelled-abhängig vom Destruktionskomplex. Zytosolisches, freies $\beta$-Catenin akkumuliert und gelangt in den Nukleus. Durch Assoziation mit seinen nukleären Kofaktoren T-Zell-Faktor (TCF) und Lymphozyten-Enhancer-Faktor (LEF) induziert $\beta$-Catenin die Genexpression spezifischer Zielgene, wie beispielsweise MYC, Axin2 und Cyclin D1 (Jho et al. 2002; Kim et al. 2013).

Wnt-Proteine koordinieren die Zellkommunikation über kurze Distanzen mittels parakriner und autokriner Sekretion. Das Funktionieren der Wnt-Signalwege ist dabei von der Syntheserate und der posttranslationalen Modifikation der Wnt-Proteine abhängig. Nach der Synthese im endoplasmatischen Retikulum werden die Proteine an zwei Stellen, einem Cystein- und einem Serin-Rest, palmitoyliert sowie durch NGlykosylierung modifiziert, so dass ein funktionsfähiges Protein resultiert (Willert et al. 2003; Gross und Boutros 2013). Die Wnt-Proteine werden mithilfe von EVI/Wntless vom Golgi-Apparat zur Plasmamembran befördert (Jin et al. 2010). Aufgrund ihrer hydrophoben Eigenschaften werden sie im Extrazellulärraum mittels Carrier-Proteinen oder Membranvesikeln transportiert. Kürzlich veröffentlichte Studien zeigen, dass 
Wnt-Proteine bei humanen Zellen an der Oberfläche von Exosomen zu finden sind (Gross et al. 2012).

Die Frizzled-Rezeptoren, von denen beim Menschen mindestens 10 Typen vorkommen, enthalten einen extrazellulären Anteil, der Cystein-reich ist. Diese Cystein-reiche Domäne (CRD) beinhaltet zehn hochkonservierte Cysteine und ist für die hochaffine Bindung der Wnt-Liganden an den Rezeptor verantwortlich (Hsieh et al. 1999; Wu und Nusse 2002).

\subsubsection{Die Bedeutung des kanonischen Wnt-Signalwegs für Malignome und Lymphozytenentwicklung}

Die Relevanz dieses Signalwegs wird durch seine klinische Bedeutung bei Krebserkrankungen belegt. Schon früh wurden die Wnt-Proteine als Proto-Onkogene identifiziert (McMahon und Bradley 1990; Nusse und Varmus 2012). Eine erhöhte Aktivität des kanonischen Wnt-Signalwegs wurde in zahlreichen Malignomen festgestellt (Kinzler und Vogelstein 1996; Groen et al. 2008; Polakis 2012), wobei eine höhere $\beta$-Catenin-Expression häufig mit einer schlechteren Prognose assoziiert ist (Howe und Brown 2004; Wang et al. 2013). Dabei kommen verschiedene Anomalien im kanonischen Wnt-Signalweg für die Tumorgenese infrage: aktivierende Mutationen im $\beta$-Catenin, Störungen im Destruktionskomplex, Überexpression von Wnt-Liganden oder Inaktivierung von Wnt-Antagonisten.

Speziell für NHL wurden Veränderungen im kanonischen Wnt-Signalweg als eine Komponente der Tumorentstehung und des Tumorwachstums gezeigt (Bellei et al. 2004). Als Ursachen für die veränderte Signalweiterleitung konnten autokrine Stimulation sowie $\beta$-Catenin-Mutationen mit konstitutiver Signalweg-Aktivierung identifiziert werden. Verschiedene Punktmutationen im Exon 3 des für $\beta$-Catenin kodierenden CTNNB1-Gens können zu einer solchen Dysregulation führen, indem sie die Degradation von $\beta$-Catenin verhindern (Groen et al. 2008).

Der kanonische Wnt-Signalweg ist zudem essentiell für die frühe Entwicklung der Lymphozyten. Der Defekt verschiedener Komponenten des Signalweges kann zu einer Entwicklungsstörung von B- sowie von T-Lymphozyten führen. Dabei wurden Mängel von Frizzled-Rezeptor 9 (Ranheim et al. 2005), LEF-1 (Reya et al. 2000), TCF-1 (Schilham et al. 1998) und $\beta$-Catenin (Xu et al. 2003) bereits als mögliche Ursachen für die gehemmte Vermehrung der Lymphozyten identifiziert und so der wachstumsregulierende Effekt des kanonischen Wnt-Signalwegs auf LymphozytenPopulationen demonstriert. 
Zur Bedeutung des kanonischen Wnt-Signalwegs in DLBCL liegen aktuell nur wenige publizierte Daten vor. Neben Untersuchungen des nukleären $\beta$-Catenin-Gehalts in DLBCL-Zellen als Maß für die Aktivität des Signalwegs (Groen et al. 2008; Ge et al. 2012) wurde entdeckt, dass das Ansprechen auf die Rituximabtherapie mit der Genexpression von Wnt-Signalweg-Komponenten wie Dkk-1 assoziiert ist (Koivula et al. 2011).

\subsubsection{Secreted frizzled-related protein 4 (SFRP4)}

Bei dem Protein SFRP4 handelt es sich um einen natürlichen Wnt-Antagonisten. Dieses lösliche, sezernierte Protein beinhaltet eine Cystein-reiche Domäne, die ausgeprägte Homologien zur Wnt-bindenden Domäne von Frizzled-Rezeptoren zeigt. Die am besten untersuchte Erklärung für die Wnt-antagonistische Wirkung von SFRP4 basiert auf einer Konkurrenz von SFRP4 mit den Membran-ständigen Frizzled-Rezeptoren um die Bindung von Wnt-Liganden. Sofern SFRP4 ein WntProtein extrazellulär bindet, kann dieses keine Aktivierung des Wnt-Signalwegs am Frizzled-Rezeptor auslösen (Jones und Jomary 2002). Für einige SFRPs ist die physikalische Interaktion mit Wnt3a, welches in unserer Arbeitsgruppe vornehmlich untersucht wird, nachgewiesen (Wawrzak et al. 2007). Speziell für SFRP4 und Wnt3a ist die Komplexbildung der beiden Proteine mittels Immunpräzipitation gezeigt worden (Constantinou et al. 2008). Ergänzend postuliert ein weiterer Erklärungsansatz zur Funktionsweise von SFRP4 die Bildung von nonfunktionalen Komplexen aus SFRP4 und Frizzled-Rezeptoren, so dass die Wnt-Liganden nicht mehr an die Membranständigen Rezeptoren binden können (Bafico et al. 1999).

Die biologischen Effekte von SFRP4 in gesunden sowie in Tumorzellen sind vielfältig. SFRP4-Expression ist in verschiedenen gesunden Geweben mit vermehrtem Zelltod durch Apoptose sowie terminaler Differenzierung assoziiert (Schumann et al. 2000; Maganga et al. 2008). Für zahlreiche Malignome konnte eine Proliferationshemmende Wirkung von SFRP4 nachgewiesen werden (Horvath et al. 2007; Carmon und Loose 2008). Dabei führte sowohl die Überexpression von SFRP4 als auch der Einsatz von rekombinantem SFRP4 zu einer Proliferationshemmung der Tumorzellen (Carmon und Loose 2008). Darüber hinaus kann SFRP4 das Metastasierungspotential von Tumorzellen reduzieren (Horvath et al. 2007) sowie die Angioneogenese durch Hemmung des Effekts von VEGF auf Endothelzellen vermindern (Muley et al. 2010). Auch das Therapieansprechen wird durch erhöhte Expression von SFRP4 in 
Tumorzellen in Form einer gesteigerten Zytostatikasuszeptibilität beeinflusst (Saran et al. 2012).

In verschiedenen Malignomen wurden eine inverse Relation von SFRP4 und $\beta$ Catenin sowie eine Reduzierung des zellulären $\beta$-Catenin-Gehalts durch SFRP4 festgestellt (Wong et al. 2002; Hrzenjak et al. 2004; Saran et al. 2012; Ford et al. 2013). Diese Beobachtungen legen unter Einbeziehung der biologischen Effekte die Vermutung nahe, dass SFRP4 als Tumorsuppressor fungiert, indem es durch eine Reduzierung des zellulären $\beta$-Catenin-Gehalts in den kanonischen Wnt-Signalweg eingreift.

Hinsichtlich der biologischen Wirkungen von SFRP4 in diffusen großzelligen B-ZellLymphomen liegen aktuell keine ausreichenden Evidenzen vor.

Neben Malignomen wurde SFRP4 bereits im Zusammenhang mit Osteomalazie und Diabetes mellitus Typ 2 untersucht (Nakanishi et al. 2008; Mahdi et al. 2012). Hierbei wurde unter anderem festgestellt, dass SFRP4 im Serum von gesunden Menschen vorkommt. Möglicherweise wird die SFRP4-Konzentration im Serum als Prädiktor bei Diabetes mellitus Typ 2 Bedeutung erlangen.

\subsection{Epigenetische Faktoren in der Tumorbiologie}

Der Begriff Epigenetik bezeichnet vererbbare Modifikationen der Genexpression, die nicht auf Veränderungen der DNA-Sequenz beruhen und somit keine Mutationen darstellen. Die wesentlichen epigenetischen Mechanismen sind DNA-Methylierung, Histon-Modifikationen und RNA-Interferenz.

\subsubsection{Epigenetische DNA-Methylierung}

DNA-Methylierung spielt eine Rolle bei der genomischen Prägung, der XInaktivierung, gewebespezifischer Genexpression, der Stabilität des Genoms sowie bei der Abwehr von Effekten durch retrovirale Sequenzen. Methylierung des Promotors oder einer anderen regulatorischen Sequenz eines Gens führen in der Regel zu einer verminderten Expression des betroffenen Gens, was auch als „epigenetische Ruhigstellung“ bezeichnet wird. Im Gegensatz hierzu kann eine Reduzierung der vorhandenen Methylierung einen Verlust der oben genannten Wirkungen der DNA-Methylierung auslösen. Sowohl die gesteigerte als auch die verminderte Methylierung können zur Tumorentstehung beitragen (Taylor et al. 2013). 
Üblicherweise handelt es sich um die Methylierung von Cytosin, wobei solche Cytosine methyliert werden, die innerhalb von CpG-Dinukleotiden liegen. Dabei bedeutet CpG, dass sich Desoxycytidin und Desoxyguanosin auf demselben DNAStrang befinden und über eine Phosphodiesterbindung verbunden sind (Knippers 2006). Andere Cytosine werden durch die bekannten menschlichen DNAMethyltransferasen (DNMT) nicht verändert (Jeltsch 2006). Unter CpG-Inseln versteht man DNA-Abschnitte von $0,5 \mathrm{~kb}$ bis $2 \mathrm{~kb}$ Länge, die einen GC-Gehalt von über $60 \%$ aufweisen (Gardiner-Garden und Frommer 1987). Insgesamt sind $70-80 \%$ aller CpG-Dinukleotide einer normalen somatischen Zelle methyliert, wobei vor allem innerhalb von CpG-Inseln umethylierte CpGs anzutreffen sind (Taylor et al. 2013).

DNA-Methyltransferasen sind eine Gruppe von Enzymen, die Methylgruppen an die DNA transferieren. Dabei kommen beim Menschen DNMT1, DNMT3A und DNMT3B vor, wobei DNMT1 die am häufigsten vorkommende DNA-Methyltransferase ist. DNMT1 ist für Aufrechterhaltung des Methylierungsmusters der DNA zuständig, da sie vorzugweise hemimethylierte CpG-Dinukleotide methyliert und so nach einer Zellteilung das vorherige Methylierungsmuster wiederherstellt. In humanen Malignomzellen ist die DNMT1 zusätzlich für de novo Methylierungen an Tumorsuppressorgenen verantwortlich (Jair et al. 2006; Ting et al. 2006). Eine Überexpression von DNMT1 findet sich in $48 \%$ der DLBCL und ist mit einer schlechteren Prognose sowie einem fortgeschrittenen Tumorstadium assoziiert (Amara et al. 2010), so dass eine mögliche Therapie mit DNMT1-inhibierenden Substanzen evaluiert werden sollte.

Die DNA-Methylierung führt zu einer Veränderung der dreidimensionalen Struktur des Chromatins. An hypermethylierte CpG-Dinukleotide lagern sich verschiedene Methylbindende Proteine an, die wiederum Histondeacetylasen (HDACs) rekrutieren. Der entstehende Komplex aus DNA und verschiedenen Proteinen führt zu einer Verdichtung des Chromatins und einer Hemmung der Transkription (Jones et al. 1998; Prokhortchouk und Hendrich 2002).

\subsubsection{Epigenetik und Wnt-Signalwege}

Das Gen SFRP4 und andere SFRP-Gene wurden in zahlreichen Malignomen bezüglich ihres Methylierungsstatus und dessen Auswirkungen untersucht. Eine abnorme Methylierung Wnt-antagonistischer Gene als Mechanismus der SignalwegAktivierung wurde für verschiedene Malignome berichtet (Suzuki et al. 2004; Aguilera et al. 2006; Moskalev et al. 2012; Yang et al. 2012). Zusätzlich wurde gezeigt, dass 
eine epigenetische Aktivierung des Wnt-Signalwegs bei Malignomen mit einer schlechteren Prognose assoziiert ist (Ying und Tao 2009). Analysen belegen, dass die Hypermethylierung des SFRP4-Gens beim myelodysplatischen Syndrom mit einer geringeren Überlebenswahrscheinlichkeit verknüpft ist (Wang et al. 2013).

Für DLBCL liegen bisher nur wenige Daten zu epigenetischen Modifikationen vor, in denen die Assoziation verschiedener Methylierungsmarker mit einem aggressiveren Krankheitsverlauf gezeigt werden konnte (Amara et al. 2008; Lee et al. 2009). Über den Methylierungsstatus der Promotorregion von SFRP4 sind keine publizierten Daten verfügbar.

\subsubsection{Modifikation der DNA-Methylierung mittels 5-Azacytidine}

Bei 5-Azacytidine handelt es sich um ein als Medikament eingesetztes chemisches Analogon des Nukleosids Cytidin. Es unterscheidet sich vom Cytidin durch ein Stickstoffatom anstelle eines Kohlenstoffatoms an Position 5.

Aktuell wird es unter dem Handelsnamen Vidaza therapeutisch hauptsächlich bei bestimmten Subtypen des myelodysplatischen Syndroms (MDS) und der AML eingesetzt (Arzneimittelkommission der deutschen Ärzteschaft 2009; Deutsche Gesellschaft für Hämatologie und Medizinische Onkologie e.V. 2013). Die Anwendung dieses Medikaments führt zu einem verbesserten Gesamtüberleben bei MDS (Fenaux et al. 2010). Zuvor wurde die Krankheit in erster Linie supportiv behandelt, die einzig kurative Therapie besteht in der allogenen Stammzelltransplantation (Cazzola und Malcovati 2005).

Die Besonderheit dieses Medikaments besteht darin, dass es zum einen als Basenanalogon zytotoxisch wirkt und zum anderen aufgrund seiner DNAdemethylierenden Wirkung Veränderungen der epigenetischen Regulierung der Zellen auslösen kann.

Die verschiedenen Mechanismen seiner Wirkung beruhen dabei auf der Ähnlichkeit mit Cytidin und führen zu einer Inhibition der DNA-, RNA- und Proteinbiosynthese (Cihak und Vesely 1978; Christman 2002). Wie andere Basenanaloga kann 5Azacytidine in seiner aktivierten Form als Nukleosidtriphosphat in die DNA eingebaut werden mit der Folge einer fehlerhaften DNA-Synthese, die letztlich zum Zelltod führt. Darüber hinaus führt der Einbau in die DNA zu einer kovalenten Bindung von DNAMethyltransferasen an die DNA. 
DNMT1 gehört zur Gruppe der m5C-Methyltransferasen und überträgt eine Methylgruppe auf Position C5 von Cytosin. Durch den Austausch des Kohlenstoffatoms an Position C5 bei 5-Azacytidine gegen ein Stickstoffatom im Vergleich zu Cytidin, verbleibt die DNMT1 bei dem enzymatischen Methyltransfer an der DNA und kann keine weiteren Methylierungen ausführen. Letztlich führt dieser Mangel an aktiven DNMT1 zu einer Hypomethylierung der DNA und die Addukte aus DNMT1, DNA und weiteren Proteinen wirken darüber hinaus zytotoxisch (Bhagwat und Roberts 1987; Jackson-Grusby et al. 1997; Yoo und Jones 2006).

Der Einbau von 5-Azacytidine in RNA bewirkt eine Hemmung von tRNAMethyltransferasen durch einen ähnlichen Mechanismus wie bei den DNAMethyltransferasen. Dies führt zu einer fehlerhaften Funktion der tRNA mit Zerfall von Polyribosomen und daraus resultierender verminderter Proteinsynthese (Lee und Karon 1976; Lu et al. 1980).

Die Wirkung von 5-Azacytidine ist dabei konzentrationsabhängig: in geringen Konzentrationen hemmt es in erster Linie die DNA-Methyltransferasen, während es in hohen Konzentrationen zusätzlich zytotoxisch wirkt (Cihak 1974).

Eine Behandlung mit 5-Azacytidine steigert bei verschiedenen hämatologischen und soliden Neoplasien die Expression von SFRPs im Sinne einer Re-Expression, die mit einer besseren Prognose verknüpft sein kann (Moskalev et al. 2012; Saran et al. 2012; Wang et al. 2013). Während beim MDS unter 5-Azacytidine- Behandlung das $\beta$ Catenin in den Tumorzellen abfällt (Wang et al. 2013), steigt es bei chronischen lymphatischen B-Zell-Leukämie (B-CLL) an (Moskalev et al. 2012). Zur 5-AzacytidineBehandlung von Patienten mit DLBCL liegen derzeit nur wenige Daten vor (Kalac et al. 2011).

\subsection{Exosomen und Mikrovesikel zur interzellulären Kommunikation}

Exosomen sind membranöse Vesikel mit einer Größe von 40-100 nm. Unter physiologischen Bedingungen werden Exosomen von verschiedenen Zelltypen hämatopoetischer und nicht-hämatopoetischer Herkunft produziert und können in verschiedenen Körperflüssigkeiten gefunden werden (Raposo und Stoorvogel 2013). Tumorzellen sind ebenso in der Lage, Exosomen zu generieren und in den Extrazellulärraum zu sezernieren (Bard et al. 2004; Savina et al. 2005). Auch die in unserem Labor verwendeten DLBCL-Zelllinien produzieren Exosomen (Aung et al. 2011). 
Exosomen gelangen in den Extrazellulärraum, indem multivesikuläre Körper (MVBs) mit der Plasmamembran fusionieren und dabei ihre inneren Vesikel, die späteren Exosomen, in den Extrazellulärraum entlassen. Diese inneren Vesikel entstehen durch Einwärtsstülpung der Membran später Endosomen und enthalten dementsprechend Zytosol (Denzer et al. 2000).

Die extrazellulären Exosomen erreichen Zielzellen und können entweder via Endozytose aufgenommen werden, mit der Membran fusionieren oder in stabilem Zustand an der Zellmembran verbleiben (Denzer et al. 2000; Montecalvo et al. 2012; Raposo und Stoorvogel 2013).

Exosomen verfügen über vielfältige Funktionen und dienen der interzellulären Kommunikation mittels Lipid-, RNA- und Proteintransfer (Raposo und Stoorvogel 2013). Über den genauen Mechanismus, wie diese Komponenten in die Exosomen gelangen, liegen aktuell nur wenige Daten vor. Exosomale Proteine können grundsätzlich über zwei Wege in die Exosomen gelangen: Entweder per Endozytose mit anschließendem Transport der Membranproteine in frühe Endosomen, späte Endosomen und schließlich in die inneren Vesikel der MVBs oder per direktem Transport nach ihrer Synthese vom Golgi-Apparat in die MVBs. Beide Wege beschreiben vornehmlich Möglichkeiten für Proteine, die in die Membran integriert sind oder Membran-gebunden vorliegen. Kürzlich wurde gezeigt, dass auch WntProteine mittels Exosomen transportiert werden können und an den Zielzellen eine Aktivierung von Wnt-Signalwegen erfolgen kann (Gross et al. 2012; Koch et al. 2014).

Im Zusammenhang mit Malignomen wurden sowohl Exosomen-vermittelte immunologische Mechanismen gesunder Zellen beobachtet, die der Tumorabwehr dienen, als auch Untersuchungen durchgeführt, die eine Tumorprogression im Sinne vermehrter Angiogenese und Metastasenbildung durch Exosomenfreisetzung aus den Krebszellen zeigen (Zitvogel et al. 1998; Hood et al. 2011).

Ähnlich wie bei den Exosomen handelt es sich auch bei Mikrovesikeln um Membranvesikel, die jedoch im Unterschied zu den Exosomen definitionsgemäß durch Abschnürung von der äußeren Zellmembran entstehen. Mikrovesikel haben keine exakt definierte Größe, reichen aber in der Regel von 100 bis 1000 nm. Über den Mechanismus ihrer Entstehung sowie ihre Funktion ist weniger bekannt als bei den Exosomen, es werden aber ähnliche Funktionen wie bei den Exosomen diskutiert (Raposo und Stoorvogel 2013). 


\subsection{Aufgabenstellung}

Basierend auf den Erkenntnissen der Vorarbeiten sollte die Rolle von SFRP4 in der Wachstumsregulation von DLBCL-Zellen in vier aufeinander aufbauenden Aspekten untersucht werden:

1) Um DLBCL-Zelllinien als in vitro-Modell verwenden zu können, sollte die Expression von SFRP4 in den DLBCL-Zelllinien nachgewiesen werden.

2) Unter Verwendung von rekombinantem Protein sowie durch Expressionsreduktion mittels shRNA sollte die Rolle von SFRP4 für Expansionsverhalten, klonogenes Potential und Ausprägung von putativen Tumorstammzellen (Side Population) in den Zelllinien untersucht werden.

3) Mithilfe des DNA-demethylierenden Medikamentes 5-Azacytidine sollte dessen Wirkung auf das Wachstumsverhalten von DLBCL-Zellen, die Expression von SFRP4 sowie der Einfluss auf den kanonischen Wnt-Signalweg untersucht werden.

4) Bezüglich der extrazellulären Wnt-Signalwegregulation sollte die Interaktion von SFRP4 mit Wnt-Proteinen auf Transportvesikeln (Exosomen) untersucht werden. 


\section{Material und Methoden}

\subsection{Material}

\subsubsection{Geräte}

Absaugsystem EcoVac

Agarosegel-Elektrophoresekammer

Axiovert 100 Lichtmikroskop

Brutgerät BSS300

Cytospin 2-Zentrifuge (inkl. zugehöriger Shandon, Frankfurt, GER Metallklemmen und Plastikeinsätze)

Dampfsterilisator Varioklav ${ }^{\circledR}$

Einfach-Pipetten, $10 \mu \mathrm{l}, 200 \mu \mathrm{l}, 1000 \mu \mathrm{l}$ Eppendorf, Hamburg, GER

Eismaschine

Electrophoresis Power Supply

(Consort EV202)

FACS Aria II

FACSCanto II

Fluoreszenzmikroskop Leica DM IL

Gefrierschrank $-150^{\circ} \mathrm{C}$

Gefrierschrank $-20{ }^{\circ} \mathrm{C}$

Gefrierschrank $-80^{\circ} \mathrm{C}$ Forma, Serie 88000

Heizblock

Horizontalrotierer Rotamax 120

IKAMAG RCT Magnet-Heizplatte

iMark Microplate Reader
H.u.P. Labortechnik, Oberschleißheim, GER

Schütt Labortechnik, Göttingen, GER

Biotec Fischer, Reiskirchen, GER

Zeiss, Jena, GER

Grumbach Brutgeräte, Aßlar, GER

ZIEGRA, Isernhagen, GER

Invitrogen, Karlsruhe, GER

Becton Dickinson, Franklin Lakes, USA

Becton Dickinson, Franklin Lakes, USA

Leitz, Oberkochen, GER

SANYO, Wiesloch, GER

Liebherr, Biberach, GER

Thermo Fisher Scientific, Waltham, USA

Liebisch Labortechnik, Bielefeld, GER

Heidolph, Bremen, GER

IKA Labortechnik, Staufen, GER

Bio-Rad, München, GER 
Inkubator Labotect C200

LAS-4000 Image Reader

MC1 Waage

Mehrkanal-Pipetten, $50 \mu \mathrm{l}, 300 \mu \mathrm{l}$

Mikrowellenherd

Multifuge 3LR

NanoDrop ND-1000

Neubauer-Zählkammer, 0,0025 mm²

pH-Meter, $\mathrm{pH} 211$

Pipetus Pipettierhilfe

Power Pac 300 Power Supply

Rotationsmischer 5432; 3300

Stemi SV11 Mikroskop

Sterilbank HERA safe

Taqman-Reader 7500 HAT (ABI PRISM)

Thermocycler 60

Transilluminator TI3

Trockenschrank

Ultraschallgerät Sonifier B-12

Ultrazentrifugen-Einsätze SW-32 Ti

Ultrazentrifugen-Einsätze SW-32.1 Ti

Ultrazentrifuge Optima XPN-80

Vortex Genie 2

Wasserbad

Wipptisch SSL4

XCell Blot-Modul
Labotect, Göttingen, GER

Fuijifilm, Düsseldorf, GER

Sartorius, Göttingen, GER

Thermo Labsystems, Egelsbach, GER

AEG Micromat, Stockholm, SE

Heraeus Instruments, Hanau, GER

Thermo Fisher Scientific, Waltham, USA

Brand Gläser, Wertheim, GER

HANNA Instruments, Kehl am Rhein, GER

Hirschmann Laborgeräte, Heilbronn, GER

Bio-Rad, München, GER

Eppendorf, Hamburg, GER

Zeiss, Jena, GER

Heraeus, Osterode, GER

Applied Biosystems, Darmstadt, GER

Biomed, Theres, GER

Biometra, Göttingen, GER

Memmert, Schwabach, GER

Branson, Dietzenbach, GER

Beckman Coulter, Fullerton, USA

Beckman Coulter, Fullerton, USA

Beckman Coulter, Fullerton, USA

Schütt Labortechnik, Göttingen, GER

Köttermann Labortechnik, Hänigsen, GER

Stuart, Burlington, USA

Invitrogen, Karlsruhe, GER 
XCell Elektrophorese-Zelle

Zentrifuge 5415D

\subsubsection{EDV}

Adobe Photoshop 7

AxioVision

Cell Quest Version 3.3

GraphPad Prism 5

Microplate Manager 6

Office XP

SDS 2.4

WinMDI 2.9

Windows XP

\subsubsection{Verbrauchsmaterialien}

Amicon Ultra-0.5 ml Filter 10 kDa, $30 \mathrm{kDa}$

Deckgläschen, rund, $\varnothing 1 \mathrm{~cm}$

Einfrierboxen

Filter $(0,22 \mu \mathrm{m})$

Filter $(0,45 \mu \mathrm{m})$

Gewebekulturflaschen $25 \mathrm{~cm}^{2}, 75 \mathrm{~cm}^{2}$, $175 \mathrm{~cm}^{2}$

Gewebekulturschalen $\varnothing 35 \mathrm{~mm}$, $\varnothing 10 \mathrm{~cm}, \varnothing 15 \mathrm{~cm}$

Multi-Well-Platten:

- 6-Well-Platte

- 12-Well-Platte

- 24-Well-Platte
Invitrogen, Karlsruhe, GER

Eppendorf, Wesseling-Berzdorf, GER

Adobe Systems Inc., München, GER

Zeiss, Oberkochen, GER

Becton Dickinson, Heidelberg, GER

GraphPad Software, La Jolla, USA

BioRad, München, GER

Microsoft, Redmond, USA

Applied Biosystems, Darmstadt, GER

Freeware, Joe Trotter

Microsoft, Redmond, USA

Millipore, Schwalbach/Ts, GER

Menzel Gläser, Nümbrecht, GER

Nalgene, Herford, GB

Roth, Karlsruhe, GER

Sartorius, Göttingen, GER

Sarstedt, Nümbrecht, GER

Sarstedt, Nümbrecht, GER

Greiner Bio-One, Kremsmünster, AUT

Greiner Bio-One, Kremsmünster, AUT

Greiner Bio-One, Kremsmünster, AUT 
- 96-Well-Platte (Rund-, Flachboden)

- 384-Well-Platte (qRT-PCR)

Nitrozellulosemembran HybondTM-C extra, $0,2 \mu \mathrm{M}$

Objektträger, 76 × 26 mm, Mattrand

Origninal-Perfusor Spritzen OPS $50 \mathrm{ml}$

Parafilm ${ }^{\circledR}$

Pipetten:

- Pasteurpipetten, 230 mm

- Serologische Pipetten, $5 \mathrm{ml}$, $10 \mathrm{ml}, 25 \mathrm{ml}$

- Pipettenspitzen $10 \mu \mathrm{l}, 200 \mu \mathrm{l}, 1000 \mu \mathrm{l}$

- Reaktionsgefäße, 0,5 ml, 1,5 ml, $2 \mathrm{ml}$

ProGel Tris-Glycin 8-16 \%, $1 \mathrm{~mm}$,

$1,5 \mathrm{~mm}$

Röhrchen:

- FACS-Analyse 5 ml-Röhrchen

- Kryoröhrchen 1,8 ml

- Sterile Plastikröhrchen, 15 ml, $50 \mathrm{ml}$

- Ultrazentrifugen-Röhrchen Ultra-Clear $102 \times 16 \mathrm{~mm}$

$89 \times 25 \mathrm{~mm}$

\subsubsection{Chemikalien}

Agar

Alexa Fluor® 647 Annexin V

Ampicillin

Ampuwa
Sarstedt, Nümbrecht, GER

GreinerBio-One, Kremsmünster, AUT

Amersham Biosciences, Glattbrugg, $\mathrm{CH}$

Knittel Gläser, Braunschweig, GER

Braun, Melsungen, GER

American National CanTM, Chicago, USA

Sarstedt, Nümbrecht, GER

Sarstedt, Nümbrecht, GER

Sarstedt, Nümbrecht, GER

Sarstedt, Nümbrecht, GER

Anamed, Bieberau, GER

Sarstedt, Nümbrecht, GER

Beckman, München, GER

Nalgene, Herford, GB

Beckman, München, GER

Beckman, München, GER

Sigma, Deisenhofen, GER

BioLegend, London, GB

Roche Diagnostics, Mannheim, GER

Fresenius, Bad Homburg, GER 
Annexin V Bindepuffer

Bromphenolblau

Dimethylsulfoxid (DMSO)

Dithiothreitol (DTT, 0,1 M)

dNTP Mix (2,5 mM)

FACSFIow $^{\mathrm{TM}}$

HEPES

Isopropanol

Ladepuffer (6x)

LB Broth Base

Magermilchpulver

Methanol

$\mathrm{MgCl}_{2}$

$\beta$-Mercaptoethanol

Paraformaldehyd

Propidiumiodid

Protaminsulfat

Puromycin

RNase Out ${ }^{\mathrm{TM}}(5.000 \mathrm{U}, 40 \mathrm{U} / \mu \mathrm{l})$

RotiMount Fluor Care DAPI

Stain G

Sucrose

Triton X-100

Trypanblau $(0,4 \%)$

Tween® 20, SigmaUltra

Universal Agarose
BioLegend, London, GB

BioRad, München, GER

Merck, Darmstadt, GER

Invitrogen, Karlsruhe, GER

Invitrogen, Karlsruhe, GER

Becton Dickinson, Heidelberg, GER

Sigma-Aldrich, München, GER

J.T.Baker, Griesheim, GER

Peqlab, Erlangen, GER

Invitrogen, Karlsruhe, GER

Roth, Karlsruhe, GER

J.T.Baker, Griesheim, GER

Invitrogen, Karlsruhe, GER

Merck, Darmstadt, GER

Sigma-Aldrich, München, GER

Sigma-Aldrich, München, GER

Sigma-Aldrich, München, GER

Invivogen, San Diego, USA

Invitrogen, Karlsruhe, GER

Roth, Karlsruhe, GER

Serva, Heidelberg, GER

Sigma-Aldrich, München, GER

Merck, Darmstadt, GER

Sigma-Aldrich, München, GER

Sigma, Deisenhofen, GER

Peqlab, Erlangen, GER 


\subsubsection{Gebräuchliche Puffer, Lösungen und Zellkulturmedien}

\begin{tabular}{|c|c|}
\hline $\begin{array}{l}\text { 4x Ladepuffer NuPage } \AA \text { LDS Sample } \\
\text { Puffer }\end{array}$ & Invitrogen, Carlsbad, USA \\
\hline \multirow[t]{4}{*}{ BSA-reiches Zellkulturmedium } & $\begin{array}{l}\text { DMEM, Glucose-haltig (4,5 g/L) (PAA, Pasching, } \\
\text { AUT) }\end{array}$ \\
\hline & $\begin{array}{l}10 \% \text { (v/v) Hitze-inaktiviertes FCS (Sigma-Aldrich, } \\
\text { München, GER) }\end{array}$ \\
\hline & $\begin{array}{l}200 \text { mM L-Glutamine (Sigma-Aldrich, München, } \\
\text { GER) }\end{array}$ \\
\hline & $1 \%$ BSA (Serva, Heidelberg, GER) \\
\hline \multirow[t]{4}{*}{ DMEM-Zellkulturmedium } & $\begin{array}{l}\text { DMEM, Glucose-haltig ( } 4,5 \mathrm{~g} / \mathrm{L}) \text { (PAA, Pasching, } \\
\text { AUT) }\end{array}$ \\
\hline & $\begin{array}{l}10 \%(v / v) \text { Hitze-inaktiviertes FCS (Sigma-Aldrich, } \\
\text { München, GER) }\end{array}$ \\
\hline & $\begin{array}{l}100 \mathrm{U} / \mathrm{ml} \text { Penicillin + } 200 \mathrm{U} / \mathrm{ml} \text { Streptomycin } \\
\text { (Sigma-Aldrich, München, GER) }\end{array}$ \\
\hline & $\begin{array}{l}200 \text { mM L-Glutamin (Sigma-Aldrich, München, } \\
\text { GER) }\end{array}$ \\
\hline $\begin{array}{l}\text { Fugene HP DNA } \\
\text { Transfektionsreagenz }\end{array}$ & Roche Diagnostics, Mannheim, GER \\
\hline \multirow[t]{4}{*}{ IMDM-Zellkulturmedium } & IMDM (PAN Biotech GmbH, Regensburg, GER) \\
\hline & $20 \%$ (v/v) FCS (Sigma-Aldrich, München, GER) \\
\hline & $\begin{array}{l}100 \mathrm{U} / \mathrm{ml} \text { Penicillin + } 200 \mathrm{U} / \mathrm{ml} \text { Streptomycin } \\
\text { (Sigma-Aldrich, München, GER) }\end{array}$ \\
\hline & $\begin{array}{l}200 \text { mM L-Glutamine (Sigma-Aldrich, München, } \\
\text { GER) }\end{array}$ \\
\hline LB-Medium & Invitrogen, Karlsruhe, GER \\
\hline $\begin{array}{l}\text { Luminata }^{\mathrm{TM}} \text { Crescendo Western HRP } \\
\text { Substrate }\end{array}$ & Merck Millipore, Schwalbach/Ts, GER \\
\hline
\end{tabular}




\begin{tabular}{|c|c|}
\hline \multirow[t]{4}{*}{ Lysepuffer } & $10 \mathrm{mM}$ Tris-HCl, pH 7,4, Merck, Darmstadt, GER \\
\hline & $10 \mathrm{mM} \mathrm{NaCl}$, Merck, Darmstadt, GER \\
\hline & $3 \mathrm{mM} \mathrm{MgCl}_{2} .6 \mathrm{H}_{2} \mathrm{O}$, Merck, Darmstadt, GER \\
\hline & 0,5 \% NP-40, Merck, Darmstadt, GER \\
\hline Methylzellulose ColonyGel & ReachBio, Seattle, USA \\
\hline \multirow[t]{4}{*}{ Nicoletti-Puffer } & $0,1 \%(w / v)$ Natriumcitrat, Merck, Darmstadt, GER \\
\hline & $0,1 \%(v / v)$ Triton X-100, Merck, Darmstadt, GER \\
\hline & 50 g/ml Propidiumiodid, Sigma-Aldrich, \\
\hline & München, GER \\
\hline Optimem & Invitrogen, Karlsruhe, GER \\
\hline Panserin-401 & PAN Biotech GmbH, Regensburg, GER \\
\hline \multirow{3}{*}{$\begin{array}{l}\text { PBS (engl.: phosphate buffered } \\
\text { saline) }\end{array}$} & $137 \mathrm{mM} \mathrm{NaCl}$, Merck, Darmstadt, GER \\
\hline & 10 mM Phosphat, Merck, Darmstadt, GER \\
\hline & 2,7 mM KCL, pH 7,4, Merck, Darmstadt, GER \\
\hline \multirow[t]{2}{*}{ Ponceau-Rot } & $1 \%$ (v/v) Essigsäure, Merck, Darmstadt, GER \\
\hline & 0,5 \% (w/v) Ponceau-S, Merck, Darmstadt, GER \\
\hline Roti-Quant Universal-Reagenz 1 & \multirow[t]{2}{*}{ Roth, Karlsruhe, GER } \\
\hline Roti-Quant Universal-Reagenz 2 & \\
\hline \multirow[t]{3}{*}{ RPMI-Zellkulturmedium } & RPMI-1640 (PAA, Pasching, AUT) \\
\hline & $\begin{array}{l}10 \%(v / v) \text { Hitze-inaktiviertes FCS (Sigma-Aldrich, } \\
\text { München, GER) }\end{array}$ \\
\hline & $\begin{array}{l}100 \mathrm{U} / \mathrm{ml} \text { Penicillin + } 200 \mathrm{U} / \mathrm{ml} \text { Streptomycin } \\
\text { (Sigma-Aldrich, München, GER) }\end{array}$ \\
\hline $\begin{array}{llll}\text { Taq-DNA } & \text { Polymerase } & \text { PCR } & \text { Buffer } \\
(10 \mathrm{X}) & & & \\
\end{array}$ & Invitrogen, Karlsruhe, GER \\
\hline TBE-Puffer (10x) & $\begin{array}{l}\text { 10,8 g Tris-Base pH 8, Merck, Darmstadt, GER } \\
\text { 5,5 g Borsäure, Merck, Darmstadt, GER }\end{array}$ \\
\hline
\end{tabular}




\begin{tabular}{|l|l|}
\hline TBE-Puffer (10x) (Fortsetzung) & $\begin{array}{l}4 \mathrm{ml} 0,5 \mathrm{M} \text { EDTA, Merck, Darmstadt, GER } \\
1 \mathrm{I} \mathrm{H}_{2} \mathrm{O}\end{array}$ \\
\hline \multirow{3}{*}{ TBST } & $\begin{array}{l}\text { 1xTBS, Merck, Darmstadt, GER } \\
\text { GER }\end{array}$ \\
\cline { 2 - 2 } & $24,7 \mathrm{v} / \mathrm{v})$ Tween ${ }^{\circledR}$ 20, Sigma, Deisenhofen, \\
\cline { 2 - 2 } & $160 \mathrm{mM}$ Glycin, Merck, Darmstadt, GER \\
\cline { 2 - 2 } & $10 \%(\mathrm{v} / \mathrm{v})$ MeOH, Merck, Darmstadt, GER \\
\hline Tris-Glycin-SDS-Laufpuffer (10x) & Anamed, Bieberau, GER \\
\hline
\end{tabular}

Tabelle 1 Verwendete Puffer, Lösungen und Zellkulturmedien

\subsubsection{Enzyme}

Taq-DNA Polymerase (500 U, $5 \mathrm{U} / \mu \mathrm{l}) \quad$ Invitrogen, Karlsruhe, GER

SuperScript ${ }^{\mathrm{TM}}$ II Reverse Transcriptase Invitrogen, Karlsruhe, GER

\subsubsection{Kits zur Bearbeitung von RNA, DNA und Proteinen}

$\mathrm{DC}^{\mathrm{TM}}$ Protein Assay

ECL ${ }^{T M}$ Western Blotting Detection Reagents

EpiQuik ${ }^{T M}$ Methylated DNA

Immunoprecipitation Kit

NucleoBond® Xtra Maxi Plus

SYBR® Green PCR Mastermix

RNeasy-Mini-Kit

SuperScript ${ }^{\mathrm{TM}}$ First-Strand Synthesis System
Bio-Rad, München, GER

Amersham Buchler, Braunschweig, GER

Epigentek, Farmingdale, USA

Macherey-Nagel, Düren, GER

QIAGEN, Hilden, GER

QIAGEN, Hilden, GER

Invitrogen, Karlsruhe, GER 


\subsubsection{Rekombinante Proteine, Proteaseinhibitoren und Proteinstandards \\ Bovines Serumalbumin (BSA) \\ Serva, Heidelberg, GER \\ Page Ruler Plus Prestained Protein Ladder \\ Bio-Rad, München, GER \\ Proteinaseinhibitor-Cocktail \\ New England Biolabs, Hitchin, GB \\ Rekombinantes humanes SFRP4 \\ R\&D Systems, Minneapolis, USA \\ Rekombinantes humanes Wnt3a \\ R\&D Systems, Minneapolis, USA}

\subsubsection{Plasmide}

\subsubsection{1 shRNA-Konstrukte}

\begin{tabular}{|l|l|l|}
\hline Name & Herkunft & Hairpin-Sequenz $5^{\circ} \rightarrow 3^{\star}$ \\
\hline $\begin{array}{l}\text { pLKO.1 scramble } \\
\text { shRNA }\end{array}$ & $\begin{array}{l}\text { Addgene } \\
\# 1864\end{array}$ & $\begin{array}{l}\text { CCTAAGGTTAGTCGCCCTCGCTCGA } \\
\text { GCGAGGCGACTTAACCTTAGG }\end{array}$ \\
\hline $\begin{array}{l}\text { pLKO.1 SFRP4 } \\
\text { TRCN0000014490 } \\
\text { (The RNAi } \\
\text { Consortium) }\end{array}$ & Addgene & $\begin{array}{l}\text { CCGGCCAGAAGAGAACAAACCCGA } \\
\text { ACTCGAGTTCGGGTTTGTTCTCTTC } \\
\text { TGGTTTTT }\end{array}$ \\
\hline $\begin{array}{l}\text { pLKO.1 Wnt3a } \\
\text { TRCN0000089120 } \\
\text { (The RNAi } \\
\text { Consortium) }\end{array}$ & Addgene & $\begin{array}{l}\text { CCGGCGCCAGTCACATGCACCTCA } \\
\text { ACTCGAGTTGAGGTGCATGTGACTG } \\
\text { GCGTTTTTG }\end{array}$ \\
\hline
\end{tabular}

Tabelle 2 Verwendete shRNA-Konstrukte

\subsubsection{Verpackungsplasmide}

Name

pCMV-dR8.91

pCMV-VSV-G
Herkunft

Addgene \#8455

Addgene \#8454 


\subsubsection{DNA-Standards und Primer}

DNA Ladder-Mix (c=500 ng DNA/ $\mu$ l) Peqlab, Erlangen, GER

\subsubsection{1 cDNA-Primer}

\begin{tabular}{|l|l|}
\hline Gene & Oligonukleotide $5^{\prime} \rightarrow 3^{\prime}$ \\
\hline \multirow{3}{*}{-Actin } & fwd CACACTGTGCCCATCTACGA \\
\cline { 2 - 2 } & rev TGAGGATCTTCATGAGCTAGTCAG \\
\hline SFRP4 & fwd ACACCCTCTTAAGCAGCACCAG \\
\cline { 2 - 2 } & rev AGGGTGGATGTCCTGGGAAGTAAG \\
\hline
\end{tabular}

Tabelle 3 Verwendete cDNA-Primer

\subsubsection{2 gDNA-Primer}

\begin{tabular}{|l|l|l|}
\hline Gene & Oligonukleotide 5' $\rightarrow$ 3' & \multirow{2}{*}{ Produktgröße } \\
\hline \multirow{2}{*}{ Wnt3a CpG 66 } & fwd CAACCCGACTTCCGCGCCAT & \multirow{2}{*}{$214 \mathrm{bp}$} \\
\cline { 2 - 2 } & rev TGCCGAAGGAGCCCGTCTCA & \\
\hline SFRP4 CpG 92 & fwd CGAGATGCACACGCCACGGT & \multirow{2}{*}{$272 \mathrm{bp}$} \\
\cline { 2 - 2 } & rev ACAGCACGCAGGAGAACGCC & \\
\hline
\end{tabular}

Tabelle 4 Verwendete gDNA-Primer

Die verwendeten Primer wurden als $0,1 \mathrm{nmol} / \mu$ Stocklösung von IBA, Göttingen, bezogen und mit Ampuwa auf eine Konzentration von $10 \mu \mathrm{M}$ eingestellt. Lagerung bei $-20^{\circ} \mathrm{C}$.

\subsubsection{Antikörper}

\subsubsection{Primärantikörper}

\begin{tabular}{|c|c|c|c|c|}
\hline Antikörper & Spezies & Verwendung & Verdünnung & Herkunft \\
\hline $\begin{array}{l}\text { Anti- } \beta \text {-Catenin } \\
\text { Klon \# } 14\end{array}$ & Maus & WB & 1:2000 in TBST & $\begin{array}{l}\text { BD Transduction } \\
\text { Laboratories, San } \\
\text { Jose, USA }\end{array}$ \\
\hline
\end{tabular}




\begin{tabular}{|c|c|c|c|c|}
\hline $\begin{array}{l}\text { Anti-DNMT1 } \\
\text { ab19905, } \\
\text { polyklonal }\end{array}$ & Kaninchen & WB & 1:500 in TBST & $\begin{array}{l}\text { Abcam, } \\
\text { Cambridge, GB }\end{array}$ \\
\hline $\begin{array}{l}\text { Anti-Flotillin-2 } \\
\text { Klon \# } 29\end{array}$ & Maus & WB & 1:5000 in TBST & $\begin{array}{l}\text { BD Transduction } \\
\text { Laboratories, San } \\
\text { Jose, USA }\end{array}$ \\
\hline $\begin{array}{l}\text { Anti-GAPDH } \\
\text { Klon \# 6C5 }\end{array}$ & Maus & WB & $\begin{array}{l}1: 10000 \text { in } \\
\text { TBST }\end{array}$ & $\begin{array}{l}\text { Abcam, } \\
\text { Cambridge, GB }\end{array}$ \\
\hline $\begin{array}{l}\text { Anti-SFRP4 } \\
\text { AF1827, } \\
\text { polyklonal }\end{array}$ & Ziege & WB & $1: 100$ in TBST & $\begin{array}{l}\text { R\&D Systems, } \\
\text { Wiesbaden, GER }\end{array}$ \\
\hline $\begin{array}{l}\text { Anti-SFRP4 } \\
\text { HPA009712, } \\
\text { polyklonal }\end{array}$ & Kaninchen & Immunfluoreszenz & $1: 100$ in PBS & $\begin{array}{l}\text { Sigma-Aldrich, St } \\
\text { Louis, USA }\end{array}$ \\
\hline $\begin{array}{l}\text { Anti-Wnt3a } \\
\text { Klon \# } \\
217804\end{array}$ & Ratte & WB, EM & $1: 1000$ in TBST & $\begin{array}{l}\text { R\&D Systems, } \\
\text { Wiesbaden, GER }\end{array}$ \\
\hline
\end{tabular}

Tabelle 5 Verwendete Primärantikörper

\subsubsection{Sekundärantikörper}

\begin{tabular}{|l|l|l|l|l|}
\hline Antikörper & Spezies & Verwendung & Verdünnung & Herkunft \\
\hline $\begin{array}{l}\text { Anti-Kaninchen, } \\
\text { HRP-konjugiert }\end{array}$ & Ziege & WB & $\begin{array}{l}1: 10000 \text { in } \\
\text { TBST }\end{array}$ & $\begin{array}{l}\text { Santa Cruz, Heidelberg, } \\
\text { GER }\end{array}$ \\
\hline $\begin{array}{l}\text { Anti-Ziege, } \\
\text { HRP-konjugiert }\end{array}$ & Maus & WB & $\begin{array}{l}1: 10000 \text { in } \\
\text { TBST }\end{array}$ & $\begin{array}{l}\text { Santa Cruz, Heidelberg, } \\
\text { GER }\end{array}$ \\
\hline $\begin{array}{l}\text { Anti-Ratte, } \\
\text { HRP-konjugiert }\end{array}$ & Ziege & WB & $\begin{array}{l}1: 10000 \text { in } \\
\text { TBST }\end{array}$ & $\begin{array}{l}\text { Santa Cruz, Heidelberg, } \\
\text { GER }\end{array}$ \\
\hline $\begin{array}{l}\text { Anti-Maus, } \\
\text { HRP-konjugiert }\end{array}$ & Ziege & WB & $\begin{array}{l}1: 10000 \text { in } \\
\text { TBST }\end{array}$ & $\begin{array}{l}\text { Santa Cruz, Heidelberg, } \\
\text { GER }\end{array}$ \\
\hline $\begin{array}{l}\text { Anti-Ratte, } \\
\text { ImmunoGold }\end{array}$ & Ziege & EM & $1: 10$ in TBS & $\begin{array}{l}\text { Aurion, Wageningen, } \\
\text { NL }\end{array}$ \\
\hline $\begin{array}{l}\text { Alexa Fluor } \AA \\
\text { 488 Anti- } \\
\text { Kaninchen }\end{array}$ & Ziege & $\begin{array}{l}\text { Immun- } \\
\text { fluoreszenz }\end{array}$ & $1: 250$ in PBS & $\begin{array}{l}\text { Invitrogen, Karlsruhe, } \\
\text { GER }\end{array}$ \\
\hline
\end{tabular}




\subsubsection{Medikamente}

5-Azacytidine

Sigma-Aldrich, St. Louis, USA

\subsubsection{Bakterien}

Für die Amplifikation der Plasmide wurde folgender E.coli-Stamm verwendet:

TOP10F`Escherichia coli Invitrogen, Karlsruhe, GER

\subsubsection{Zelllinien}

Es wurden folgende eukaryotische Zelllinien verwendet:

\begin{tabular}{|c|c|c|c|}
\hline Zelllinie & Charakteristika & Herkunft & Referenz \\
\hline HEK293T & $\begin{array}{l}\text { Humane Nierenzelllinie mit } \\
\text { stabiler Expression von SV40 } \\
\text { large T-Antigen }\end{array}$ & $\begin{array}{l}\text { American Type } \\
\text { Culture Collection }\end{array}$ & $\begin{array}{l}\text { Sena- } \\
\text { Esteves et al. } \\
1999\end{array}$ \\
\hline $\begin{array}{l}\text { Karpas } \\
422\end{array}$ & $\begin{array}{l}\text { Humane B-Zelle, } \\
\text { GCB-DLBCL-Zelllinie }\end{array}$ & DSMZ & $\begin{array}{l}\text { Dyer et al. } \\
1990\end{array}$ \\
\hline OCl-Ly1 & $\begin{array}{l}\text { Humane B-Zelle, } \\
\text { GCB-DLBCL-Zelllinie }\end{array}$ & DSMZ & $\begin{array}{l}\text { Chang et al. } \\
1995\end{array}$ \\
\hline OCl-Ly3 & $\begin{array}{l}\text { Humane B-Zelle, } \\
\text { ABC-DLBCL-Zelllinie }\end{array}$ & $\begin{array}{l}\text { Zur Verfügung gestellt } \\
\text { von Dana Farber, } \\
\text { Cancer Institute } \\
\text { Boston }\end{array}$ & $\begin{array}{l}\text { Tweeddale et } \\
\text { al. } 1989\end{array}$ \\
\hline SUDHL4 & $\begin{array}{l}\text { Humane B-Zelle, } \\
\text { GCB-DLBCL-Zelllinie }\end{array}$ & DSMZ & $\begin{array}{l}\text { Epstein et al. } \\
1976\end{array}$ \\
\hline U2932 & $\begin{array}{l}\text { Humane B-Zelle, } \\
\text { ABC-DLBCL-Zelllinie }\end{array}$ & DSMZ & $\begin{array}{l}\text { Amini et al. } \\
2002\end{array}$ \\
\hline
\end{tabular}

Tabelle 7 Verwendete Zelllinien 


\subsection{Zellbiologische Methoden}

\subsubsection{Kultivierung von Zellen}

Alle Zellen wurden in wassergesättigter Atmosphäre unter $5 \% \mathrm{CO}_{2}$ bei $37{ }^{\circ} \mathrm{C}$ kultiviert. Medien und Lösungen wurden bei $37^{\circ} \mathrm{C}$ vorgewärmt.

\subsubsection{Passagieren von Zellen}

Die Zellkulturen wurden mit zuvor auf $37^{\circ} \mathrm{C}$ erwärmten Medien versorgt und in einem Inkubator bei $37{ }^{\circ} \mathrm{C}$ mit einer $\mathrm{CO}_{2}$-Atmosphäre von $5 \%$ kultiviert. Dies erfolgte in Zellkulturflaschen der Größe $75 \mathrm{~cm}^{2}$ als Erhaltungskultur und der Größe $175 \mathrm{~cm}^{2}$ für anstehende Experimente. Die Ausdünnung der Suspensionszellen mit frischem Medium erfolgte regelmäßig dreimal die Woche, i.d.R. zwischen 1:3 und 1:5, so dass die Zellen in einer Konzentration zwischen 0,5-1 x 106/ml vorlagen.

\subsubsection{Zellzahlbestimmung}

Die Zellzahlbestimmung erfolgte in einer Neubauer-Zählkammer. Dazu wurde aus einem Aliquot der Zellsuspension eine 1:10-Verdünnung mit Trypanblau hergestellt und dann in der Neubauer-Zählkammer 4 Großquadrate ausgezählt. Die Zellzahlberechnung erfolgte nach folgender Formel:

Zellzahl $=($ Mittelwert der 4 Großquadrate $) \times 10^{4} \times$ Verdünnungsfaktor $\times$ Volumen [ml]

\subsubsection{Bestimmung der Expansionskapazität}

$\mathrm{Zu}$ vergleichende Zellen wurden je nach Versuchsaufbau in bestimmten Konzentrationen in entsprechendem Medium ausgesät und nachfolgend manuell nach festgelegtem Zeitschema über mehrere Tage mittels Neubauer-Zählkammer ausgezählt. Die Versuche unterschieden sich hinsichtlich der untersuchten Zelllinien (OCl-Ly3, OCl-Ly1), hinsichtlich der Inkubation mit rekombinantem Protein oder 5Azacytidine sowie hinsichtlich transduzierter shRNA-Konstrukte.

\subsubsection{Kryokonservierung von Zellen}

Die Zellen wurden nach Aufnahme in Medium in der Laborfuge für 5 min bei $300 \times \mathrm{g}$ pelletiert. Nach Absaugen des Überstandes wurde das Pellet in 1,5 ml Einfriermedium vorsichtig resuspendiert und dann in Kryoröhrchen überführt. Die Zellen wurden sofort 
in Kryoboxen mit Isopropanol, das ein kontinuierliches Abkühlen von ca. $1^{\circ} \mathrm{C} / \mathrm{min}$ gewährleisten sollte, überführt und bei $-80^{\circ} \mathrm{C}$ gelagert.

\begin{tabular}{|l|l|}
\hline \multicolumn{2}{|l|}{ Einfriermedium } \\
\hline $90 \%$ & FCS \\
\hline $10 \%$ & DMSO \\
\hline
\end{tabular}

Tabelle 8 Zusammensetzung des verwendeten Einfriermediums

\subsubsection{Revitalisierung von Zellen}

Nach der Entnahme des Kryoröhrchens aus dem Gefrierschrank wurde es bei $37^{\circ} \mathrm{C}$ im Wasserbad aufgetaut. Die Zellsuspension wurde vorsichtig entnommen, in $8,5 \mathrm{ml}$ vorgewärmtes Medium $\left(37^{\circ} \mathrm{C}\right)$ überführt und $5 \mathrm{~min}$ bei $300 \times \mathrm{g}$ in der Laborfuge sedimentiert. Das Zellpellet wurde nach nochmaligem Waschen in Kultivierungsmedium aufgenommen und in die Zellkulturflasche überführt. Am nächsten Tag wurden die Zellen 1x mit PBS gewaschen, um restliches DMSO und Zelldetritus zu entfernen.

\subsubsection{Durchflusszytometrische Analysen}

Mithilfe der Durchflusszytometrie können anhand optischer Signale verschiedene Zelleigenschaften untersucht werden. Es können sowohl Proteine auf der Zelloberfläche mittels fluorochrom markierter Antikörper als auch der DNA-Gehalt und andere Eigenschaften der Zelle analysiert werden.

In der vorliegenden Arbeit fand die Durchflusszytometrie Anwendung bei der Bestimmung der Side Population, der Zellzyklusanalyse sowie der ApoptoseNiabilitätsmessung.

Für die Bestimmung der Side Population wurden die Zellen für 90 min bei $37^{\circ} \mathrm{C}$ im Wasserbad mit dem Farbstoff Hoechst 33342 inkubiert. Die Konzentration von Hoechst 33342 war dabei abhängig von der Zelllinie: für OCl-Ly3 wurden $100 \mu \mathrm{l} \mathrm{je} 10^{7}$ Zellen in $10 \mathrm{ml}$ verwendet, wohingegen die anderen DLBCL-Zelllinien mit $50 \mu \mathrm{l}$ je $10^{7}$ Zellen in $10 \mathrm{ml}$ inkubiert wurden. Vor der anschließenden Analyse mit dem FACSCanto II wurden den Proben jeweils $10 \mu \mathrm{l}$ Propidiumiodid $(50 \mu \mathrm{g} / \mathrm{ml})$ zugefügt, um die Detektion der toten Zellen zu ermöglichen.

Die Zellzyklusanalyse erfolgte mittels Nicoletti-Puffer, bestehend aus 0,1\% NatriumCitrat, $0,1 \%$ Triton X-100 und $50 \mu \mathrm{g} / \mathrm{ml}$ Propidiumiodid (PI). PI interkaliert in die DNA, 
so dass anhand dieses Farbstoffs der DNA-Gehalt bestimmt werden konnte. Damit der Farbstoff in den Zellkern gelangen konnte, wurden die Zellen mit Triton X-100 permeabilisiert. $1 \times 10^{5}$ Zellen wurden für $10 \mathrm{~min}$ in $1 \mathrm{ml}$ PBS mit $10 \mu$ Nicoletti-Puffer inkubiert und im Anschluss mittels FACSCanto II hinsichtlich ihres DNA-Gehalts analysiert. Anhand des DNA-Gehalts konnte nachfolgend bestimmt werden, in welchem Teil des Zellzyklus sich die einzelnen Zellen zum Zeitpunkt der Zugabe des Nicoletti-Puffers befanden und so ein Zellzyklusprofil der getesteten Zellen erstellt werden.

Eine zweite verwendete Variante zur Analyse des Zellzyklus war die Färbung mit Hoechst 33342. Der Farbstoff lagert sich ebenfalls an die DNA, bevorzugt an der so genannten „kleinen Grube“ der DNA, und erlaubt somit eine Bestimmung des DNAGehalts, von dem Rückschlüsse auf die Phase des Zellzyklus möglich sind. Im Unterschied zum Einsatz von Hoechst 33342 bei der Bestimmung der Side Population fand hier eine kürzere Inkubation von 15 min statt.

Für die Apoptose-/Viabilitätsmessung wurde Alexa Fluor® 647 Annexin V dem Datenblatt entsprechend verwendet. In der frühen Apoptose geht die Asymmetrie der Plasmamembran verloren und das Phospholipid Phosphatidylserin wird an die Außenseite der Plasmamembran transloziert. Alexa Fluor® 647 Annexin V bindet an Phosphatidylserin. Die gleichzeitige Verwendung von PI diente der Erkennung toter Zellen sowie von Zellen, die den nekrotischen Signalweg durchlaufen. An die viablen Zellen binden weder Annexin V noch PI; Annexin V-positive/ PI-negative Zellen befinden sich in der frühen Apoptose; Annexin V-positive/ PI-positive Zellen sind tot, wobei die Unterscheidung zwischen den Zelltodursachen Apoptose und Nekrose nicht mehr möglich ist.

Die Proben wurden am FACSCanto II gemessen und die Ergebnisse mit den Programmen Cell Quest und WinMDI analysiert.

\subsubsection{Sortierung von Zellen mittels FACS}

Die Sortierung von Zellen in Side Population und non-Side Population wurde von der eingewiesenen MTA Frau Sabrina Becker am FACS Aria II durchgeführt. Die zuvor erfolgte Hoechst 33342-Färbung erfolgte analog zu obiger Beschreibung zur Bestimmung der Side Population. 


\subsubsection{Produktion lentiviraler Partikel}

Einen Tag vor der Transfektion wurden HEK293T-Zellen mit einer Konzentration von $3 \times 10^{5}$ Zellen/ml in $2 \mathrm{ml}$ DMEM-Medium ohne Antibiotikum in 6-Well-Platten ausgesät. Bei den HEK293T-Zellen handelt es sich um eine bestimmte Variante der HEK-293Zellen, die zusätzlich das "SV40 large T-Antigen" exprimieren, welches die Replikation von episomalen Plasmiden ermöglicht. Somit lassen sich bestimmte Retroviren, wie beispielsweise die im Rahmen dieser Arbeit verwendeten Lentiviren, in den HEK293T-Zellen vermehren.

Die Transfektion wurde entsprechend folgendem Protokoll je Well durchgeführt:

Tag 0: Nachdem das Transfektionsreagenz FuGENE HP (Roche, Mannheim) Raumtemperatur erreicht hatte, wurden $18 \mu \mathrm{l}$ FuGENE vorsichtig zu $500 \mu \mathrm{l}$ Optimem gegeben. Außerdem wurden $500 \mathrm{ng}$ shRNA-pLKO.1-Plasmide (für Informationen über Sequenz und Herkunft siehe 2.1.9. Plasmide), 50 ng pCMV-dR8.91-Plasmide sowie $500 \mathrm{ng}$ pCMV-VSV-G-Plasmide zu weiteren $500 \mu \mathrm{l}$ Optimem hinzugefügt. Bei den Plasmiden pCMV-VSV-G und pCMV-dR8.91 handelt es sich um lentivirale Verpackungsplasmide. Während das Plasmid pCMV-VSV-G für die Hülle des Partikels kodiert, enthält das pCMV-dR8.91-Plasmid die viralen Gene gag, pol und rev, die für die virale Replikation gebraucht wurden. Diese die Plasmide enthaltende Lösung wurde langsam in die FuGENE-Lösung gegeben und für $30 \mathrm{~min}$ bei Raumtemperatur inkubiert. Anschließend wurde die Mischung auf die Zellen gegeben und für 24 Stunden dort belassen $\left(37^{\circ} \mathrm{C}, 5 \% \mathrm{CO}_{2}\right)$.

Tag 1: Am nächsten Tag wurde das Medium entfernt und durch $2 \mathrm{ml} \mathrm{BSA-reiches}$ Medium mit hohem BSA-Gehalt (engl.: high BSA medium) je Well ersetzt.

Tag 2: Am Folgetag wurde dieses Medium, das nun die lentiviralen Partikel enthielt, entnommen und durch neues BSA-reiches Medium ersetzt. Im Anschluss wurde das entnommene Medium durch einen 0,45 $\mu \mathrm{M}$ Filter filtriert, um gegebenenfalls verbliebene HEK293T-Zellen zu entfernen, und bei $-80^{\circ} \mathrm{C}$ eingefroren.

Tag 3: Wie an Tag 2 erfolgte die Ernte der lentiviralen Partikel.

\subsubsection{Lentivirale Transduktion der Zielzellen}

Bei einer small hairpin RNA (shRNA) handelt es sich um ein RNA-Molekül, das eine Haarnadelstruktur bildet und genutzt werden kann, um Zielgene künstlich durch RNAInterferenz stillzulegen. Mittels lentiviraler Transduktion kann die für die entsprechende shRNA kodierende Sequenz in das Genom einer Zielzelle integriert 
werden. Die shRNA wird dann durch die Polymerase II oder III, abhängig von der Promotorwahl, transkribiert. Das Produkt imitiert die physiologisch vorkommende primicroRNA, die eine der natürlichen Möglichkeiten einer Zelle zur Genstilllegung darstellt. Analog wird daher auch das Transkriptionsprodukt der shRNA zu pre-shRNA prozessiert, welche im Folgenden aus dem Kern exportiert wird und weiteren Prozessierungsschritten, insbesondere durch das Enzym Dicer, unterliegt. Sobald die shRNA auf den RNA-induzierten Silencing-Komplex (RISC) geladen ist, wird der Sinnstrang abgebaut, während der Gegensinnstrang mit der Komplementärsequenz der Ziel-mRNA hybridisiert. Da RISC die mRNA im Falle perfekter Komplementarität schneidet und im Falle unvollständiger Komplementarität die Translation der mRNA verhindert, wird das Gen in beiden Fällen durch die shRNA stillgelegt.

Die Zielzellen (in Fall der vorliegenden Arbeit Zellen der DLBCL-Zellinien OCI-Ly1 und OCl-Ly3) wurden hierfür in 24-Well-Platten mit einer Konzentration von $5 \times 10^{5}$ Zellen/Well in $1 \mathrm{ml}$ Medium, bestehend aus $250 \mu \mathrm{l}$ viralem Überstand und $750 \mu \mathrm{l}$ Zellkulturmedium ohne Penicillin oder Streptomycin, ausgesät. Zusätzlich wurden $2 \mu \mathrm{l}$ Protaminsulfat je Well hinzugefügt, das die Transduktion durch Neutralisieren der geladenen Zellmembran unterstützt. Die Zellen wurden für 2,5 Stunden bei 2000 rpm zentrifugiert und über Nacht bei $37{ }^{\circ} \mathrm{C}$ und $5 \% \mathrm{CO}_{2}$ inkubiert. Die Prozedur wurde am folgenden Tag wiederholt. $24 \mathrm{~h}$ nach der zweiten Transduktion wurden die Zellen mittels $2 \mu \mathrm{g} / \mathrm{ml}$ Puromycin selektiert und im Anschluss bei allen Versuchen unter Selektionsdruck gehalten.

\subsubsection{Klonogenitäts-Versuch}

Je nach Versuchsaufbau wurden 1-2,5 x 104 Zellen in $1 \mathrm{ml}$ Methylzellulose in kleine Gewebekulturschalen ausgesät und nach 10 Tagen mittels Mikroskop die Koloniebildenden Einheiten (colony forming units (CFU)) ausgezählt. Die Ansätze erfolgten als Triplikate.

Der grundlegende Unterschied zur Suspensionskultur besteht in der Separierung der Zellen als Einzelzellen, so dass beurteilbar wird, ob eine Einzelzelle in der Lage ist, eine neue Kolonie $z u$ bilden. Diese Klonogenität ist im Rahmen von Tumorerkrankungen sehr wichtig, um einschätzen zu können, welches maligne Potenzial verbliebene Einzelzellen haben.

Sowohl die Wirkung verschiedener Proteine wie beispielsweise rekombinantes humanes SFRP4 oder Medikamente wie 5-Azacytidine als auch die Effekte von 
Expressionsreduktionen mittels lentiviraler shRNA konnten vergleichend untersucht werden.

\subsubsection{CAM-Assay}

Der CAM-Assay wurde im Rahmen dieser Arbeit verwendet, um Zellen von DLBCLZelllinien in ovo zu passagieren und zusätzliche, über die Suspensionszellkultur hinausgehende Aussagen zu ermöglichen. Durch den Aufbau des Zellverbunds und die Interaktion mit den umliegenden Zellen ähnelt dieses Vorgehen der realen in vivoSituation eher als die Suspensionskultur.

Bei dem CAM-Assay wurden befruchtete und bebrütete Vogeleier verwendet, deren Chorion-Allantois-Membran (CAM) freigelegt wurde, um verschiedene Zellen auf die Membran aufbringen zu können. Nach dem Aufbringen von Tumorzellen konnte im Verlauf deren Wachstum beobachtet werden.

Es wurden frische Hühnereier im Inkubator $\left(37^{\circ} \mathrm{C}, 80 \%\right.$ Luftfeuchtigkeit) bebrütet und regelmäßig gewendet. An Tag 2 wurden die Schalen der Eier gefenstert und die Eier auf ihre Befruchtung hin überprüft. An Tag 9 wurden $3 \times 10^{6}$ der entsprechenden Tumorzellen in $50 \mu \mathrm{l}$ Matrigel aufgenommen und zur Aushärtung für 15 min bei $37^{\circ} \mathrm{C}$ inkubiert. Anschließend wurden die Zellen auf die CAM pipettiert. Das Matrigel diente aufgrund seiner besonderen Temperatur-abhängigen Aggregatzustandsveränderungen dazu, die Zellen im Ei im Verbund zu halten und so die Bildung eines Lymphoms zu ermöglichen. An Tag 17 wurden die Lymphome aus den Eiern entnommen und nach Abtrennung der CAM gewogen.

\subsubsection{Isolation von Mikrovesikeln und Exosomen}

Die für den Versuch vorgesehene Zelllinie wurde mit $1 \times 10^{8}$ Zellen für 72 Stunden in $180 \mathrm{ml}$ Panserin kultiviert. Der Inhalt einer Zellkulturflasche wurde je in ein $50 \mathrm{ml}-$ Falkonröhrchen überführt und 15 min bei 500 x g zentrifugiert. Der Inhalt einer Zellkulturflasche wurde je in ein $50 \mathrm{ml}$-Plastikröhrchen überführt und $15 \mathrm{~min}$ bei 500 x g zentrifugiert. Das resultierende Pellet bestand vornehmlich aus Zellen sowie Zelldetritus. Der Überstand dieses ersten Zentrifugationsschrittes wurde in sechs Ultrazentrifugenröhrchen $(89 \times 25 \mathrm{~mm})$ überführt und nach erfolgreicher Austarierung bei 14.000 x g für 20 min ultrazentrifugiert. Das bei diesem 2. Zentrifugationsschritt (= 1. Ultrazentrifugen-Lauf) entstandene Pellet beinhaltete vornehmlich die Mikrovesikel. Vor der zweiten Ultrazentrifugation wurde der Überstand mithilfe von 0,22 $\mu \mathrm{m}$ Filtern 
filtriert und anschließend bei 120.000 x g für zwei Stunden zentrifugiert. Das bei diesem 3. Zentrifugationsschritt $(=2$. Ultrazentrifugen-Lauf $)$ entstandene Pellet beinhaltete die Exosomen.

\begin{tabular}{|l|l|l|}
\hline Zentrifugationsschritt (ZS) & Pellet & Überstand (ÜS) \\
\hline 1. ZS & Zellen und Zelldetritus & 1. ÜS \\
\hline 2. ZS (=1. UZ-Lauf) & Mikrovesikel & 2. ÜS \\
\hline 3. ZS (=2. UZ-Lauf) & Exosomen & 3. ÜS \\
\hline $\begin{array}{l}\text { Tabelle 9 Übersicht über die aus den einzelnen Zentrifugationsschritten entstandenen Pellets und } \\
\text { Überstände. Zentrifugationsschritt (ZS), Ultrazentrifugen-Lauf (UZ-Lauf), Überstand (USS) }\end{array}$
\end{tabular}

Je nach Intention des Versuchs konnten die in den Zwischenschritten entstandenen Pellets lysiert, in frisches Medium aufgenommen oder verworfen werden. Zusätzlich konnten aus den Überständen der einzelnen Zentrifugationsschritte wenige Milliliter entnommen werden und mithilfe von Amicon-Filtern weiterverarbeitet werden.

Für den Versuch in Abbildung 29 wurden die Pellets lysiert sowie jeweils $3 \mathrm{ml}$ der Überstände entnommen (500 $\mu \mathrm{l}$ je Röhrchen). Absicht des Versuchs war, die verschiedenen gewonnenen Komponenten (Exosomen, Mikrovesikel, Zellen) hinsichtlich ihres SFRP4- und Wnt3a-Gehalts zu vergleichen. Da es sich bei SFRP4 um ein sezerniertes Protein handelt, waren auch die Überstände von Interesse. Diese wurden mittels Amicon-Filtern (10 kDa) filtriert, was zu einer Anreicherung von Proteinen mit einer Molekülmasse oberhalb von $10 \mathrm{kDa}$ führte und das Volumen dermaßen reduzierte, dass es auf ein SDS-Gel aufgetragen werden konnte.

Im Fall der Exosomengewinnung für Stimulationsversuche wie in Abbildung 30 wurden bis auf das letzte Pellet, das die Exosomen enthielt, alle Pellets verworfen bzw. die Zellen zur Weiterkultivierung in frisches Medium aufgenommen. Das Pellet des 3. Zentrifugationsschrittes wurde in $100 \mu \mathrm{l}$ Panserin bei Raumtemperatur über 2-3 Stunden resuspendiert und anschließend auf $1 \times 10^{6}$ Zellen in Panserin zur Stimulation gegeben.

\subsubsection{Sucrose-Gradienten-Sedimentierung}

Zum Nachweis der Effizienz und der Spezifität der beschriebenen Isolierung von Exosomen sollten die dabei entstandenen Exosomen mittels einer Sucrose- 
Gradienten-Sedimentierung aufgetrennt werden. Exosomen werden charakteristischerweise bei einer Dichte von 1,16 g/ml im Sediment des Sucrose-Gradienten gefunden.

Zur Herstellung einer 2,5 M Sucroselösung wurden 42,75 g Sucrose in eine Glasflasche gegeben, mit 20 mM HEPES auf $50 \mathrm{ml}$ aufgefüllt und anschließend in der Mikrowelle erhitzt. Um die Sucrose vollständig zu lösen, wurde diese für mindestens eine Stunde auf den Rührtisch gestellt.

Im Anschluss an die oben beschriebene Isolierung der Exosomen wurde das Pellet in 0,25 M Sucroselösung resuspendiert.

Die entsprechend Tabelle Tabelle 10 konzentrierten Sucroselösungen wurden, mit der höchsten Konzentration beginnend, in ein Ultrazentrifugen-Röhrchen (102 x 16 mm) geschichtet und die Grenzen der einzelnen Schichten markiert.

\begin{tabular}{|l|l|l|}
\hline $2.5 \mathrm{M}$ Sucrose $[\mu \mathrm{l}]$ & HEPES $[\mu \mathrm{l}]$ & Konzentration $[\mathrm{M}]$ \\
\hline 3500 & 1500 & 1,75 \\
\hline 3000 & 2000 & 1,5 \\
\hline 2500 & 2500 & 1,25 \\
\hline 1500 & 3500 & 0,75 \\
\hline 1000 & 4000 & 0,5 \\
\hline 500 & 4500 & 0,25 \\
\hline
\end{tabular}

Tabelle 10 Zusammensetzung der unterschiedlich konzentrierten Sucroselösungen des Sucrose-Gradienten

Anschließend wurden die zuvor isolierten Exosomen oben auf den SucroseGradienten aufgetragen und für 3 Stunden bei 100.000 x g zentrifugiert. Entsprechend ihrer Dichte wanderten die aufgetragenen Partikel während der Zentrifugation durch mehr oder weniger Schichten des Sucrose-Gradienten hindurch und lagerten sich im Sediment ihrer Eigendichte ab. Anhand der Markierungen wurden die Schichten einzeln abgenommen und die Sedimente für die Gelelektrophorese entsprechend vorbereitet. Für den anschließenden Western Blot wurden gegen Wnt3a (R\&D Systems, Klon \# 217804) und Flotillin-2 (BD Transduction Laboratories, Klon \# 29) gerichtete Antikörper verwendet. Flotillin-2 gilt als vermehrt in Exosomen angereichertes Protein und damit als Marker für diese Vesikel (Raposo und Stoorvogel 2013). 


\subsection{Mikroskopische Techniken}

\subsubsection{Trypanblaufärbung}

Zur Bestimmung der Viabilität einer Zellsuspension wurde ein Aliquot von $10 \mu \mathrm{l}$ der Suspension mit $90 \mu \mathrm{l}$ Trypanblau gefärbt, $10 \mu$ dieser Suspension in eine NeubauerZählkammer gegeben und unter dem Mikroskop betrachtet.

Da Trypanblau nur die Membran toter oder stark geschädigter Zellen durchdringen kann, vitale Zellen aber nahezu ungefärbt bleiben, ließ sich so anhand der Blaufärbung im Mikroskop die Zellviabilität beurteilen. Es wurde eine Viabilität von mindestens 85 \% für die Verwendung der Zellen für Versuche angestrebt.

Die Zellzahl wurde (wie in 2.2.3 Zellzahlbestimmung beschrieben) ebenfalls mittels Trypanblaufärbung bestimmt.

\subsubsection{Herstellung von Zytospins}

Zur Herstellung von Zytospins wurden zunächst $5 \times 10^{5}$ Zellen in $1 \mathrm{ml}$ PBS aufgenommen. Objektträger (76 x 26 mm, Knittel Gläser), Filter-Karten und Plastikeinsätze (Shandon) wurden in eine Metallklemme (Shandon) gespannt und diese in der Cytospin 2-Zentrifuge (Shandon) platziert. Je $100 \mu \mathrm{l}$ der Zellsuspension wurden in die Öffnung des Plastikeinsatzes gefült und die Cytospin 2-Zentrifuge mit 1000 rpm für zehn Minuten gestartet. Anschließend wurden die Objektträger aus der Metallklemme entfernt und die Objektträger für mindestens $20 \mathrm{~min}$ bei Raumtemperatur getrocknet. Im Anschluss wurden die fixierten Zellen mit einem Gummierstift (Dako) „eingekreist“.

\subsubsection{Immunfluoreszenz}

Zur Fixierung wurden die Zellen für 20 min mit $3 \%$ Paraformaldehyd bei Raumtemperatur behandelt und anschließend mittels 0,5\% Triton X-100 für 10 min permeabilisiert. Um unspezifische Bindungen des Primärantikörpers zu verhindern, wurden die Zytospins für 30 min mit zehnprozentigem Kälberserum behandelt. Zur Antikörperinkubation wurden gegen SFRP4 gerichtete Primär-Antikörper (SigmaAldrich) 1:200 in PBS verdünnt und die Zytospins damit über Nacht bei $4^{\circ} \mathrm{C}$ inkubiert. Die unbehandelten Kontrollen wurden mit PBS versorgt, um nicht auszutrocknen. Nach drei Waschschritten mit PBS für je 10 min erfolgte dann für 30 min die Inkubation mit den Sekundärantikörpern bei $37^{\circ} \mathrm{C}$ im Dunkeln. Nach erneutem 
dreimaligem Waschen mit PBS wurden die Zellen in RotiMount Fluor Care DAPI eingebettet. Nach dem Trocknen über Nacht standen die Zellen schließlich zur mikroskopischen Auswertung durch das Fluoreszenzmikroskop Leica DM IL zur Verfügung.

\subsubsection{Elektronenmikroskopie}

Die elektronenmikroskopischen Bilder wurden von Dirk Wenzel (MPI für Biophysikalische Chemie, Göttingen) unter Verwendung des Wnt3a-Antikörpers (R\&D Systems, Klon \# 217804) erstellt. Die Isolierung der Exosomen wurde, wie auf S.42 beschrieben, durchgeführt.

Anschließend erfolgte die Markierung der Exosomen nach folgendem Protokoll: Grids wurden bei $37^{\circ} \mathrm{C}$ für 10 min auf einem Tropfen $0,1 \mathrm{M}$ TBS inkubiert. Grids wurden insgesamt 10 min bei Raumtemperatur auf drei Tropfen 0,1 M TBS/0,1 M Glycin inkubiert. Grids wurden für 5 min bei Raumtemperatur auf einem Tropfen 0,1 M TBS/1 \% BSA inkubiert. Grids wurden für 20 min bei Raumtemperatur mit dem primären $\mathrm{AK}$ in TBS/0,5 \% BSA inkubiert. Grids wurden für $10 \mathrm{~min}$ in drei Tropfen TBS/0,5 \% BSA gewaschen. Grids wurden für 20 min bei Raumtemperatur in dem sekundären AK (Anti-Ratte, Aurion)/ProteinA-Gold (TBS/0,5\% BSA) inkubiert. Grids wurden für 15 min in 5 Tropfen TBS/0,5 \% BSA gewaschen. Grids wurden für 15 min in 5 Tropfen TBS gewaschen. Grids wurden in $1 \%$ Glutaraldehyd in PBS inkubiert. Grids wurden in $\mathrm{dH} 2 \mathrm{O}$ (5 Tropfen) für 30 min bei Raumtemperatur gewaschen. Grids wurden für 10 min auf Eis auf einem Tropfen 0,9\% Methylcellulose in destilliertem Wasser und 0,4\% Uranylacetat (Kontrastierung) inkubiert. Überschüssige Lösung wurde abgesaugt (Grids wurden mit einem Metalloop aus dem Tropfen genommen, und auf feuchtem Filterpapier wurde die überschüssige Lösung abgesaugt).

\subsection{Molekularbiologische Methoden}

\subsubsection{RNA-Extraktion}

Die Extraktion der RNA wurde mit dem RNeasy-Mini-Kit (Qiagen) durchgeführt. Alle verwendeten Puffer und Säulen entstammen dem RNeasy-Mini-Kit.

Das Zellpellet (maximal $1 \times 10^{7}$ Zellen) wurde zunächst durch Zentrifugation bei $300 \times \mathrm{g}$ für $10 \mathrm{~min}$ mit PBS gewaschen und anschließend in $350 \mu \mathrm{l}$ 1\%igem ß- 
Mercaptoethanol-haltigem RLT-Puffer lysiert. Die Lysate wurden sofort auf Eis gehalten und die RNA nach Anweisung des Herstellers an einem RNase-freien Platz aufgearbeitet. Die Zentrifugationsschritte wurden mit der Eppendorf-Zentrifuge 5415D durchgeführt. Die Elution der RNA erfolgte mit $30 \mu \mathrm{l}$ Rase-freiem $\mathrm{H}_{2} \mathrm{O}$. Die gewonnene RNA wurde nach photometrischer Konzentrationsbestimmung mittels NanoDropTM entweder direkt für die cDNA-Synthese verwendet oder zur Aufbewahrung bei $-80^{\circ} \mathrm{C}$ gelagert.

\subsubsection{Reverse Transkription (cDNA-Synthese)}

Um die gewonnene RNA in cDNA umzuschreiben, wurde die reverse Transkription genutzt. Dazu wurden zunächst die RNA-Proben auf Eis aufgetaut und $1 \mu \mathrm{g}$ der jeweiligen Probe mit $\mathrm{H}_{2} \mathrm{O}$ auf ein Volumen von $15 \mu$ l eingestellt. Die RNA-Proben wurden anschließend bei $65^{\circ} \mathrm{C}$ für 4 min denaturiert. Anschließend wurden zu den Proben $20 \mu \mathrm{l}$ des Mastermixes für die reverse Transkription gegeben (benötigte Reagenzien für den Mastermix siehe Tabelle 11). Die Reaktion im Thermocycler 60 (Biomed) wurde unter den in Tabelle 12 aufgeführten Bedingungen durchgeführt. Die hergestellten cDNA-Proben wurden zur Aufbewahrung bei $-20^{\circ} \mathrm{C}$ gelagert.

\begin{tabular}{|l|l|}
\hline \multicolumn{2}{|l|}{ Mastermix (ein Ansatz): } \\
\hline $8 \mu \mathrm{l}$ & 5fach 1st Strand Puffer \\
\hline $4 \mu \mathrm{l}$ & DTT $(0,1 \mathrm{M})$ \\
\hline $3,5 \mu \mathrm{l}$ & dNTPs $(10 \mathrm{mM})$ \\
\hline $2 \mu \mathrm{l}$ & Random Primer $(200 \mathrm{ng} / \mu \mathrm{l})$ \\
\hline $1,5 \mu \mathrm{l}$ & SuperScript ${ }^{\mathrm{TM}} \mathrm{II} \mathrm{RT}$ \\
\hline $1 \mu \mathrm{l}$ & RNase Inhibitor $(40 \mathrm{U} / \mu \mathrm{l})$ \\
\hline \multicolumn{2}{|l|}{ Tabelle 11 Mastermix für reverse Transkription }
\end{tabular}

\begin{tabular}{|l|l|}
\hline \multicolumn{2}{|l|}{ Thermocycler } \\
\hline $1 \mathrm{~h}$ & $42^{\circ} \mathrm{C}$ \\
\hline $10 \mathrm{~min}$ & $65^{\circ} \mathrm{C}$ \\
\hline Pause & $4^{\circ} \mathrm{C}$ \\
\hline
\end{tabular}

Tabelle 12 Einstellungen Thermocycler für cDNA-Synthese 


\subsubsection{Quantitative Realtime-PCR}

Die quantitativen Genexpressionsanalysen erfolgten mittels SYBR $\circledast$ Green in einer Taqman Realtime-PCR.

Die Quantifizierung wird in der Realtime-PCR mit Hilfe von Fluoreszenz-Messungen während eines PCR-Zyklus durchgeführt. Die Fluoreszenz nimmt proportional mit der Menge der PCR-Produkte zu. Die Quantifizierung der PCR-Produkte wird unter Nutzung des SYBR® Green (QIAGEN) durchgeführt. Dieser Fluoreszenzfarbstoff lagert sich in die DNA ein (interkaliert) bzw. bindet an doppelsträngige DNA. Somit ist die Messung der DNA-Amplifikation in Realzeit möglich.

Zur Überprüfung, ob es sich bei der doppelsträngigen DNA um ein amplifiziertes Produkt handelt, bedient man sich der Schmelzkurvenanalyse. Dazu wird die amplifizierte DNA wieder aufgeschmolzen, indem die Temperatur langsam kontinuierlich erhöht wird $\left(50^{\circ} \mathrm{C} \rightarrow 95^{\circ} \mathrm{C}\right)$. Bei einer für das Fragment spezifischen Schmelztemperatur wird der Doppelstrang wieder zu zwei einzelsträngigen Molekülen. Dabei wird der Fluoreszenzfarbstoff $\mathrm{SYBR} \otimes$ Green freigesetzt, und es wird eine Fluoreszenzabnahme registriert.

Für die Quantifizierung wurde das housekeeping-Gen $\beta$-Aktin für jede Probe mitgemessen. Jede Probe wurde als Triplikat gegen das gene of interest (SFRP4) und gegen das housekeeping-Gen $\beta$-Aktin aufgetragen. Als Negativkontrolle wurde $\mathrm{H}_{2} \mathrm{O}$ für beide Gene mitgeführt. Für die jeweiligen Ansätze von SFRP4 und $\beta$-Aktin wurde je ein Mastermix (Tabelle 13) mit ihren spezifischen Primern angesetzt. Vom jeweiligen Mastermix wurden $8 \mu \mathrm{l}$ in eine 384-Well-Platte mit $2 \mu \mathrm{l}$ der jeweiligen cDNA-Probe pipettiert und die Platte mit einer Folie überzogen. Die Platte wurde kurz anzentrifugiert und in den Taqman-Cycler gestellt. Das gewählte Programm der Reaktion ist der Tabelle 14 zu entnehmen.

\begin{tabular}{|l|l|}
\hline \multicolumn{2}{|l|}{ Mastermix (ein Ansatz): } \\
\hline $5,25 \mu \mathrm{l}$ & SYBR $\odot$ Green \\
\hline $0,3 \mu \mathrm{l}$ & forward Primer $(10 \mu \mathrm{M})$ \\
\hline $0,3 \mu \mathrm{l}$ & reverse Primer $(10 \mu \mathrm{M})$ \\
\hline $2,15 \mu \mathrm{l}$ & $\mathrm{H}_{2} \mathrm{O}$ \\
\hline
\end{tabular}

Tabelle 13 Mastermix für quantitative Realtime-PCR 


\begin{tabular}{|l|l|l|l|}
\hline \multicolumn{3}{|l|}{ Thermocycler } & \multicolumn{2}{|l|}{ Stage 1} & $2 \mathrm{~min}$ & $50^{\circ} \mathrm{C}$ & \\
\hline Stage 2 & $10 \mathrm{~min}$ & $95^{\circ} \mathrm{C}$ & \\
\hline Stage3 & $15 \mathrm{~S}$ & $95^{\circ} \mathrm{C}$ & \multirow{4}{*}{40 Zyklen } \\
\cline { 2 - 3 } & $45 \mathrm{~s}$ & $60^{\circ} \mathrm{C}$ & \\
\cline { 2 - 3 } & $1 \mathrm{~min}$ & $72^{\circ} \mathrm{C}$ & \\
\hline Stage 4 & $15 \mathrm{~s}$ & $95^{\circ} \mathrm{C}$ & \\
\cline { 2 - 3 } & $15 \mathrm{~S}$ & $60^{\circ} \mathrm{C}$ & \\
\cline { 2 - 3 } & $15 \mathrm{~s}$ & $95^{\circ} \mathrm{C}$ & \\
\hline
\end{tabular}

Tabelle 14 Einstellungen Taqman-Cycler

Die Analyse erfolgte mittels der SDS 2.4 Software. Hiermit lässt sich die Zykluszahl (CT-Wert $=$ Threshold $=$ "Schwellenwert") bestimmen, bei der sich das Fluoreszenzsignal gerade deutlich vom Reaktionshintergrund abhebt. Führt man parallel zur eigentlichen Messung die gleiche Reaktion mit bekannten cDNAMatrizenmengen (z. B. mit housekeeping-Gen) durch, erhält man eine Standardkurve mit CT-Werten, die einen Rückschluss auf die Produktmengen zulassen. Für die quantitative Analyse wurde dabei die $\Delta \Delta C T$-Methode genutzt:

Relative Menge $=2-[($ CT (SFRP4 Side Population) - CT ( $\beta$-Aktin Side Population) $)-($ CT(SFRP4 non-Side Population) - CT ( $\beta$-Aktin non-Side Population))].

\subsubsection{Immunpräzipitation methylierter DNA}

Das EpiQuik ${ }^{\mathrm{TM}}$ Methylated DNA Immunoprecipitation Kit von Epigentek dient der Präzipitation methylierter DNA und half bei der Beantwortung epigenetischer Fragestellungen. Das Kit wurde gemäß Protokoll benutzt. Nach Gewinnung von DNA der zu untersuchenden Zellen, wird diese mittels Ultraschallbehandlung in DNAFragmente einer Länge von 200-1000 bp zerkleinert. Die DNA wird in drei Proben eingeteilt: „input DNA“ (Positivkontrolle), „methylierte DNA“ und „IgG“ (Negativkontrolle). Bei der „input DNA“ handelt es sich um im Weiteren nicht bearbeitete DNA, das heißt sie präsentiert die gesamte DNA der untersuchten Zellen und enthält dementsprechend erwartungsgemäß alle Gene. Bei der „methylierten DNA“ handelt es sich um methylierte DNA. Mittels eines Antikörpers, der methylierte DNA bindet, wurde diese fest gebunden, während die unmethylierte DNA über mehrere Waschvorgänge entfernt wurde. Letztlich blieb die methylierte DNA übrig. Bei der Negativkontrolle „IgG“ wurde ein so genannter isotype-matched control antibody 
verwendet; in diesem Fall entsprechend ein IgG-Antikörper aus der Maus. Bindet dieser Antikörper DNA, handelt es sich um eine unspezifische Bindung, die keine Methylierung nachweist.

Die anschließende PCR erfolgte wie unten beschrieben.

\subsubsection{Polymerase-Kettenreaktion (PCR)}

Die Polymerase-Kettenreaktion ist eine Methode, um DNA in vitro zu vervielfältigen. Der PCR-Prozess besteht aus einer Anzahl von 25-50 Zyklen, wobei jeder Zyklus aus den drei Schritten Denaturierung (Schmelzen), Annealing (Primerhybridisierung) und Elongation (Verlängerung) besteht.

In dieser Arbeit wurde die Methode in Kombination mit dem EpiQuik ${ }^{\mathrm{TM}}$ Methylated DNA Immunoprecipitation Kit (MeDIP-Kit) verwendet, um die Methylierung der DNA weiter zu analysieren. Die verwendeten Primer sind spezifisch für bestimmte CpGInseln im Promotorbereich von SFRP4 und Wnt3a erstellt worden.

Die Zusammensetzung des Mastermixes sowie die Einstellungen des Thermocyclers sind den nachfolgenden Tabellen (Tabelle 15, Tabelle 16) zu entnehmen.

\begin{tabular}{|l|l|}
\hline \multicolumn{2}{|l|}{ Mastermix (ein Ansatz): } \\
\hline $5 \mu \mathrm{l}$ & $10 x$ PCR-Puffer \\
\hline $2 \mu \mathrm{l}$ & $50 \mathrm{mM} \mathrm{MgCl} 2$ \\
\hline $1 \mu \mathrm{l}$ & forward Primer $(10 \mu \mathrm{M})$ \\
\hline $2,5 \mu \mathrm{l}$ & reverse Primer $(10 \mu \mathrm{M})$ \\
\hline $2,5 \mu \mathrm{l}$ & Taq-Polymerase \\
\hline $0,25 \mu \mathrm{l}$ & $\mathrm{H}_{2} \mathrm{O}$ \\
\hline $34,75 \mu \mathrm{l}$ & \\
\hline Tabelle 15 Mastermix PCR
\end{tabular}

\begin{tabular}{|l|l|l|}
\hline \multicolumn{2}{|l|}{ Thermocycler } \\
\hline $3 \mathrm{~min}$ & $94^{\circ} \mathrm{C}$ & \\
\hline $45 \mathrm{~s}$ & $94^{\circ} \mathrm{C}$ & 35 Zyklen \\
\hline $30 \mathrm{~s}$ & $55^{\circ} \mathrm{C}$ & \\
\hline
\end{tabular}




\begin{tabular}{|l|l|l|}
\hline $90 \mathrm{~s}$ & $72^{\circ} \mathrm{C}$ & \\
\hline $10 \mathrm{~min}$ & $72^{\circ} \mathrm{C}$ & \\
\hline Pause & $4^{\circ} \mathrm{C}$ & \\
\hline
\end{tabular}

Tabelle 16 Einstellungen Thermocycler für PCR

\subsubsection{Auftrennen von DNA in Agarosegelen}

Zur Auftrennung der in der PCR entstandenen DNA-Fragmente entsprechend ihrer Größe wurden 2\%ige Agarosegele verwendet.

Die erforderliche Agarose-Menge wurde in $300 \mathrm{ml}$ 1x TBE (Tris-Borat-EDTA-Puffer) aufgekocht (Mikrowelle) und nach Abkühlen auf $55{ }^{\circ} \mathrm{C}$ mit Stain $\mathrm{G}$ versetzt (Endkonzentration 0,1 $\mu \mathrm{g} / \mathrm{ml}$ ). Die Agarose wurde in eine Gelform gegossen und bei Raumtemperatur abgekühlt. Das erstarrte Gel wurde in die Elektrophoresekammer überführt, die Proben wurden mit 6x Ladepuffer in die vorgeformten Geltaschen pipettiert. Zum Vergleich wurde der DNA Ladder-Mix von Peqlab aufgetragen. Die Elektrophorese wurde mit einer Spannung von $80 \mathrm{~V}$ durchgeführt. Durch Stain $\mathrm{G}$ wurden die DNA-Fragmente unter UV-Licht als Banden sichtbar und das Gel konnte auf dem UV-Transilluminator TI3 analysiert werden. Zur Dokumentation wurde das Agarosegel auf dem UV-Transilluminator mit einem Videosystem aufgenommen und ein Ausdruck des Bildes erstellt.

\subsubsection{Herstellung LB-Agarplatten}

Transformierte Bakterien wurden bei $37^{\circ} \mathrm{C}$ auf LB-Platten kultiviert. Zur Herstellung der LB-Platten wurden $20 \mathrm{~g}$ LB Broth Base (Invitrogen) und $12 \mathrm{~g}$ Agar (Sigma) in $1 \mathrm{I}$ deionisiertem $\mathrm{H}_{2} \mathrm{O}$ gelöst und anschließend autoklaviert. Nach dem Autoklavieren und Abkühlen auf $<50{ }^{\circ} \mathrm{C}$ wurde zur Selektion der klonierten Plasmide Ampicillin (Endkonzentration $100 \mathrm{mg} / \mathrm{l}$ ) zugefügt. Anschließend wurde das Medium in der Sterilbank in $10 \mathrm{~cm}$-Petrischalen gegossen und nach dem Aushärten im Kühlraum gelagert.

\subsubsection{Transformation von E.coli}

TOP10F' Escherichia coli (E.coli)-Bakterien wurden für die Plasmid-Amplifikation genutzt. Dafür wurden kompetente Bakterien auf Eis aufgetaut und je $30 \mu$ Bakterien für 30 min auf Eis mit 100 ng DNA inkubiert. Dann wurden die Zellen für $30 \mathrm{~s}$ einem Hitzeschock von $42{ }^{\circ} \mathrm{C}$ ausgesetzt und im Anschluss wieder für 10 min auf Eis 
gegeben. Nach einer Stunde Inkubation in $500 \mu \mathrm{l}$ LB-Medium (Invitrogen) ohne Antibiotika wurden $100 \mu \mathrm{l}$ der Bakteriensuspension auf Ampicillin-haltige $(100 \mu \mathrm{g} / \mathrm{ml})$ LB-Agarplatten gegeben, um die transformierten Klone zu selektieren. Um die positiv transformierten Bakterien zu amplifizieren, wurden sie über Nacht mit $5 \mathrm{ml}$ Antibiotikahaltigem LB-Medium kultiviert.

\subsubsection{Isolierung der Plasmid-DNA}

Die Isolierung der Plasmide wurde mit dem NucleoBond® Xtra Maxi Plus (MachereyNagel) durchgeführt. Die präzipitierte DNA wurde in $100 \mu$ TE-Puffer gelöst und die DNA-Konzentration wurde photometrisch bestimmt.

\subsection{Proteinbiochemische Methoden}

\subsubsection{Herstellung der Zelllysate}

Zur Herstellung der Western-Blot-Lysate aus den zu analysierenden Zellen wurden ca. $1 \times 10^{6}$ Zellen für 10 min bei $500 \times$ g zentrifugiert und das Zellpellet anschließend in $80 \mu \mathrm{l}$ Lysepuffer (Zusammensetzung siehe Tabelle 1) aufgenommen.

Diese Zellsuspension wurde für 30 min auf Eis geschüttelt und anschließend für 15 min bei $14.000 \mathrm{rpm}$ (Eppendorf, Zentrifuge 5415 D) bei $4{ }^{\circ} \mathrm{C}$ zentrifugiert. Der Überstand wurde zur weiteren Verarbeitung abgenommen und in ein neues Eppendorf-Cup gefüllt.

\subsubsection{Bestimmung der Proteinkonzentration}

Die Proteinkonzentration wurde unter Nutzung des Roti®-Quant-Systems bestimmt. Dafür wurden die Proben zunächst 1:10 mit Ampuwa (Fresenius, Bad Homburg) verdünnt. $50 \mu \mathrm{l}$ der zu messenden Proben sowie eine serielle Verdünnung von BSA, die eine Standardreihe von 0-2 mg Protein/ml ergab, wurden als Duplikate in eine 96 Well-Platte gegeben. Je $100 \mu \mathrm{l}$ des frisch hergestellten Reagenzienmixes (15 Teile Reagenz 1, 1 Teil Reagenz 2) wurden hinzugefügt. Nach 30 min Inkubation bei $37^{\circ} \mathrm{C}$ wurden die Proteinkonzentrationen mittels spektralphotometrischer Analyse bei 490 nm unter Nutzung des iMark Microplate Readers mit der Software Microplate Manager 6 bestimmt. 


\subsubsection{SDS-PAGE}

Zur Auftrennung von Proteinen entsprechend ihrer Molekülmasse wurden von der Firma Anamed gefertigte 8-16\%ige Tris-Glycin-Gele von $1 \mathrm{~mm}$ oder 1,5 mm Dicke verwendet. Dazu wurden die Proben zunächst auf Eis aufgetaut und $25 \mu \mathrm{g}$ Protein mit 4fach NuPage ${ }^{\circledR}$-LDS-Ladepuffer sowie DTT in ein 1,5 ml-Eppendorf-Cup pipettiert und mit $\mathrm{H}_{2} \mathrm{O}$ auf ein Endvolumen von $20-40 \mu$ eingestellt. Die Menge von DTT und dem Ladepuffer waren dabei von gewählten Gel, dem Endvolumen sowie der Probe abhängig. Für Versuche, die ohne vorherige Proteinbestimmung erfolgten, wurden definierte Volumina zwischen 15 und $30 \mu l$ in ein Eppendorf-Cup gegeben. Dies betraf insbesondere die Versuche mit Überständen, Medium und vesikulären Partikeln. Die weitere Behandlung erfolgte identisch zu den anderen Proben. Danach wurden die Proben kurz auf dem Vortexer gemischt und eine Minute bei maximaler Geschwindigkeit zentrifugiert. Zur Denaturierung wurden die Proben für zehn Minuten bei $95{ }^{\circ} \mathrm{C}$ auf einem Heizblock inkubiert. In der Zwischenzeit wurde die Elektrophorese-Apparatur (XCell Elektrophorese-Zelle, Invitrogen) zusammengebaut und die Gele darin fixiert. Die Elektrophorese-Kammer wurde dann mit AnamedLaufpuffer aufgefült. Um Luftblasen in den Taschen zu vermeiden, wurden diese zuvor mit Laufpuffer gespült. Nach zehnminütiger Denaturierung der Proben wurden diese vorsichtig in die Taschen des SDS-Gels pipettiert. Neben den Proben wurden immer $6 \mu$ l Molekulargewichtsstandard (Page Ruler Plus Prestained Protein Ladder) mitgeführt. Die Auftrennung der Proteine im Gel wurde bei $100 \mathrm{~V}$ für $120 \mathrm{~min}$ durchgeführt.

\subsubsection{Nassblot auf Nitrozellulosemembranen}

Zum Proteintransfer auf eine Nitrozellulose-Membran wurde für jedes SDS-Gel eine Nitrozellulose-Membran sowie zwei Filterpapiere auf die Gelgröße zurechtgeschnitten und kurz vor dem Gebrauch zusammen mit den Blot-Schwämmen in den Transferpuffer (Zusammensetzung siehe Tabelle 1) gebracht. Nach der Elektrophorese wurde das Gel aus seiner Platte entfernt. Zum Proteintransfer wurden die einzelnen Bestandteile luftblasenfrei in den Bloteinsatz, wie vom Hersteller Invitrogen angegeben, geschichtet.

Der Bloteinsatz wurde in die Blotkammer eingesetzt und die Mitte des Bloteinsatzes mit Transferpuffer aufgefüllt. Um ein zu starkes Erwärmen der Blotkammer zu vermeiden, wurde die Blotkammer auf Eis gestellt. Der Transfer wurde für $1 \mathrm{~h}$ bei 
konstanter Spannung von $30 \mathrm{~V}$ durchgeführt. Die Effizienz des Transfers wurde mittels Ponceau-Färbung festgestellt.

\subsubsection{Immundetektion}

Alle Inkubationen und Waschschritte erfolgten auf dem Wipptisch SSL4. Nach dem Proteintransfer wurde die Nitrozellulose-Membran für mindestens eine Stunde mit $5 \%$ Magermilchpulver in TBST bei Raumtemperatur geblockt, um freie Proteinbindungsstellen zu sättigen. Nach dreimaligem Waschen mit TBST für je 10 min wurde der Primärantikörper den Herstellerangaben entsprechend auf die Membran gegeben und über Nacht bei $4{ }^{\circ} \mathrm{C}$ zum Inkubieren belassen. Um einer Austrocknung durch Transpiration vorzubeugen, wurde das Gefäß abgedeckt. Nach dieser Inkubation wurde die Membran fünfmal $5 \mathrm{~min}$ mit TBST gewaschen und mit dem HRP-konjugierten Sekundärantikörper, der 1:10.000 in TBST verdünnt wurde, für $1 \mathrm{~h}$ bei Raumtemperatur inkubiert. Im Anschluss wurde fünfmal $5 \mathrm{~min}$ mit TBST gewaschen.

Zur Detektion wurde die Chemilumineszenz-Lösung LuminataTM Crescendo Western HRP Substrate (Merck Millipore, Schwalbach/Ts, GER) verwendet. Das Signal wurde mit der Chemolumineszenz-Kamera des LAS-4000 Image Readers detektiert und als elektronisches Bild gespeichert. Die Expositionszeiten (5 s bis $10 \mathrm{~min}$ ) richteten sich nach der Stärke der Signale.

\subsection{Statistische Auswertungen}

Die angegebenen statistischen Tests wurden mithilfe von GraphPad Prism Version 5 (GraphPad Software, La Jolla, USA) durchgeführt und Unterschiede mit $p<0,05$ wurden als signifikant betrachtet. Fehlerbalken repräsentieren in den Abbildungen die Standardabweichung. 


\section{Ergebnisse}

\subsection{Vorkommen von SFRP4 in bovinem Serum}

Zu Beginn der Arbeit stellte sich zunächst die Frage, welches Medium im Rahmen der Versuche zur Versorgung der Zelllinien verwendet werden sollte, um Verfälschungen der Untersuchungen durch Wnt-Signalwegkomponenten aus Serumzusätzen zu vermeiden. Hierzu wurden verschiedene Zellkulturmedien mittels SDS-PAGE aufgetrennt und im Western Blot mit Antikörpern gegen SFRP4 (R\&D Systems, AF1827) und Wnt3a (R\&D Systems, Klon \# 217804) analysiert. Dabei zeigte sich, dass sich in FCS-haltigen Medien SFRP4 sowie Wnt3a in erheblicher Menge befanden. IMDM und RPMI waren ohne Zugabe von fetalem Kälberserum SFRP4und Wnt3a-frei, was belegt, dass das nachgewiesene SFRP4 und Wnt3a aus dem FCS stammen (Abbildung 2).

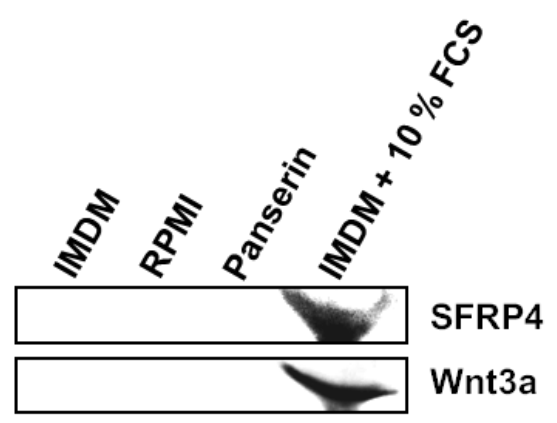

Abbildung 2 Vorkommen von SFRP4 und Wnt3a in fetalem Kälberserum als Mediumzusatz

Je $25 \mu \mathrm{l}$ Kulturmedium wurden mittels SDS-PAGE aufgetrennt und anschließend mittels Antikörpern gegen Wnt3a (R\&D Systems, Klon \# 217804) und SFRP4 (R\&D Systems, AF1827) im Western Blot analysiert. Panserin als Serum-freies Medium enthielt wie FCS-freies IMDM und RPMI kein Wnt3a oder SFRP4. Im FCSangereicherten Kulturmedium zeigten sich erhebliche Mengen von SFRP4 und Wnt3a.

Um eine exogene Aufnahme in die Zellen bzw. eine andere Beeinflussung der Versuche durch das im Serum enthaltene SFRP4 zu verhindern, wurde im Folgenden für alle Versuche Panserin, ein Serum-freies und damit SFRP4- und Wnt3a-freies Medium, genutzt (Abbildung 2).

\subsection{SFRP4-Expression in DLBCL-Zelllinien}

Es galt, das Vorkommen von SFRP4 in verschiedenen DLBCL-Zelllinien mittels Western Blot und Immunfluoreszenz zu belegen, um diese als in vitro-Modell für die vorliegende Arbeit zu verwenden. Hierfür wurden zunächst Gesamtzelllysate der 
DLBCL-Zelllinien Karpas 422, OCI-Ly1, OCI-Ly3, SUDHL4 und U2932 hergestellt, mittels SDS-PAGE aufgetrennt und im Western Blot mit Antikörpern gegen SFRP4 (R\&D Systems, AF1827) analysiert. In allen getesteten Zellinien wurde die Expression von SFRP4 gefunden. Die stärkste Expression zeigte sich in den ABCDLBCL-Linien OCl-Ly3 und U2932 (Abbildung 3).

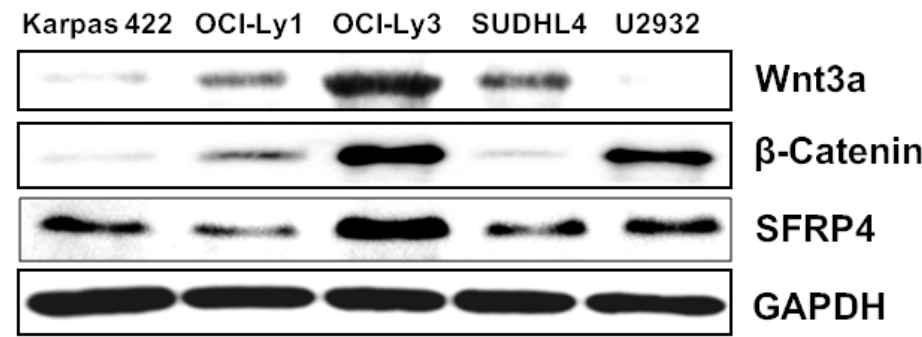

Abbildung 3 Expression von Wnt3a, $\beta$-Catenin und SFRP4 in DLBCL-Zelllinien

$25 \mu \mathrm{g}$ Protein von Gesamtzelllysaten der Zelllinien Karpas 422, OCI-Ly1, OCI-Ly3, SUDHL4 und U2932 aus serumfreier Zellkultur wurden mittels SDS-PAGE aufgetrennt, und im Western Blot mit Antikörpern gegen Wnt3a (R\&D Systems, Klon \# 217804), $\beta$-Catenin (BD Transduction Laboratories, Klon \# 14) und SFRP4 (R\&D Systems, AF1827) analysiert. Wnt3a, $\beta$-Catenin und SFRP4 waren in allen Zelllinien nachweisbar, mit der stärksten Expression von Wnt3a in OCl-Ly3. Eine besonders starke Expression von $\beta$-Catenin und SFRP4 fand sich in OCl-Ly3 und in U2932.

Da es sich bei SFRP4 um einen natürlichen Wnt-Antagonisten handelt, wurde gleichzeitig die Expression von Wnt3a und $\beta$-Catenin betrachtet. Dabei zeigte sich die stärkste Expression von Wnt3a bei OCl-Ly3. Eine hohe Proteinexpression von $\beta$ Catenin fand sich in den ABC-DLBCL-Linien OCI-Ly3 und U2932 (Abbildung 3).

Mithilfe der Immunfluoreszenz bestätigte sich die Expression von SFRP4 in allen aufgeführten DLBCL-Zelllinien und zeigte konstant eine diffuse Darstellung von SFRP4 im Zytoplasma der Zellen (Abbildung 4). 


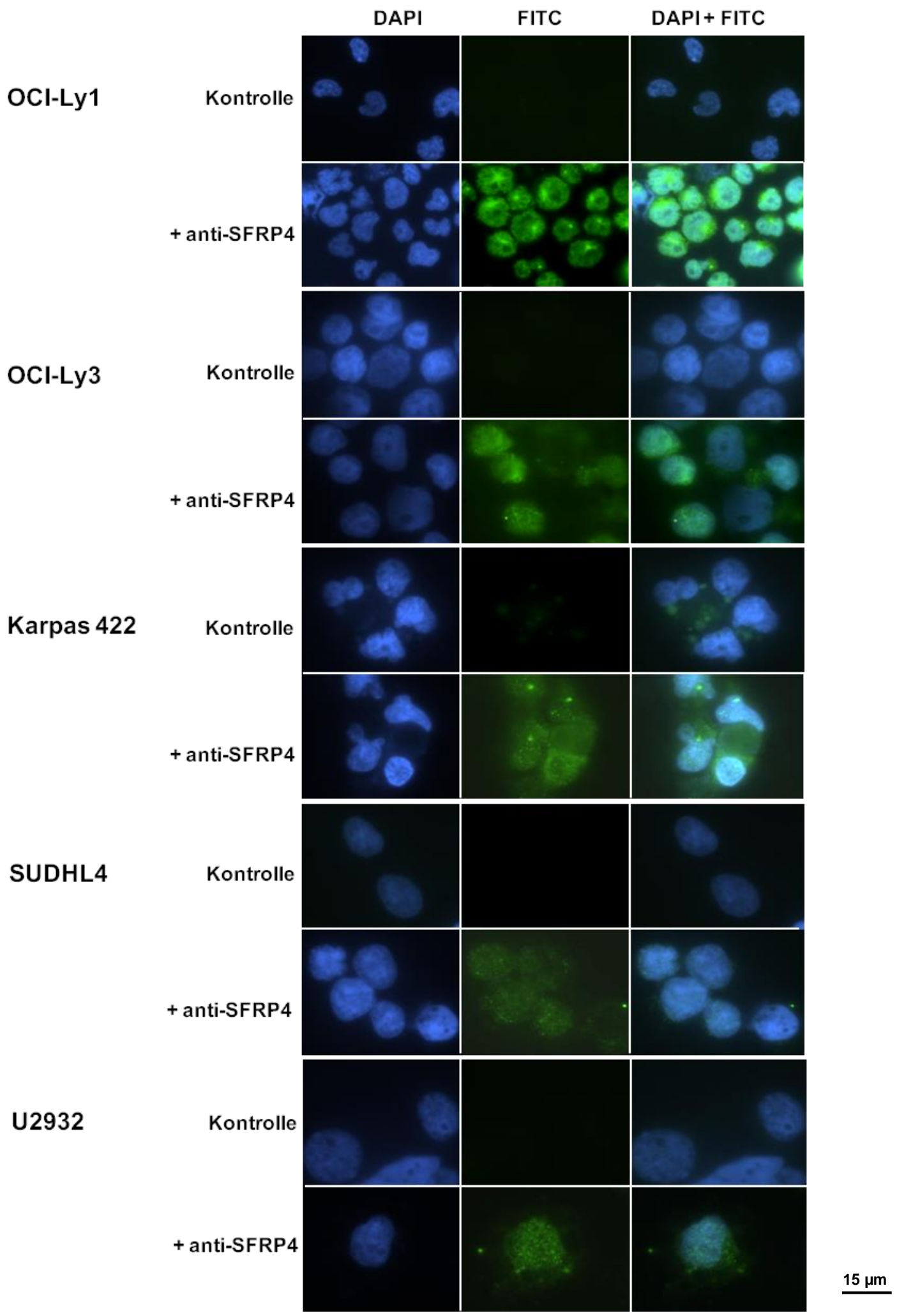

Abbildung 4 Nachweis der zytoplasmatischen Expression von SFRP4 in verschiedenen DLBCLZelllinien

Für die DLBCL-Zelllinien OCI-Ly1, OCI-Ly3, Karpas 422, SUDHL4 und U2932 wurden $3 \times 10^{4}$ Zellen mittels der Cytospin 2-Zentrifuge auf Objektträger gebracht. Anschließend wurden die Zellen mit dem Primärantikörper gegen SFRP4 (Sigma-Aldrich) und dem Sekundärantikörper Anti-Kaninchen (Alexa Fluor ${ }^{\circledR}$ 488, Invitrogen) bzw. allein dem Sekundärantikörper als Kontrolle und DAPI gefärbt. Es wurde in allen getesteten Zelllinien eine diffuse Darstellung von SFRP4 im Zytoplasma gefunden. 


\subsection{Differentielle Expression von SFRP4 in Side Population- und non-Side Population-Zellen}

Die differentielle Expression von SFRP4 in SP- versus nonSP-Zellen wurde sowohl auf der mRNA- als auch auf der Proteinebene betrachtet. Zunächst wurde die Gesamtpopulation der jeweiligen DLBCL-Zelllinie mittels durchflusszytometrischer Sortierung in beide Subpopulationen aufgetrennt.

Um den differentiellen mRNA-Gehalt zu analysieren, wurde direkt im Anschluss an die Sortierung die RNA isoliert, cDNA synthetisiert und mittels PCR das SFRP4Transkript amplifiziert. Sowohl für die ABC-DLBCL-Zelllinien OCI-Ly3 und U2932 als auch für die GCB-Zelllinien SUDHL4 und OCI-Ly1 zeigte sich eine verstärkte SFRP4mRNA-Expression in der non-Side Population im Vergleich zur Side Population. Dabei war das Ergebnis für die Zelllinien OCl-Ly3 und U2932 signifikant (Abbildung 5).

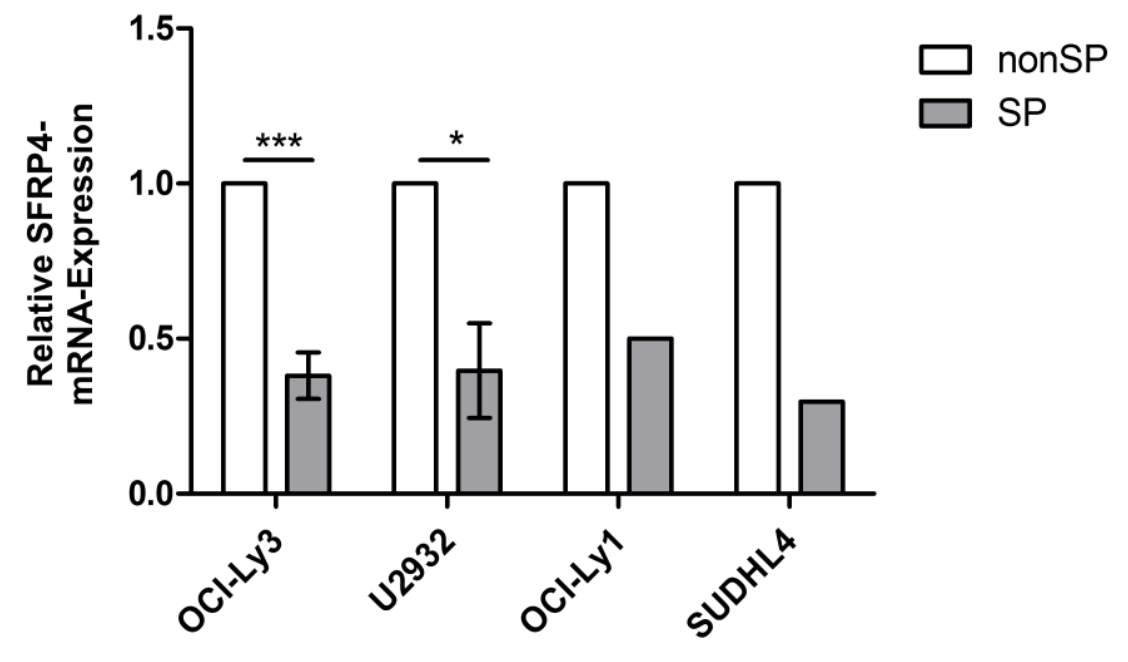

Abbildung 5 Differentielle SFRP4-mRNA-Expression zwischen Side Population und non-Side Population in verschiedenen DLBCL-Zelllinien

Nach durchflusszytometrischer Sortierung der verschiedenen DLBCL-Zelllinien in SP und nonSP erfolgte die RNA-Isolierung sowie cDNA-Synthese mit anschließender qRT-PCR. Die qRT-PCR ergab für alle aufgeführten DLBCL-Zelllinien eine relativ vermehrte Expression von SFRP4-mRNA in der non-Side Population im Vergleich zur Side Population. Unpaired two-sided t-test; * $p<0,05$, ${ }^{* *} p<0,001 ; n=3$ für OCILy3 und U2932; n=1 für OCl-Ly1 und SUDHL4; Fehlerbalken repräsentieren die Standardabweichung.

Auf Ebene der Proteinexpression wurde für die Zelllinien OCI-Ly3 und OCl-Ly1 gezeigt, dass die Zellen der Side Population weniger SFRP4 enthielten als Zellen der zugehörigen non-Side Population (Abbildung 6). Für OCl-Ly3-Zellen konnte darüber hinaus gezeigt werden, dass die Überstände der Side Population-Zellen ebenfalls weniger SFRP4 enthielten als die Überstände der non-Side Population-Zellen (Abbildung 6). 


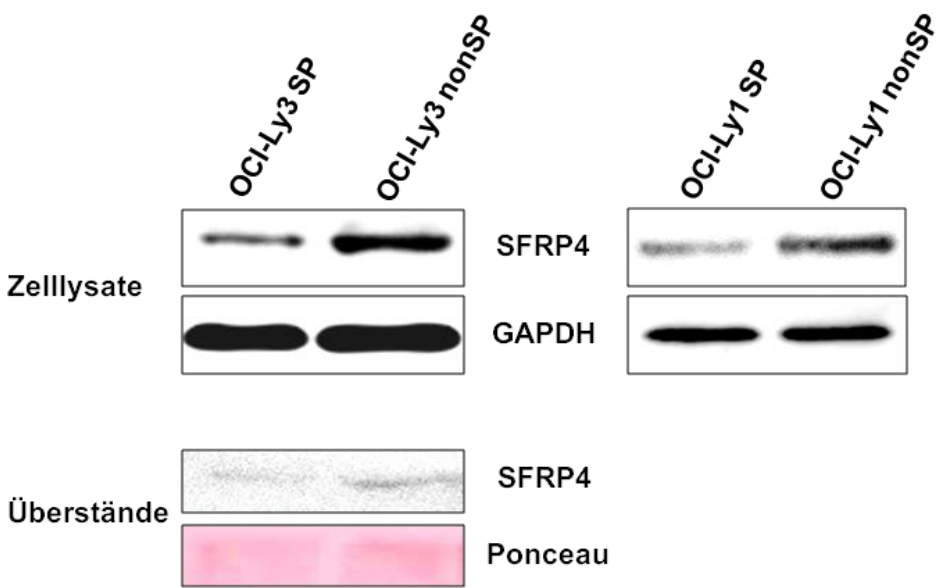

\section{Abbildung 6 Differentielle Proteinexpression von SFRP4 in Side Population und non-Side Population von OCl-Ly1 und OCl-Ly3}

Nach durchflusszytometrischer Sortierung der Gesamtpopulation von OCI-Ly1 und OCI-Ly3 in SP und nonSP sowie anschließender Kultivierung für $24 \mathrm{~h}$ in FCS-freiem Medium erfolgte die Auftrennung der Gesamtzelllysate von SP und nonSP mittels SDS-PAGE und die Analyse mittels Antikörpern gegen SFRP4 (R\&D Systems, AF1827) im Western Blot (oberer Abschnitt der Abbildung). Gleichzeitig wurde das FCS-freie Medium, in dem die OCl-Ly3-Zellen für $24 \mathrm{~h}$ kultiviert worden waren, mittels Amicon Ultra-Filtern (10 kDa) eingeengt und ebenfalls im Western Blot analysiert (unterer Abschnitt der Abbildung).

In der Side Population der OCI-Ly1- und OCI-Ly3-Zellen war SFRP4 niedrig exprimiert im Vergleich zu den Zellen der non-Side Population. Für die Überstände der OCl-Ly3-Zellen konnte gezeigt werden, dass die Überstände der Side Population-Zellen ebenfalls weniger SFRP4 enthielten als die Überstände der non-Side Population-Zellen.

Umgekehrtes galt für Wnt3a und $\beta$-Catenin: hier konnte bei analogem Versuchsaufbau gezeigt werden, dass die Side Population-Zellen von OCI-Ly3 einen erhöhten Gehalt an $\beta$-Catenin und Wnt3a aufwiesen im Vergleich zu den non-Side Population-Zellen (Abbildung 7).

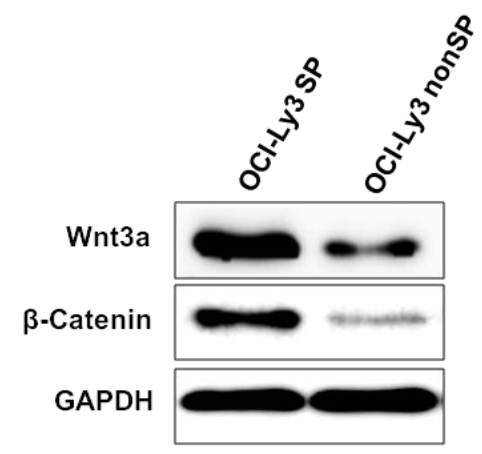

Abbildung 7 Differentielle Proteinexpression von Wnt3a und $\beta$-Catenin in Side Population und nonSide Population von OCl-Ly3

Nach durchflusszytometrischer Sortierung der Gesamtpopulation von OCl-Ly3 in SP und nonSP sowie anschließender Kultivierung für $24 \mathrm{~h}$ in FCS-freiem Medium erfolgte die Auftrennung der Gesamtzelllysate von SP und nonSP mittels SDS-PAGE und die Analyse mittels Antikörpern gegen Wnt3a (R\&D Systems, Klon \# 217804) und $\beta$-Catenin (BD Transduction Laboratories, Klon \# 14) im Western Blot. In der Side Population der OCI-Ly3-Zellen waren Wnt3a und $\beta$-Catenin hoch exprimiert im Vergleich zur non-Side Population. 


\subsection{Funktionelle Analysen zur Wachstumsregulation von DLBCL-Zellen durch SFRP4}

\subsubsection{Funktionelle Untersuchungen mit rekombinantem humanen SFRP4}

\subsubsection{Expansionskapazität unter Behandlung mit rekombinantem humanen SFRP4}

Im Rahmen der Versuche mit rekombinantem humanen SFRP4 (rhSFRP4) wurde dessen Effekt auf das Expansionsverhalten je einer ABC- und einer GCB-DLBCLZelllinie untersucht.

Analysiert wurde die Expansionskapazität durch manuelles Zählen der zunehmenden Zellzahl über 7 Tage. Verglichen wurden Zellen ohne Behandlung mit Zellen, die eine Behandlung mit $500 \mathrm{ng}$ rhSFRP4/ml alle 48 Stunden erhielten. OCI-Ly1 als Modellzelllinie für ein GCB-DLBCL und OCl-Ly3 als Modellzellinie für ein ABCDLBCL zeigten bei Zugabe von rhSFRP4 eine verminderte Expansionskapazität. Diese Hemmung des Wachstums war für beide Zellinien an Tag 7 signifikant (Abbildung 8).

(a)

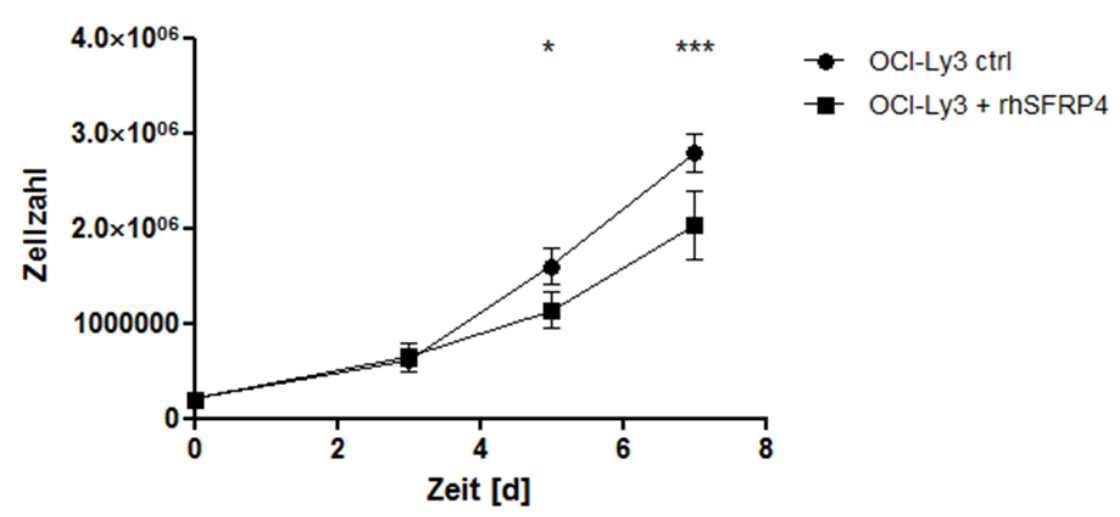

(b)

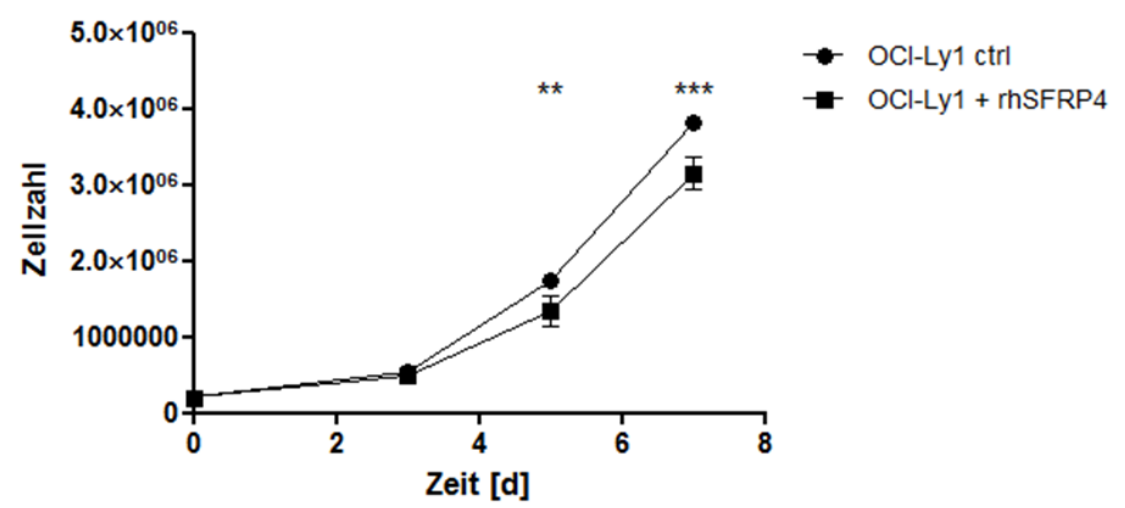

Abbildung 8 Expansionskapazität von OCI-Ly3- und OCI-Ly1-Zellen nach Stimulation mit rhSFRP4 
Die Zellen der Zelllinien OCI-Ly1 und OCI-Ly3 wurden in FCS-freiem Medium (Panserin) kultiviert und entweder alle $48 \mathrm{~h}$ mit $500 \mathrm{ng}$ rekombinantem humanen SFRP4 pro $\mathrm{ml}$ behandelt oder unbehandelt belassen. Die Zählung erfolgte mittels Trypanblau-Färbung an Tag 3, 5 und 7. Unter Zugabe von rhSFRP4 zeigte sich die Zellzahlzunahme bei (a) OCl-Ly3 und (b) OCl-Ly1 vermindert im Vergleich zur unbehandelten Kontrolle. Two-way ANOVA, Bonferroni-Post test; * $p<0,05$, ${ }^{* *} p<0,01$, ${ }^{* * *} p<0,001$; $n=3$; Fehlerbalken repräsentieren die Standardabweichung von Triplikaten; die Versuche wurden 3-mal wiederholt.

\subsubsection{Wirkung von rekombinantem humanen SFRP4 auf zelluläres $\beta$-Catenin}

$\beta$-Catenin als Mediator des kanonischen Wnt-Signalwegs ist unmittelbar an der Regulation der Zellproliferation beteiligt. Mittels rekombinantem humanen Wnt3a (rhWnt3a) sowie rhSFRP4 wurde dieser Zusammenhang für DLBCL anhand der ABCDLBCL-Zelllinie OCI-Ly3 sowie der GCB-DLBCL-Zelllinie OCI-Ly1 in vitro untersucht.

Zunächst wurde der Effekt von rhWnt3a auf den zellulären $\beta$-Catenin-Gehalt untersucht. OCl-Ly3-Zellen und OCl-Ly1-Zellen wurden für 8 Stunden nicht oder mit verschiedenen Konzentrationen von rhWnt3a (300, 500, $1000 \mathrm{ng}$ rhWnt3a/ml) stimuliert und anschließend im Western Blot mittels $\beta$-Catenin-Antikörpern (BD Transduction Laboratories, Klon \# 14) analysiert. Es zeigte sich eine Konzentrationsabhängige Zunahme des zellulären $\beta$-Catenins im Vergleich zur unbehandelten Kontrolle, wobei sich dieser Effekt bei OCl-Ly3 ab $300 \mathrm{ng} \mathrm{rhWnt3a/ml} \mathrm{und} \mathrm{bei} \mathrm{OCl-}$ Ly1 ab 500 ng rhWnt3a/ml zeigte (Abbildung 9).

(a)

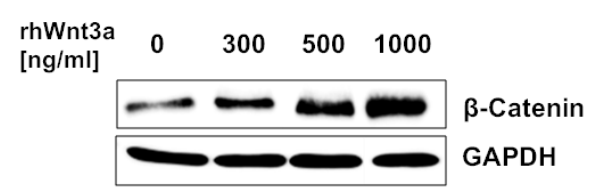

(b)

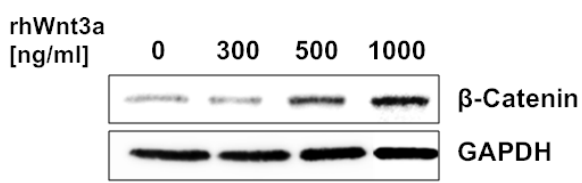

\section{Abbildung 9 Anstieg von zellulärem $\beta$-Catenin in Lymphomzellen nach rhWnt3a-Exposition}

Je $1 \times 10^{6}$ Zellen der Zelllinien OCI-Ly3 (a) und OCI-Ly1 (b) wurden in vitro für $8 \mathrm{~h}$ mit unterschiedlichen Konzentrationen von rekombinantem humanen Wnt3a in FCS-freiem Medium (Panserin) inkubiert. Nach der 8-stündigen Behandlung erfolgte die Lyse der Zellen sowie Auftrennung der Gesamtzellysate mittels SDSPAGE und Analyse mittels Antikörpern gegen $\beta$-Catenin (BD Transduction Laboratories, Klon \# 14) im Western Blot. Sowohl in der Zelllinie OCI-Ly3 (a) als auch in der Zelllinie OCl-Ly1 (b) war nach Stimulation mit rhWnt3a eine Zunahme des zellulären $\beta$-Catenins festzustellen. Bei OCl-Ly3-Zellen zeigte sich dieser Effekt ab $300 \mathrm{ng} \mathrm{rhWnt3a} / \mathrm{ml}$, bei OCl-Ly1-Zellen ab $500 \mathrm{ng} \mathrm{rhWnt3a/ml}$.

Ein ähnlicher Versuch wurde mit rhSFRP4 durchgeführt. OCI-Ly3-Zellen wurden für 8, 24 bzw. 48 Stunden nicht oder mit $1 \mu \mathrm{g}$ rhSFRP4/ml behandelt; OCl-Ly1-Zellen wurden für 8 Stunden nicht oder mit $1 \mu \mathrm{g}$ rhSFRP4/ml behandelt. Der Western Blot zeigte für beide DLBCL-Zelllinien unabhängig von der Behandlungsdauer keine Veränderung des zellulären Gesamt- $\beta$-Catenin-Gehalts durch die Behandlung mit rhSFRP4 (Abbildung 10). 
(a)

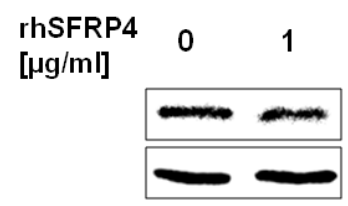

$8 \mathrm{~h}$

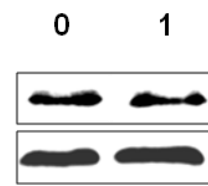

$8 \mathrm{~h}$

(b)

Abbildung 10 Keine Veränderung des zellulären $\beta$-Catenin-Gehalts durch Behandlung mit rhSFRP4

Je $5 \times 10^{5}$ Zellen (a) von OCI-Ly1 bzw. (b) von OCI-Ly3 wurden für $24 \mathrm{~h}$ in FCS-freiem Medium auf einer 24Well-Platte kultiviert, anschließend erfolgte die Zugabe von $1 \mu \mathrm{g}$ rhSFRP4 pro ml bzw. keine Zugabe in der Kontrolle. Nach 8, 24 oder 48 Stunden wurden die Zellen lysiert, mittels SDS-PAGE aufgetrennt und mittels Antikörpern gegen $\beta$-Catenin (BD Transduction Laboratories, Klon \# 14) im Western Blot analysiert. (a) zeigt die unbehandelten OCI-Ly1-Zellen (links) neben OCl-Ly1-Zellen, die für $8 \mathrm{~h}$ mit $1 \mu \mathrm{g}$ rhSFRP4/ml behandelt wurden (rechts). Dabei führte die Behandlung mit rhSFRP4 nicht zu einer Veränderung des zellulären $\beta$ Catenin-Gehalts. (b) zeigt jeweils unbehandelte OCI-Ly3-Zellen neben mit rhSFRP4 behandelten OCl-Ly3Zellen bei unterschiedlicher Inkubationsdauer (8 h, 24 h, 48 h). Die Behandlung mit rhSFRP4 führte bei keiner der aufgeführten Inkubationsdauern zu einer Veränderung des zellulären $\beta$-Catenin-Gehalts.

Um festzustellen, ob das rhSFRP4 tatsächlich keinen Effekt auf das $\beta$-Catenin und den kanonischen Wnt-Signalweg hat oder das Ergebnis des Versuchs auf der (Mit-) Detektion des bereits im Abbau befindlichen $\beta$-Catenins beruht, sollte nun untersucht werden, ob die Zugabe von rhSFRP4 den durch rhWnt3a hervorgerufenen Effekt inhibieren oder aufheben kann.

Zusätzlich zu dem in Abbildung 9 gezeigten Versuch wurden OCl-Ly3- und OCl-Ly1Zellen mit einer zweifachen Stimulation, bestehend aus rhWnt3a und rhSFRP4, behandelt. So ergaben sich für verschiedene Konzentrationen von rhWnt3a jeweils eine unbehandelte Kontrolle, eine ausschließlich mit rhWnt3a stimulierte Probe sowie eine zweifach behandelte Probe (rhWnt3a und rhSFRP4 gleichzeitig). Die Konzentration von rhSFRP4 betrug $1 \mu \mathrm{g} / \mathrm{ml}$ und wurde nicht variiert. In Anlehnung an den Vorversuch wurde eine Inkubationsdauer von 8 Stunden gewählt.

Die Analyse im Western Blot mittels der bereits zuvor verwendeten $\beta$-CateninAntikörper ergab eine Zunahme des zellulären $\beta$-Catenins nach rhWnt3a-Stimulation (wie bereits im Vorversuch gezeigt), die durch gleichzeitige Gabe von rhSFRP4 zum Teil reduziert wurde.

Für OCl-Ly1 zeigte sich sowohl bei der rhWnt3a-Konzentration von $500 \mathrm{ng} / \mathrm{ml}$ als auch bei $1000 \mathrm{ng} / \mathrm{ml}$ eine Hemmung des durch rhWnt3a induzierten $\beta$-CateninAnstiegs durch rhSFRP4-Zugabe (Abbildung 11). 


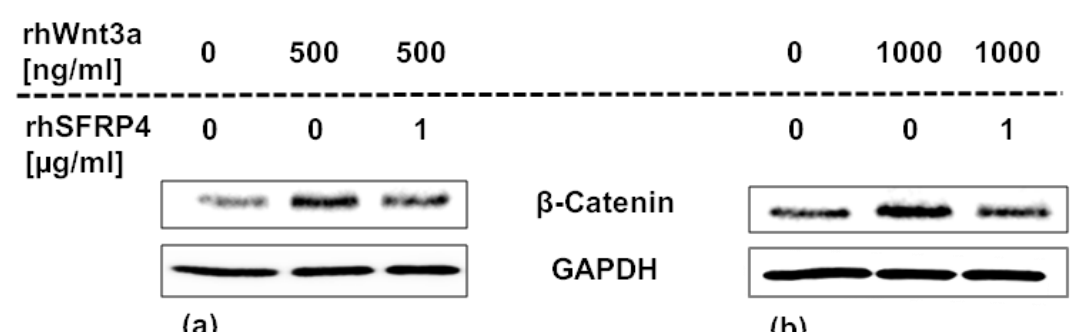

Abbildung 11 Anstieg von zellulärem $\beta$-Catenin infolge von rhWnt3a-Stimulation bei OCl-Ly1-Zellen lässt sich durch gleichzeitige Zugabe von rhSFRP4 hemmen

Die OCl-Ly1-Zellen wurden in FCS-freiem Medium kultiviert und zu Beginn des Versuchs einmalig mit rekombinantem Protein behandelt. Die Zellen wurden $8 \mathrm{~h}$ nach Behandlung lysiert. In (a) und (b) ist links die OCl-Ly1-Kontrolle, mittig die Stimulation von OCl-Ly1 mit rhWnt3a in einer Konzentration von $500 \mathrm{ng} / \mathrm{ml}$ in (a) bzw. $1 \mu \mathrm{g} / \mathrm{ml}$ in (b) und rechts die gleichzeitige Behandlung von OCl-Ly1 mit rhWnt3a (in gleicher Konzentration wie mittig) und $1 \mu \mathrm{g}$ rhSFRP4/ml dargestellt. Bei Stimulation mit rhWnt3a zeigte sich ein Anstieg des zellulären $\beta$-Catenins. Die zusätzliche gleichzeitige Gabe von rhSFRP4 führte dazu, dass das zelluläre $\beta$-Catenin nicht oder weniger anstieg als bei alleiniger Behandlung mit rhWnt3a.

Für OCl-Ly3 zeigte sich für rhWnt3a-Konzentrationen von $300 \mathrm{ng} / \mathrm{ml}$ und von $500 \mathrm{ng} / \mathrm{ml}$ eine Hemmung des durch rhWnt3a induzierten $\beta$-Catenin-Anstiegs bei rhSFRP4-Zugabe, während die Stimulation mit 1000 ng rhWnt3a/ml durch die gleichzeitige Gabe von $1 \mu \mathrm{g}$ rhSFRP4/ml nicht gehemmt werden konnte (Abbildung 12).

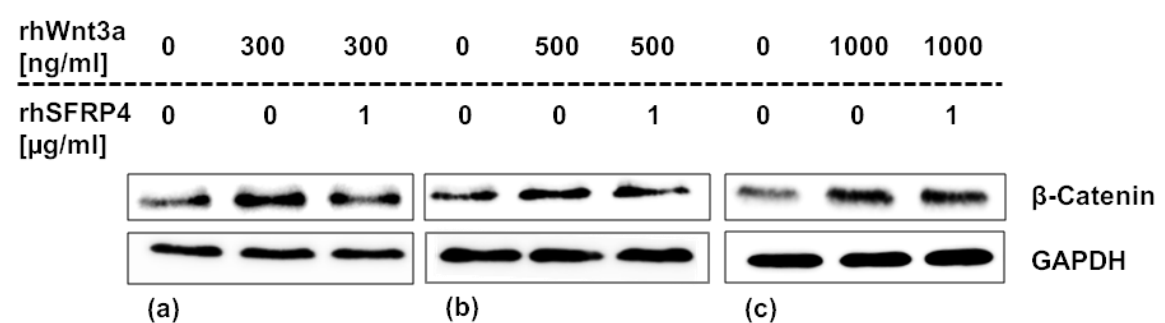

Abbildung 12 Anstieg von zellulärem $\beta$-Catenin infolge von rhWnt3a-Stimulation bei OCl-Ly3-Zellen lässt sich durch gleichzeitige Zugabe von rhSFRP4 hemmen

Die OCI-Ly3-Zellen wurden in FCS-freiem Medium kultiviert und zu Beginn des Versuchs einmalig mit rekombinantem Protein behandelt. Die Zellen wurden $8 \mathrm{~h}$ nach Behandlung lysiert.

In (a), (b) und (c) ist jeweils links die OCI-Ly3-Kontrolle, mittig die Stimulation von OCl-Ly3 mit rhWnt3a in einer Konzentration von $300 \mathrm{ng} / \mathrm{ml}$ in (a) bzw. $500 \mathrm{ng} / \mathrm{ml}$ in (b) bzw. $1 \mu \mathrm{g} / \mathrm{ml}$ in (c) und rechts die gleichzeitige Behandlung von OCl-Ly3 mit rhWnt3a (in gleicher Konzentration wie mittig) und $1 \mu \mathrm{g}$ rhSFRP4/ml dargestellt. Bei Stimulation mit rhWnt3a zeigte sich ein Anstieg des zellulären $\beta$-Catenins. In (a) und (b) führte die zusätzliche gleichzeitige Gabe von rhSFRP4 dazu, dass das zelluläre $\beta$-Catenin nicht oder weniger anstieg als bei alleiniger Behandlung mit rhWnt3a. In (c) zeigte sich kein Unterschied des zellulären $\beta$-Catenins zwischen der ausschließlich mit rhWnt3a behandelten Probe und der gleichzeitig mit rhWnt3a und rhSFRP4 behandelten Probe.

\subsubsection{Expansionskapazität bei Co-Stimulation mit rhWnt3a und rhSFRP4}

Weiterhin wurde die Expansionskapazität von OCl-Ly3-Zellen bei Behandlung mit rhWnt3a und rhSFRP4 untersucht. Über 4 Tage wurden OCI-Ly3-Zellen gezählt, die entweder kein rekombinantes Protein erhielten, ausschließlich rhWnt3a oder eine 
Kombinationsbehandlung aus rhWnt3a und rhSFRP4. Die Behandlung erfolgte einmalig zu Beginn des Versuchs mit einer Konzentration von 1 mg/ml (Abbildung 13).

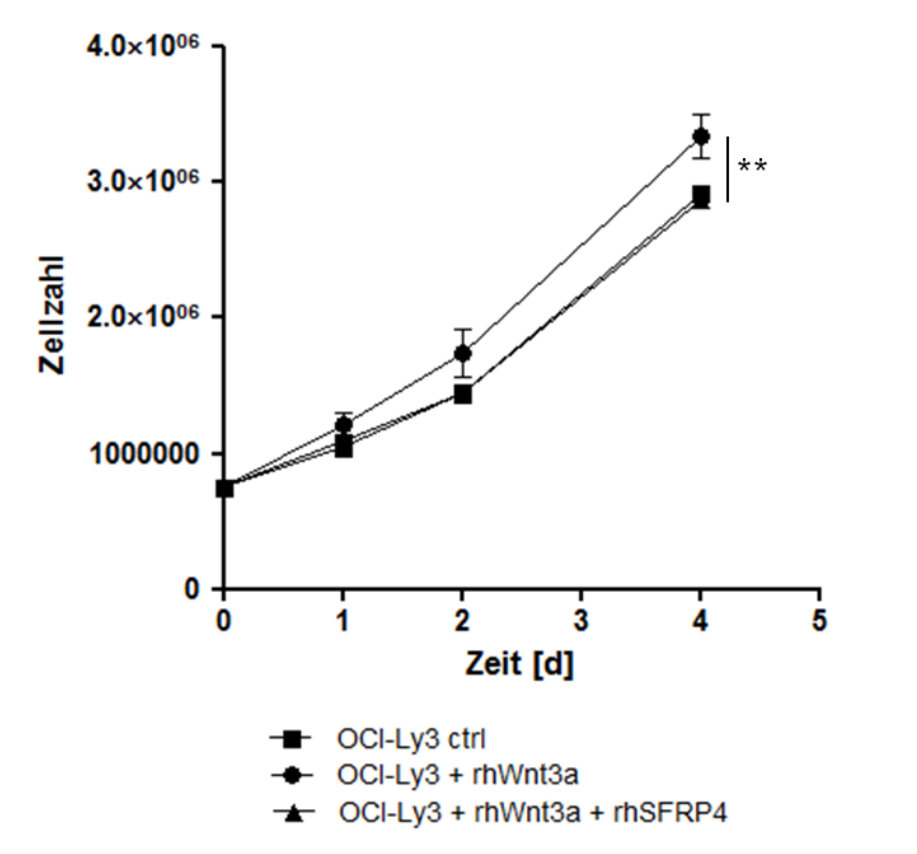

Abbildung 13 Zellvermehrung von OCl-Ly3-Zellen nach Stimulation mit rhWnt3a sowie nach gleichzeitiger Stimulation mit rhWnt3a und rhSFRP4

Die OCI-Ly3-Zellen wurden in Panserin kultiviert und die Behandlung mit rekombinantem Protein erfolgte einmalig zu Beginn des Versuchs in einer Konzentration von $1 \mu \mathrm{g} / \mathrm{ml}$ bei rhWnt3a und rhSFRP4. Die Zählung erfolgte mithilfe der Trypanblau-Färbung.

Nach Gabe von rhWnt3a zeigte sich eine signifikant erhöhte Zellzahlzunahme im Vergleich zur unbehandelten Kontrolle. Nach gleichzeitiger Gabe von rhWnt3a und rhSFRP4 im Sinne einer Co-Stimulation zeigte sich ein im Vergleich zur Kontrolle nicht verändertes Proliferationsverhalten. Two-way ANOVA, Bonferroni-Post test; ${ }^{* *} p<0,01 ; n=3$; Fehlerbalken repräsentieren die Standardabweichung von Triplikaten. Die Signifikanzangabe bezieht sich auf den Vergleich von rhWnt3a-behandelten Zellen und unbehandelter Kontrolle.

Während die mit rhWnt3a stimulierten OCI-Ly3-Zellen nach 4 Tagen eine signifikant erhöhte Zellzahl im Vergleich zur unbehandelten Kontrolle aufwiesen, zeigte sich bei den OCI-Ly3-Zellen, die die Kombinationsbehandlung erhalten hatten, kein Unterschied zur Kontrolle. RhWnt3a führte somit bei der Zelllinie OCI-Ly3 zu einer verstärkten Zellvermehrung, wobei dieser Effekt mittels rhSFRP4 inhibierbar war.

\subsubsection{Beeinflussung der Side Population durch rekombinantes humanes SFRP4}

In Assoziation mit den zuvor gezeigten Expansions-hemmenden Wirkungen wurde die Beeinflussung der Ausprägung einer Side Population in Lymphomzelllinien durch rhSFRP4 adressiert.

Die durchflusszytometrische Analyse nach Hoechst-Färbung von OCl-Ly3-Zellen, die 24 Stunden nach der Zugabe von $1 \mu \mathrm{g}$ rhSFRP4/ml erfolgte, zeigte eine signifikante Reduktion der Side Population im Vergleich zur Kontrolle (Abbildung 14). 
(a)

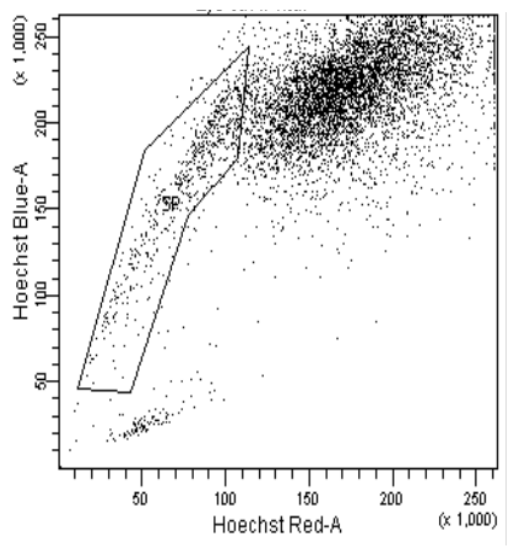

(b)

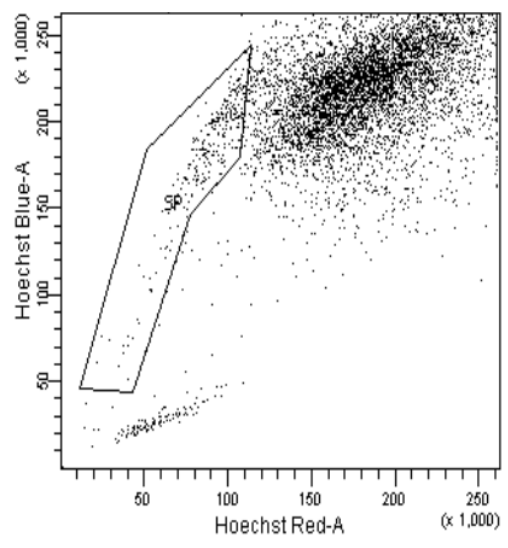

(c)

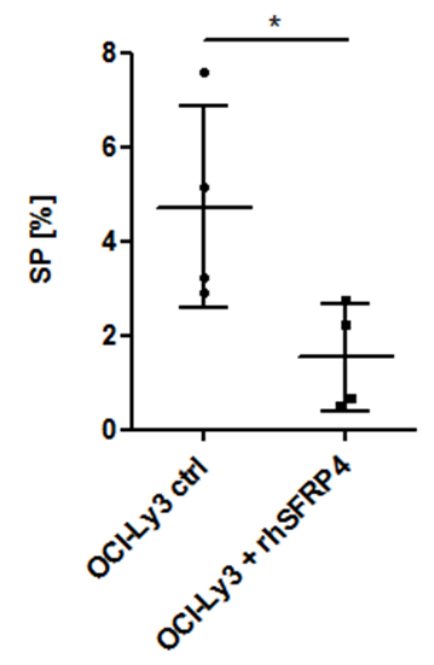

Abbildung 14 Abnahme der Side Population in OCl-Ly3-Zellen nach Behandlung mit rhSFRP4

Durchflusszytometrische Analyse nach Hoechst-Färbung (a) der OCl-Ly3-Zellen (Kontrolle, $0 \mu \mathrm{g} / \mathrm{ml}$ rhSFRP4, Kultivierung in Panserin) und (b) von OCl-Ly3-Zellen, die für $24 \mathrm{~h}$ mit $1 \mu \mathrm{g}$ rhSFRP4/ml in Panserin behandelt worden waren. Im Gate SP befindet sich jeweils die Side Population. (c) zeigt die SP von unbehandelten OCILy3-Zellen im Vergleich zu den mit rhSFRP4 behandelten OCl-Ly3-Zellen für $n=4$. Die Side Population zeigte sich nach rhSFRP4-Behandlung reduziert im Vergleich zur Kontrolle. Unpaired two-sided t-test; * $p<0,05$; $\mathrm{n}=4$; Fehlerbalken repräsentieren die Standardabweichung.

\subsubsection{Funktionelle Untersuchungen an SFRP4-expressionsredu- zierten Zellen}

Zur Untersuchung der Rolle von SFRP4 in der Wachstumsregulation von DLBCL wurde neben rekombinantem humanen SFRP4 eine Expressionsreduktion von SFRP4 hinsichtlich ihrer Wirkung auf Expansionskapazität, Klonogenität und Side Population geprüft.

Zur Herstellung der SFRP4-Expressionsreduktion wurden OCI-Ly1-Zellen mittels lentiviraler shRNA transduziert. Die Expressionsreduktion von SFRP4 in den OCI-Ly1Zellen zeigte sich als effizient bei Vergleich mit den als Kontrolle dienenden OCI-Ly1Zellen, die mit scramble-shRNA transduziert worden waren (Abbildung 15).

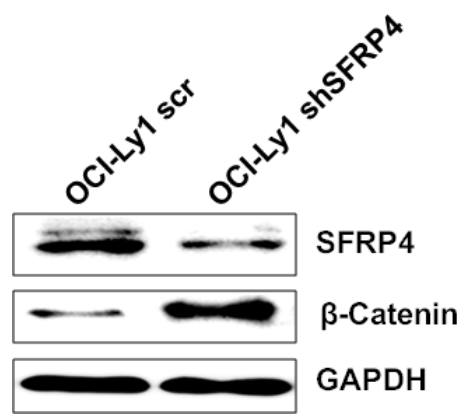

Abbildung 15 Anstieg von zellulärem $\beta$-Catenin in Lymphomzellen nach Expressionsreduktion von SFRP4 
Die effiziente Expressionsreduktion von SFRP4 in OCI-Ly1-Zellen, die mithilfe lentiviraler shRNA erzeugt wurde, ist im Vergleich zu als Kontrolle dienenden OCI-Ly1 scramble-Zellen gezeigt. Die OCI-Ly1 shSFRP4Expressionsreduktion war mit vermehrtem zellulären $\beta$-Catenin im Vergleich zu OCl-Ly1 scramble assoziiert.

\subsubsection{Expansionskapazität von SFRP4-expressionsreduzierten Zellen}

Analog zu den in Kapitel 3.4.1.1. aufgeführten Versuchen wurde die SFRP4Expressionsreduktion zunächst hinsichtlich ihrer Expansionskapazität analysiert. Im Gegensatz zu obigen Versuchen führt die SFRP4-Expressionsreduktion zur Reduzierung eines natürlichen Wnt-Antagonisten, was durch Enthemmung des kanonischen Wnt-Signalwegs zu einer verstärkten Expansion führen kann.

Über 10 Tage erfolgte die manuelle Zählung der SFRP4-expressionsreduzierten OCILy1-Zellen (im folgenden OCl-Ly1 shSFRP4 genannt) sowie der mit scramble-shRNA transduzierten OCl-Ly1-Zellen (im folgenden OCI-Ly1 scr). OCI-Ly1 shSFRP4 zeigte in diesem Versuch eine signifikant gesteigerte Expansion beim Vergleich mit OCl-Ly1scr (Abbildung 16).

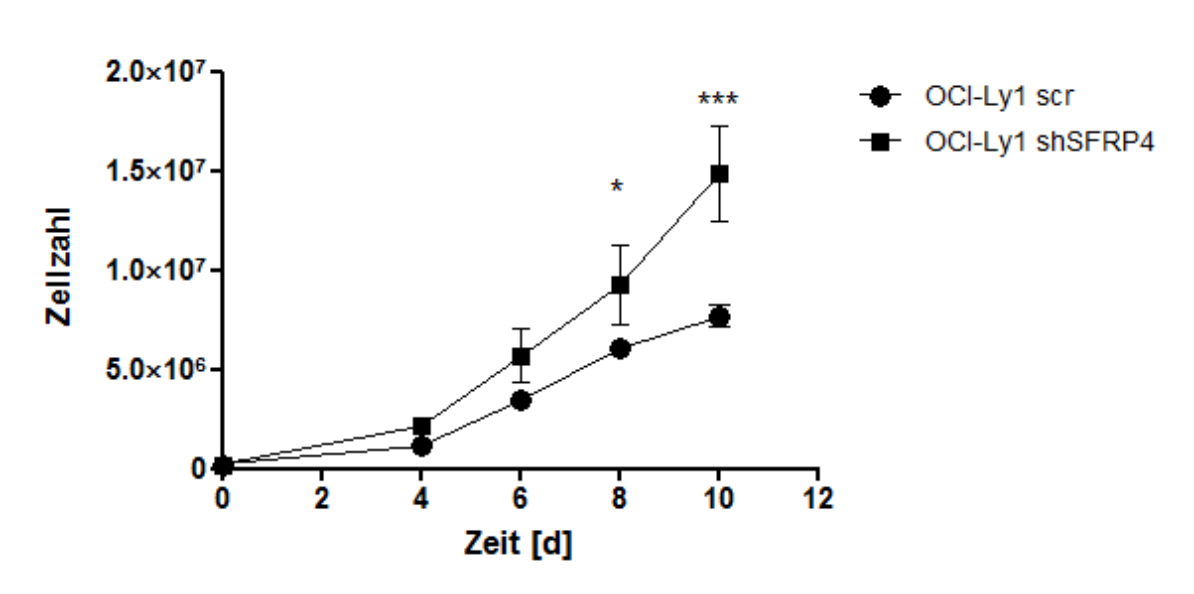

Abbildung 16 Expansionskapazität von OCl-Ly1-Zellen nach Expressionsreduktion von SFRP4

Die Kultivierung der Zellen erfolgte in Panserin, die Zählung mittels Trypanblau-Färbung. Gezeigt ist die gesteigerte Zellzahlzunahme der SFRP4-expressionsreduzierten OCI-Ly1-Zellen im Vergleich zu OCI-Ly1 scramble-Zellen. Two-way ANOVA, Bonferroni-Post test; ${ }^{*} p<0,05$; ${ }^{* *}{ }^{*} p<0,001$; $n=3$; Fehlerbalken repräsentieren die Standardabweichung von Triplikaten; der Versuch wurde 3-mal wiederholt.

\subsubsection{Effekt der SFRP4-Expressionsreduktion auf zelluläres $\beta$ - Catenin}

Um herauszufinden, ob die Expressionsreduktion von SFRP4 die Aktivität des kanonischen Wnt-Signalwegs in den Zellen beeinflusst, wurden OCI-Ly1 shSFRP4Zellen und OCI-Ly1 scr-Zellen bezüglich ihres zellulären $\beta$-Catenin-Gehalts untersucht. Mittels Western Blot zeigte sich, dass in der Expressionsreduktion von 
SFRP4 vermehrt zelluläres $\beta$-Catenin vorlag (Abbildung 15). Dieser Befund belegte die Aktivierung des kanonischen Wnt-Signalwegs durch die Reduktion von SFRP4.

\subsubsection{Zellzyklus und Viabilität der Expressionsreduktion von SFRP4 in OCl-Ly1}

Die erhöhte Expansionskapazität der Lymphomzelllinie OCI-Ly1 nach Expressionssuppression von SFRP4 warf die Frage nach biologischen Grundlagen auf, insbesondere ob die erhöhte Zellexpansion auf einer verstärkten Proliferation im Sinne eines beschleunigten Zellzyklus oder einer erhöhten Viabilität mit reduzierter Apoptose- oder Nekroserate beruhte.

Zur Untersuchung des Zellzyklus wurden OCI-Ly1 shSFRP4-Zellen sowie OCI-Ly1 scr-Zellen für 15min mit Hoechst 33342 inkubiert, um anschließend durchflusszytometrisch am FACSCanto II analysiert zu werden. Dabei zeigte sich bei vergleichender Analyse, dass sich anteilig mehr OCI-Ly1 shSFRP4-Zellen in der Mbzw. in der G2-Phase und entsprechend weniger in der G1-Phase befanden (Abbildung 17).

Zur Bestimmung der Viabiltät wurden die Zellen mit Alexa Fluor® 647 Annexin V und PI inkubiert und anschließend ebenfalls durchflusszytometrisch analysiert. Dabei zeigte sich zwischen OCI-Ly1 scramble-Zellen und OCI-Ly1 shSFRP4-Zellen kein eindeutiger Unterschied hinsichtlich Viabilität und Apoptoserate.

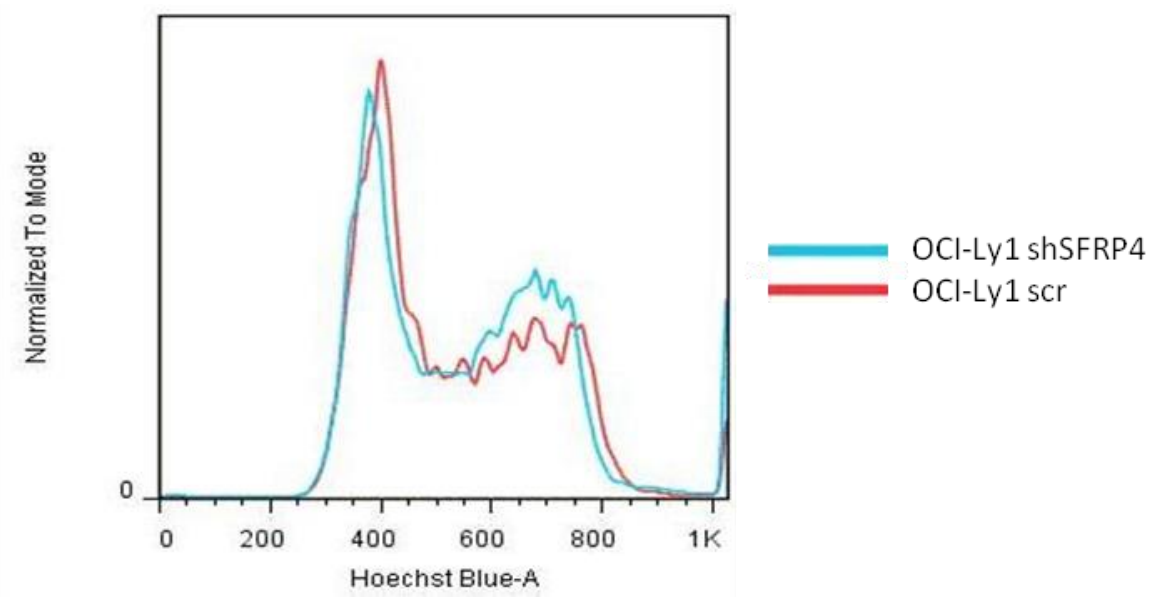

Abbildung 17 Vergleichende Zellzyklusanalyse von OCl-Ly1 shSFRP4-Zellen und OCI-Ly1 scr-Zellen

Nach 15-minütiger Inkubation der OCI-Ly1 shSFRP4- und der OCI-Ly1 scr-Zellen mit Hoechst 33342 wurden diese durchflusszytometrisch hinsichtlich ihrer Hoechst Blue-Emission, die nach Hoechst-Färbung proportional zu ihrem DNA-Gehalt ist, analysiert. Die repräsentative Abbildung zeigt, dass sich von den SFRP4expressionsreduzierten OCl-Ly1-Zellen ein größerer Anteil der Zellen in der M- bzw. G2-Phase befand, verglichen mit den der Kontrolle dienenden OCI-Ly1 scramble-Zellen. Umgekehrtes galt für die G1-Phase. Der Versuch wurde 3-mal wiederholt. 


\subsubsection{Klonogenität der SFRP4-Expressionsreduktion und Antikörper-behandelter Zellen}

Um den Einfluss von SFRP4 auf das klonale Wachstum von OCI-Ly1-Lymphomzellen zu überprüfen, wurde die Fähigkeit zur Koloniebildung in semisolidem Medium der OCI-Ly1 shSFRP4-Zellen und der OCI-Ly1 scr-Zellen im CFU-Assay (engl.: colony forming units) vergleichend überprüft. Hierfür wurden Triplikate mit je $10^{4}$ Zellen in Methylzellulose angelegt und nach 10 Tagen mikroskopisch ausgezählt. Die SFRP4Expressionsreduktion von OCI-Ly1 zeigte nach Abschluss des Versuchs signifikant mehr koloniebildende Einheiten als die zur Kontrolle dienenden OCI-Ly1 scr-Zellen (Abbildung 18).

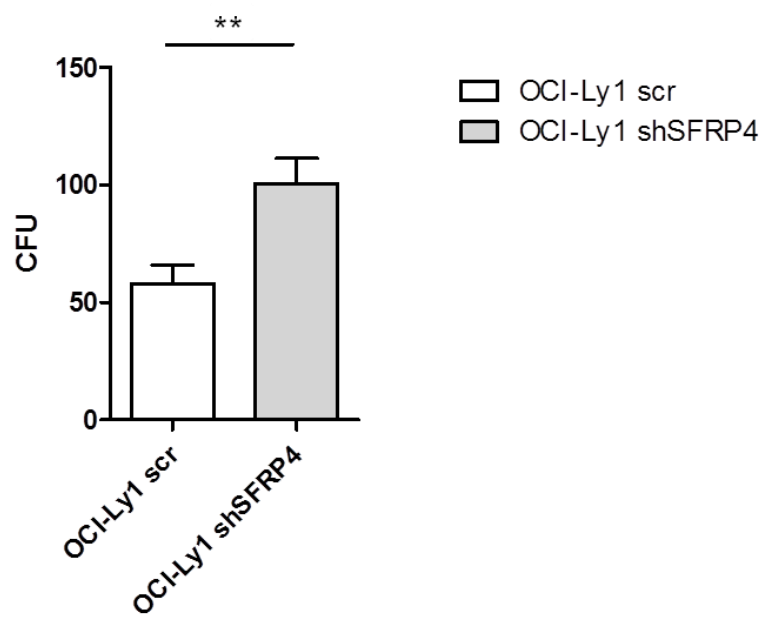

\section{Abbildung 18 Vermehrte CFU-Kapazität von OCI-Ly1 nach Expressionsreduktion von SFRP4}

Jeweils $1 \times 10^{4}$ Zellen der Zellinie OCI-Ly1 wurden in Methylzellulose ausgesät und nach 10 Tagen die Kolonie-bildenden Einheiten (colony forming units (CFU)) ausgezählt. Im Colony-Assay bildete die OCl-Ly1 shSFRP4-Variante mehr CFU als die OCI-Ly1 scramble-Variante. Unpaired two-sided t-test; ${ }^{* \star} p<0,01 ; n=3$; Fehlerbalken repräsentieren die Standardabweichung von Triplikaten; der Versuch wurde 3-mal wiederholt.

Dem Mechanismus einer Expressionsreduktion ähnlich ist die Verwendung eines Antikörpers, dem es gelingt, das entsprechende Protein vor Erreichen seines Ziels zu binden. Entsprechend wurde parallel zur Untersuchung der SFRP4-Expressionsreduktion die Wirkung von anti-SFRP4-Antikörpern untersucht.

Analog zu obigem Versuch wurden je $1 \times 10^{4}$ Zellen in Methylzellulose ausgesät und nach 10 Tagen mikroskopisch ausgezählt. Für beide untersuchten Zelllinien, OCI-Ly3 und OCI-Ly1, wurden Kontrolltriplikate sowie Triplikate, die mit $1 \mu \mathrm{g}$ anti-SFRP4Antikörpern/ml Methylzellulose behandelt wurden, angelegt. Die Auswertung zeigte, dass die mit anti-SFRP4-Antikörpern behandelten Zellen von OCI-Ly1 bzw. von OCILy3 signifikant vermehrt Kolonien bildeten (Abbildung 19). 
(a)

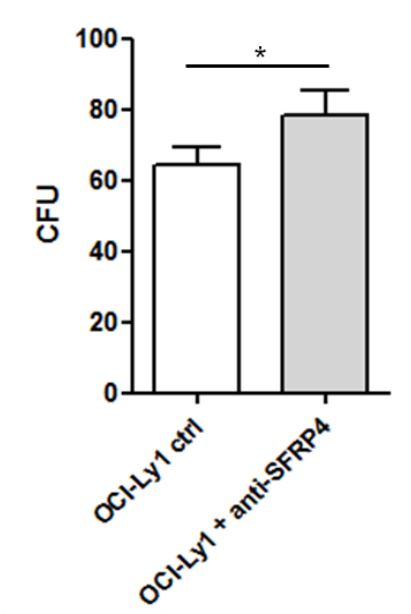

(b)

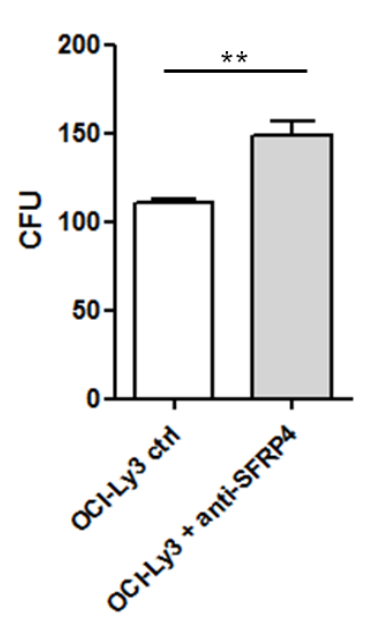

Abbildung 19 Erhöhte CFU-Aktivität von OCI-Ly1- und OCI-Ly3-Zellen bei Behandlung mit anti-SFRP4Antikörpern

Jeweils $1 \times 10^{4}$ Zellen der Zelllinie OCI-Ly1 (a) bzw. OCI-Ly3 (b) wurden in Methylzellulose ausgesät und nach 10 Tagen die colony forming units ausgezählt. Die einmalige Behandlung mit $1 \mu \mathrm{g} / \mathrm{ml}$ anti-SFRP4Antikörpern (R\&D Systems, AF1827) erfolgte zu Beginn des Versuchs. Sowohl OCI-Ly1 (a) als auch OCI-Ly3 (b) bildeten bei Behandlung mit anti-SFRP4-Antikörpern mehr colony forming units im Vergleich zur Kontrolle. Unpaired two-sided t-test; * $p<0,05$, ${ }^{* *} p<0,01 ; n=3$; Fehlerbalken repräsentieren die Standardabweichung von Triplikaten; die Versuche wurden 3-mal wiederholt.

Dieses Ergebnis ist mit dem obigen Versuch zur Koloniebildung nach SFRP4Expressionsreduktion vereinbar. In beiden Versuchen führte eine Reduktion von freiem SFRP4 im Kulturmedium zu einer erhöhten Koloniebildung.

\subsubsection{Die Ausbildung einer Side Population unter SFRP4- Expressionsreduktion}

Weiterhin wurde der Einfluss von SFRP4 auf die Ausprägung von Tumorzellsubpopulationen mit dem Phänotyp einer Side Population analysiert. Die durchflusszytometrische Analyse nach Hoechst-Färbung von OCI-Ly1 shSFRP4Zellen sowie OCI-Ly1 scr-Zellen ergab eine signifikant vergrößerte Side Population nach SFRP4-Expressionsreduktion (Abbildung 20). 
(a)

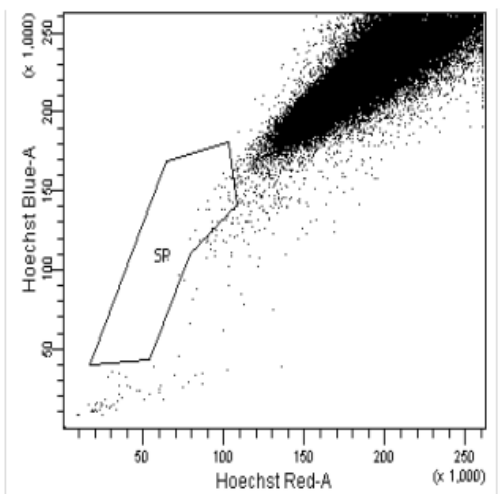

(b)

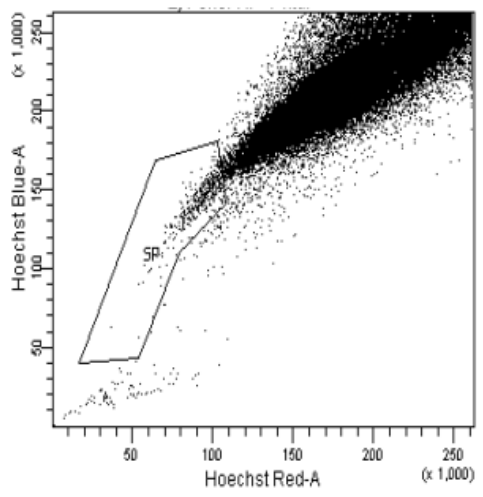

(c)

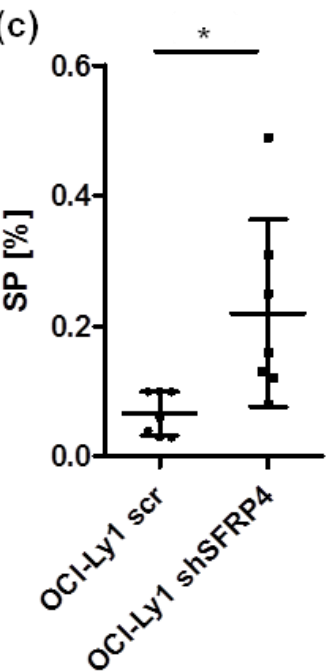

Abbildung 20 Zunahme der Side Population in der Zelllinie OCI-Ly1 nach SFRP4-Expressionsreduktion

Durchflusszytometrische Analyse nach Hoechst-Färbung (a) von OCI-Ly1 scramble-Zellen und (b) von OCILy1 shSFRP4-Zellen. Im Gate SP befindet sich jeweils die Side Population. (c) zeigt die SP von OCI-Ly1 scramble-Zellen im Vergleich zur SP von OCI-Ly1 shSFRP4-Zellen für $n=7$. Die SP der SFRP4expressionsreduzierten OCI-Ly1-Zellen war signifikant vergrößert im Vergleich zur SP der OCI-Ly1 scrambleZellen. Unpaired two-sided t-test; * $\mathrm{p}<0,05 ; \mathrm{n}=7$; Fehlerbalken repräsentieren die Standardabweichung; der Versuch wurde 2-mal wiederholt.

Dieses Ergebnis zeigt in Kombination mit den Versuchen in Abbildung 14, dass SFRP4 an der Regulation der Side Population in DLBCL beteiligt ist. Sowohl die externe Zugabe als auch die Reduktion von SFRP4 auf Transkriptebene beeinflussten den Anteil der Side Population an der Gesamtpopulation.

\subsubsection{In ovo-Passage von OCl-Ly1-Zellen nach SFRP4- Expressionsreduktion}

Um zu prüfen, ob die in der Suspensionskultur gewonnenen Daten auch in vivo gelten, wurden Lymphome der DLBCL-Zellinie OCI-Ly1 in ovo passagiert. Im Unterschied zur Suspensionskultur bilden die Zellen auf der Chorion-AllantoisMembran einen festeren Zellverbund in Interaktion mit der Umgebung.

Hierfür wurden je 4 Eier mit je $3 \times 10^{6}$ Zellen OCl-Ly1 shSFRP4 bzw. OCI-Ly1 scr beimpft. 10 Tage nach dem Beimpfen erfolgten die Lymphomentnahme und die Bestimmung der Tumormasse. Bei gleicher Zellzahl zu Beginn hatten die von OClLy1-Lymphomzellen nach SFRP4-Reduktion ausgehenden Tumoren eine signifikant größere Tumormasse, vereinbar mit einer größeren Expansionskapazität (Abbildung 21). 
(a)

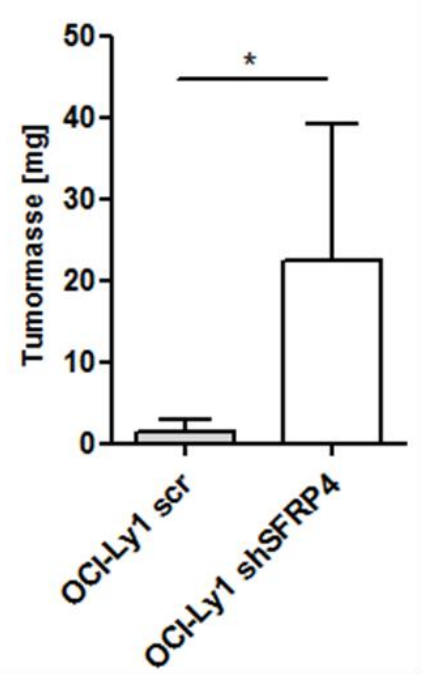

(b)

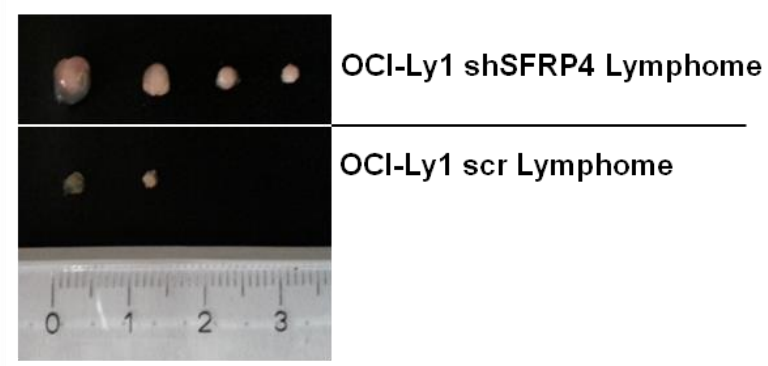

Abbildung 21 Tumormasse von in ovo-passagierten OCl-Ly1 Lymphomen unter SFRP4Expressionsreduktion

Acht Eier wurden jeweils mit $3 \times 10^{6}$ Zellen beimpft, je zur Hälfte mit OCI-Ly1 scramble-Zellen und OCI-Ly1 shSFRP4-Zellen. Die in ovo-Passage erfolgte für 10 Tage. (a) zeigt die vergrößerte Tumormasse bei Lymphomen ausgehend von den OCI-Ly1 shSFRP4-Zellen im Vergleich zu den OCI-Ly1 scramble-Zellen. Unpaired two-sided t-test; * $\mathrm{p}<0,05 ; \mathrm{n}=4$; Fehlerbalken repräsentieren die Standardabweichung. (b) zeigt ein Foto von den aus den Eiern entnommenen Lymphomen und macht den Größenunterschied zwischen den SFRP4-expressionsreduzierten OCI-Ly1-Lymphomen, die größer sind (obere Reihe), und den OCI-Ly1 scramble-Lymphomen (untere Reihe) deutlich.

\subsubsection{Expansionskapazität von OCl-Ly3-Zellen unter Expressions- reduktion von Wnt3a}

Wie oben für die SFRP4-Expressionsreduktion beschrieben, wurden OCI-Ly3-Zellen mit Wnt3a-shRNA-Konstrukten sowie scramble-shRNA-Konstrukten zur Kontrolle transduziert.

Nachdem die Effizienz der Wnt3a-Expressionsreduktion im Western Blot belegt worden war, folgte über 10 Tage die manuelle Zählung der Wnt3aexpressionsreduzierten OCI-Ly3-Zellen (im Folgenden auch: OCI-Ly3 shWnt3a) sowie der mit scramble-shRNA transduzierten OCl-Ly3-Zellen (im Folgenden auch: OCI-Ly3 scr). Die Wnt3a-expressionsreduzierten OCI-Ly3 zeigten eine signifikant verminderte Zellzahlzunahme im Vergleich zur Kontrolle (Abbildung 22). 
(a)

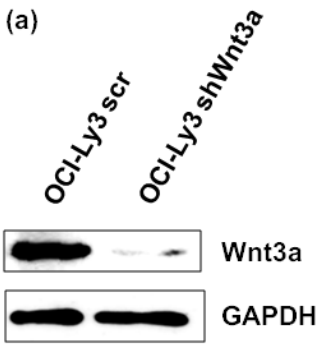

(b)

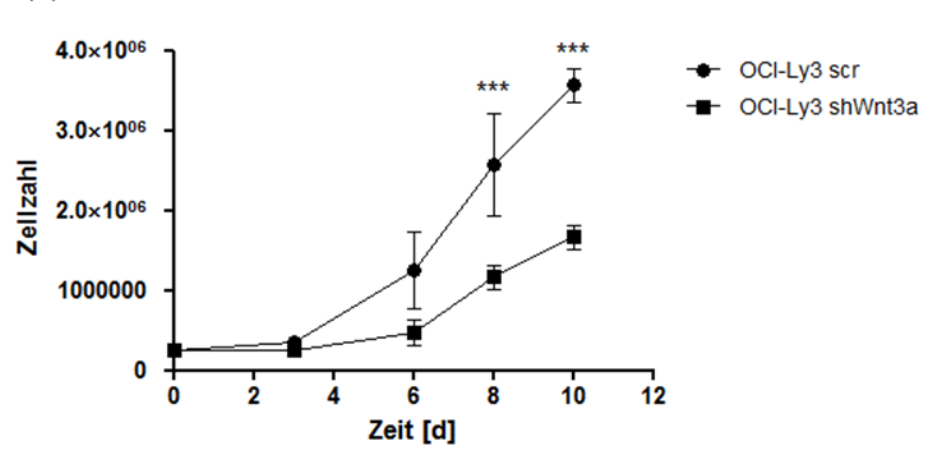

Abbildung 22 Expansionsverhalten von OCl-Ly3-Zellen nach Expressionsreduktion von Wnt3a

In (a) ist die effiziente Expressionsreduktion von Wnt3a in OCI-Ly3 shWnt3a-Zellen im Vergleich zu OCI-Ly3 scramble-Zellen im Western Blot gezeigt. In (b) ist die verminderte Expansionskapazität der Wnt3aexpressionsreduzierten OCI-Ly3-Zellen im Vergleich zu OCl-Ly3 scramble-Zellen zu erkennen. Die Kultivierung der Zellen erfolgte in Panserin, die Zählung mittels Trypanblau-Färbung. Two-way ANOVA, Bonferroni-Post test; ${ }^{* \star *} \mathrm{p}<0,001 ; \mathrm{n}=3$; Fehlerbalken repräsentieren die Standardabweichung von Triplikaten; der Versuch wurde 3-mal wiederholt.

\subsection{Epigenetische Regulation der Expression von SFRP4 in DLBCL}

Die Wnt-Signalwege wurden in verschiedenen Malignomen bereits hinsichtlich ihrer epigenetischen Regulation analysiert. Eine abnorme Methylierung der Genpromotoren von Wnt-Antagonisten als Mechanismus der Signalweg-Aktivierung wurde für verschiedene solide und hämatologische Malignome berichtet (Suzuki et al. 2004; Aguilera et al. 2006; Wang et al. 2013).

Im Rahmen der beschriebenen Vorversuche wurden die DNA-Methylierungsmuster auf Promotorebene der Side Population und der non-Side Population von OCl-Ly3 untersucht. Für SFRP4 waren die Unterschiede der Genmethylierung in Side Population-Zellen und non-Side Population-Zellen signifikant, was als Hinweis für die Bedeutung von SFRP4 bei der Regulation der Subpopulationen gedeutet wurde.

Nachfolgend wurde die Promotor-DNA-Methylierung der beiden in die WntSignalwege involvierten Gene Wnt3a und SFRP4 in den Subpopulationen analysiert. Nach der durchflusszytometrischen Sortierung von OCl-Ly3-Zellen in die beiden Subpopulationen wurde ihre DNA isoliert und mittels Ultraschall fragmentiert. Während je ein Teil der DNA-Fragmente als spätere Positivkontrolle (Input) unbehandelt verblieb, wurden mittels des EpiQuik ${ }^{\mathrm{TM}}$ Methylated DNA Immunoprecipitation (MeDIP) Kits von Epigentek die übrigen DNA-Fragmente weiterbearbeitet (siehe auch 2.4.4 Immunpräzipitation methylierter DNA). Mithilfe von 
gegen methylierte DNA gerichteten Antikörpern wurden diejenigen DNA-Fragmente immunpräzipitiert, die methyliert waren. Nach Wasch- und Ablösevorgängen sollten in dieser Probe ausschließlich noch die methylierten DNA-Anteile vorkommen. Um unspezifische Bindungen des Antikörpers detektieren zu können, wurde gleichzeitig ein Teil der DNA-Fragmente statt mit anti-Methyl-DNA-Antikörpern mit Kontrollantikörpern (murines lgG) inkubiert und als Negativkontrolle verwendet.

Unter Nutzung von Primern, die an CpG-Inseln im Promotor des SFRP4- und des Wnt3a-Gens binden, wurde eine PCR mit den entstandenen Proben der Side Population und der non-Side Population durchgeführt. Zur Veranschaulichung des Ergebnisses wurden die aus der PCR resultierenden DNA-Fragmente auf ein Agarosegel aufgetragen und entsprechend ihrer Größe aufgetrennt (Abbildung 23).

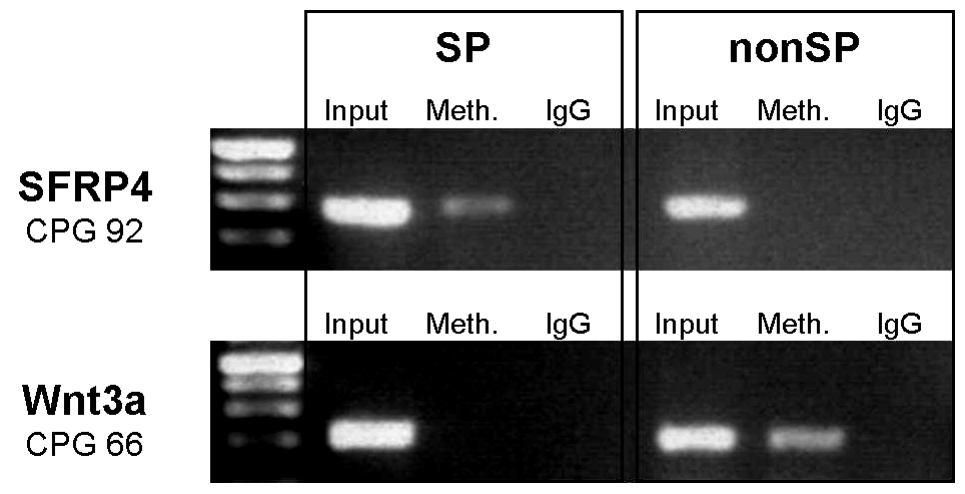

Abbildung 23 Differentielle Promotormethylierung von SFRP4 und Wnt3a in Side Population- und nonSide Population-Zellen

Im Anschluss an die durchflusszytometrische Sortierung von OCI-Ly3-Zellen in Side Population und non-Side Population wurde methylierte DNA immunpräzipitiert (MeDIP). Darauffolgend wurde mittels Primern, die spezifisch gegen CpG-Inseln der Promotorregionen von SFRP4 und Wnt3a gerichtet sind, eine PCR durchgeführt, deren Ergebnis nach Agarose-Gelelektrophorese in der Abbildung zu sehen ist. Die linksseitig abgebildeten SP-Zellen zeigten eine hypermethylierte CpG-Insel 92 des SFRP4-Promotors, während die CpG-Insel 66 des Wnt3a-Promotors hypomethyliert war beim Vergleich mit den nonSP-Zellen.

Sowohl für die Side Population als auch die non-Side Population zeigte sich, dass in der Gesamt-DNA (Positivkontrolle, in Abbildung 23 Input genannt) erwartungsgemäß sowohl Promotorabschnitte des SFRP4-Gens als auch des Wnt3a-Gens zu finden waren. Für die Side Population stellte sich heraus, dass SP-Zellen eine methylierte Promotorregion im SFRP4-Gen besaßen, während diese Region im Wnt3a-Gen bei SP-Zellen unmethyliert war. Im Gegensatz zu den SP-Zellen zeigte mindestens ein Teil der nonSP-Zellen eine methylierte Promotorregion im Wnt3a-Gen, während diese Region im SFRP4-Gen unmethyliert war. Die Negativkontrolle mittels muriner IgGAntikörper enthielt keine DNA-Fragmente, was als Beleg für die Spezifizität der Ergebnisse gewertet wurde. 


\subsubsection{Expansionskapazität und Klonogenität von DLBCL-Zellen unter 5-Azacytidine}

Grundvoraussetzung für den Einsatz eines Chemotherapeutikums in der Therapie ist die Fähigkeit, die Expansionskapazität eines Malignoms zu hemmen. Daher wurde zunächst die Wirkung des demethylierenden Medikaments 5-Azacytdine auf die Expansionskapazität von OCl-Ly3- und OCI-Ly1-Zellen bei Behandlung mit unterschiedlichen Konzentrationen (1 $\mu \mathrm{M}, 2,5 \mu \mathrm{M}, 5 \mu \mathrm{M})$ im Vergleich zur unbehandelten Kontrolle analysiert. Das manuelle Auszählen der Zellen in Suspensionskultur erfolgte über 10 Tage. Da es sich bei 5-Azacytdine um ein instabiles Molekül mit 10\%iger Degradierung in 2 Stunden bei Raumtemperatur handelt (Constantinides et al. 1977), wurde es in der entsprechenden Konzentration alle 2 Tage zugegeben. Sowohl bei den OCl-Ly3-Zellen als auch bei den OCI-Ly1Zellen zeigte sich für die aufgeführten 5-Azacytidine-Konzentrationen $(1 \mu \mathrm{M}, 2,5 \mu \mathrm{M}$, $5 \mu \mathrm{M})$ eine Verminderung der Expansionskapazität, die an Tag 10 für alle Konzentrationen im Vergleich zur Kontrolle signifkant war (Abbildung 24).

(a)

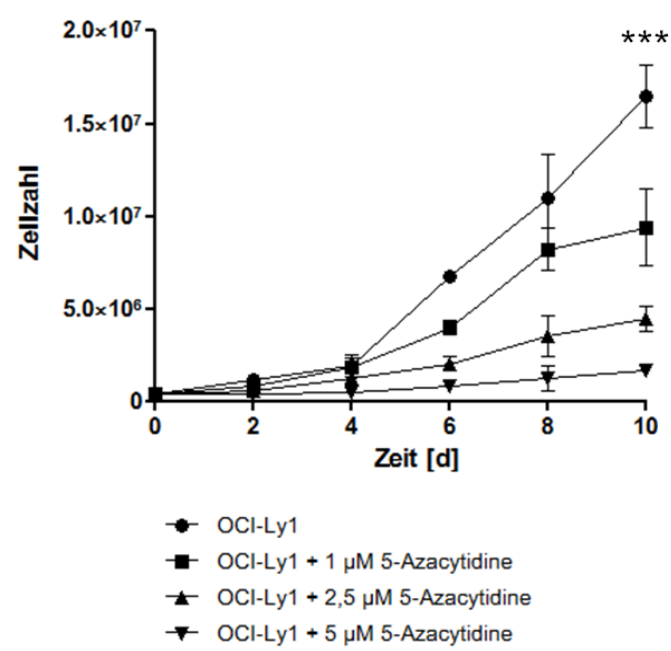

(b)

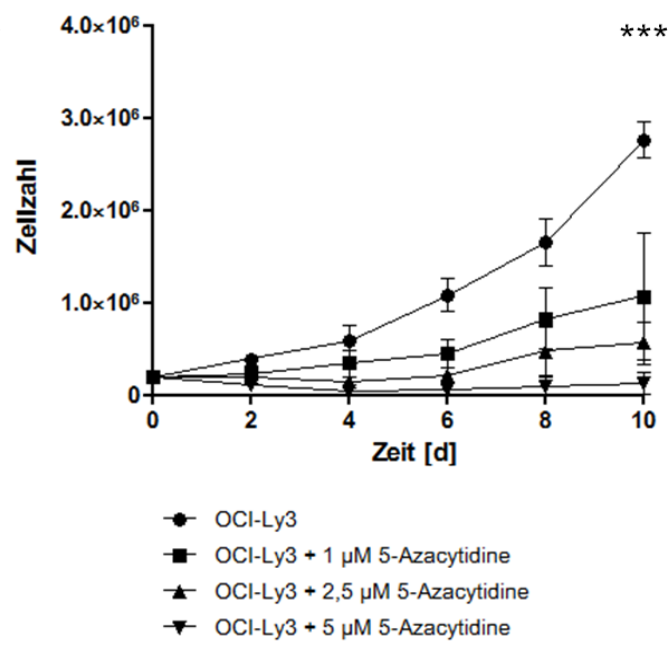

Abbildung 24 Expansionsverhalten von OCl-Ly1- und OCl-Ly3-Zellen unter 5-Azacytidine

Die OCI-Ly1-Zellen (a) und die OCl-Ly3-Zellen (b) wurden in Panserin kultiviert und alle $48 \mathrm{~h}$ mit 5Azacytidine zum Erreichen der angegebenen Endkonzentration behandelt. Die Zählung erfolgte mithilfe der Trypanblau-Färbung.

Für OCl-Ly1 (a) und OCl-Ly3 (b) zeigte sich mit zunehmender Konzentration von 5-Azacytidine eine zunehmende Hemmung des Expansionsverhaltens im Vergleich zur unbehandelten Kontrolle. Two-way ANOVA, Bonferroni-Post test; ${ }^{* * *} p<0,001 ; n=3$; Fehlerbalken repräsentieren die Standardabweichung von Triplikaten; die Versuche wurden 3-mal wiederholt. 
Um die Wirkung von 5-Azacytidine auf die Klonogenität zu untersuchen, wurde ein Kolonie-Versuch mit OCI-Ly3- und OCI-Ly1-Zellen durchgeführt. Aufgrund der starken Wirkung von $5 \mu \mathrm{M}$ 5-Azacytidine bei OCI-Ly3-Zellen wurde auf diese hohe Konzentration verzichtet, während ansonsten die gleichen Bedingungen gewählt wurden wie bei obigem Versuch in der Suspensionskultur. Je $1 \times 10^{4} \mathrm{OCI}-L y 3-Z e l l e n$ bzw. 2,5 x 104 OCl-Ly1-Zellen wurden als Triplikate in Methylzellulose ausgesät und mit den verschiedenen 5-Azacytidine-Konzentrationen behandelt. An Tag 10 beim Auszählen der koloniebildenden Einheiten zeigte sich ein deutlicher Effekt von 5Azacyitdine auf die Klonogenität, der bei den OCl-Ly3-Zellen stärker ausgeprägt war als bei den OCl-Ly1-Zellen (Abbildung 25). Zur Veranschaulichung ist in Abbildung 25c ein Foto der behandelten OCl-Ly3-Zellen abgebildet, auf dem bei der unbehandelten Probe (links) die koloniebildenden Einheiten zahlreich mit bloßem Auge sichtbar sind, während die KBE mit zunehmender Konzentration von 5Azacytidine (rechts) abnehmen.

(a)

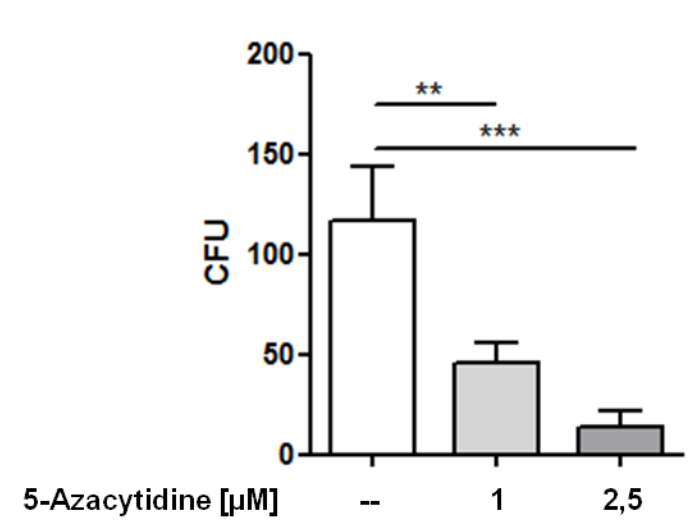

(b)

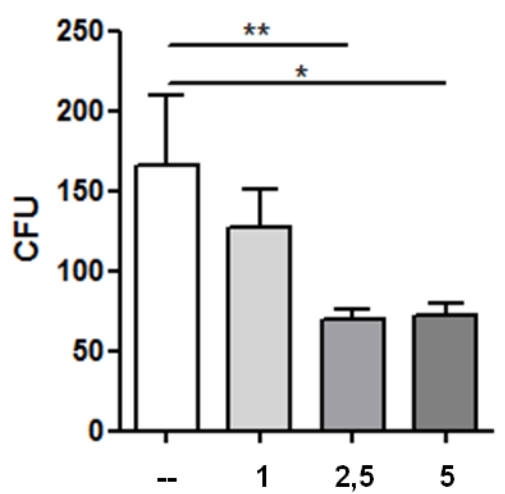

5-Azacytidine $[\mu \mathrm{M}]$ 1 2,5

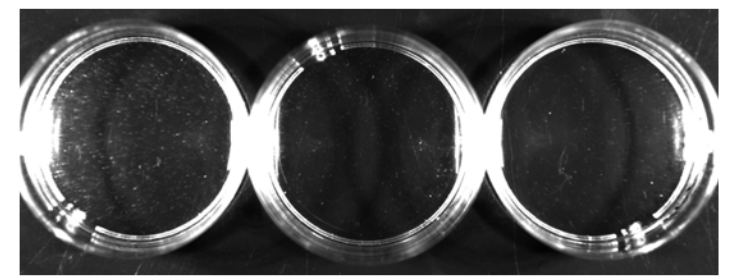

(c)

Abbildung 25 Verminderte Koloniebildung von OCl-Ly1- und OCl-Ly3-Zellen unter 5-AzacytidineBehandlung

Jeweils $1 \times 10^{4}$ Zellen OCI-Ly3 (a) bzw. $2,5 \times 10^{4}$ OCl-Ly1 (b) in Methylzellulose ausgesät und nach 10 Tagen die colony forming units ausgezählt. Die einmalige Behandlung mit 5-Azacytidine erfolgte zu Beginn des Versuchs.

Mit zunehmender Konzentration von 5-Azacytidine zeigt sich eine Verminderung der Anzahl von colony forming units (CFU) bei OCI-Ly3 (a) und bei OCl-Ly1 (b) im Vergleich zur unbehandelten Kontrolle. One-way ANOVA, Bonferroni-Post test; ${ }^{*} p<0,05,{ }^{* *} p<0,01$, ${ }^{* * *} p<0,001 ; n=3$; Fehlerbalken repräsentieren die Standardabweichung von Triplikaten. Bei (c) handelt es sich um ein Foto des in (a) beschriebenen Versuchs und zeigt die Abnahme der Zahl von colony forming units bei steigender 5-Azazytidine-Konzentration. 


\subsubsection{Wirkung von 5-Azacytidine auf den kanonischen Wnt- Signalweg bei DLBCL-Zellen}

Um den Einfluss von 5-Azacytidine auf die Expression von SFRP4 und Wnt3a zu überprüfen, wurden je $5 \times 10^{6}$ OCl-Ly3-Zellen für $72 \mathrm{~h}$ mit 5-Azacytidine in unterschiedlichen Konzentrationen $(0 \mu \mathrm{M}, 1 \mu \mathrm{M}, 2,5 \mu \mathrm{M}$ und $5 \mu \mathrm{M})$ inkubiert. Die Zugabe von 5-Azacytidine erfolgte in entsprechender Konzentration alle 24 Stunden. Nach Herstellung von Gesamtzelllysaten erfolgte die Analyse im Western Blot mittels Antikörpern gegen DNMT1 (Abcam, ab19905), SFRP4 (R\&D Systems, AF1827), $\beta$ Catenin (BD Transduction Laboratories, Klon \# 14) und Wnt3a (R\&D Systems, Klon \# 217804) (siehe Abbildung 26).

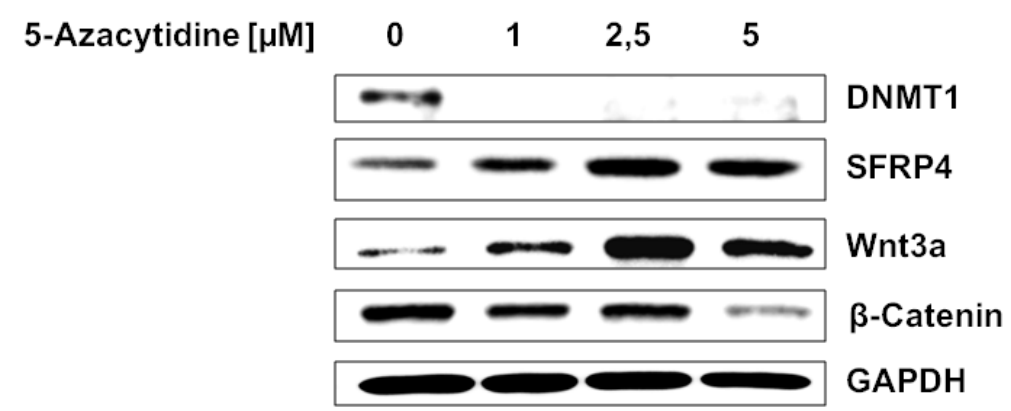

Abbildung 26 DNMT1-, $\beta$-Catenin-, Wnt3a- und SFRP4-Expression in OCl-Ly3-Zellen nach 5Azacytidine-Behandlung

$5 \times 10^{6} \mathrm{OCI}-$ Ly3-Zellen wurden für $72 \mathrm{~h}$ mit 5-Azacytidine in unterschiedlichen Konzentrationen $(0 \mu \mathrm{M}, 1 \mu \mathrm{M}$, $2,5 \mu \mathrm{M}$ und $5 \mu \mathrm{M}$ ) inkubiert. Die 5-Azacytidine-Behandlung erfolgte alle $24 \mathrm{~h}$. Die Analyse mittels Western Blot zeigte die Degradierung von DNMT1, ansteigendes zelluläres SFRP4 und zelluläres Wnt3a sowie sinkendes zelluläres $\beta$-Catenin mit zunehmender Konzentration des demethylierenden Medikaments 5-Azacytidine.

Die Degradierung von DNMT1 belegte die Wirkung von 5-Azacytidine bei dem verwendeten Inkubationsschema. Typischerweise wirkt 5-Azacytidine in niedriger Konzentration eher DNMT1-inhibierend und in höheren Konzentrationen zusätzlich zytotoxisch (Cihak 1974). Aus dem Western Blot ging hervor, dass bereits eine Konzentration von $1 \mu \mathrm{M}$ 5-Azacytidine eine effektive DNMT1-Inhibierung bei OCI-Ly3Zellen erzielt.

5-Azacytidine zeigte in diesem Versuch eine konzentrationsabhängige Wirkung auf mehrere Komponenten des kanonischen Wnt-Signalwegs. Das zelluläre SFRP4 und Wnt3a stiegen mit zunehmender Konzentration an, während das zelluläre $\beta$-Catenin abfiel. 


\subsection{SFRP4 und Exosomen bei DLBCL}

Verschiedene Malignomzellen, unter anderem DLBCL-Zellen, sind in der Lage, Exosomen zu produzieren (Aung et al. 2011; Raposo und Stoorvogel 2013). Weiterhin können Exosomen Wnt-Proteine transportieren und über diese Wnt-Signalwege aktivieren (Gross et al. 2012). Daher galt es, diese Beziehung, insbesondere im Zusammenhang mit SFRP4, an DLBCL-Zelllinien zu untersuchen.

\subsubsection{Wnt3a an der Oberfläche von Exosomen}

Zunächst erfolgte die Exosomenisolierung aus dem Überstand von 1 x $10^{8} \mathrm{OCl}$-Ly3Zellen, die über 72 Stunden in Panserin kultiviert worden waren, wie zuvor beschrieben (Aung et al. 2011). Zum Nachweis, dass die verwendete Methode vornehmlich zur Gewinnung von Exosomen führte, wurde eine Sucrose-GradientenSedimentierung durchgeführt. Die Proben unterschiedlicher Dichte wurden anschließend mittels SDS-Page aufgetrennt und im Western Blot analysiert (Abbildung 27).

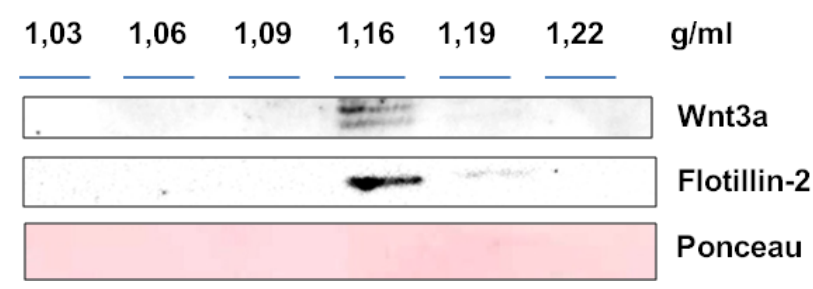

Abbildung 27 Sucrose-Gradienten-Sedimentierung zum Nachweis von Wnt3a in der Exosomenfraktion Im Anschluss an die Exosomenisolierung wurde deren Pellet in 0,25 M Sucroselösung resuspendiert und anschließend auf den Sucrose-Gradienten aufgetragen und für 3 Stunden bei $100.000 \times \mathrm{g}$ zentrifugiert. Nachfolgend wurden die Sedimente im Western Blot mittels Antikörpern gegen Flotillin-2 (BD Transduction Laboratories, Klon \# 29) und Wnt3a (R\&D Systems, Klon \# 217804) analysiert. Bei der für Exosomen charakteristischen Dichte von $1,16 \mathrm{~g} / \mathrm{ml}$ wurden Flotillin-2 und Wnt3a nachgewiesen.

Der Western Blot ergab unter Verwendung von Antikörpern gegen Wnt3a (R\&D Systems, Klon \# 217804) und Flotillin-2 (BD Transduction Laboratories, Klon \# 29) für beide Proteine ein Signal bei dem Sediment der Dichte $1,16 \mathrm{~g} / \mathrm{ml}$. Flotillin-2 gilt als vermehrt in Exosomen angereichertes Protein und damit als Marker für diese Vesikel (Raposo und Stoorvogel 2013). Der Nachweis bei einer Dichte von 1,16 g/ml belegte somit das Vorhandensein von Exosomen spezifischer Dichte (Admyre et al. 2007). Gleichzeitig wurde Wnt3a in dieser Fraktion nachgewiesen, was als Nachweis für die Assoziation von Wnt3a und Exosomen bei DLBCL interpretiert werden konnte. Eine Aussage zur Lagebeziehung von Wnt3a zur Membran ließ sich mithilfe dieses Versuchs nicht treffen. 
Um die Lagebeziehung zu klären, wurde eine Elektronenmikroskopie an Exosomen durchgeführt, die zeigte, dass Wnt3a sich außen an der Exosomenmembran befand (Abbildung 28).

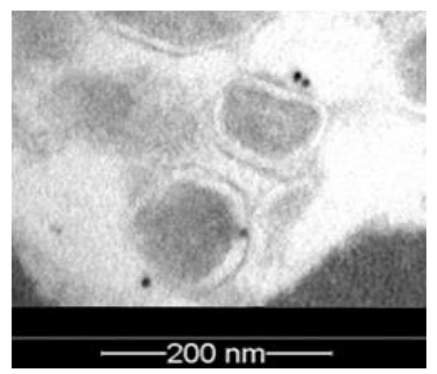

Abbildung 28 Elektronenmikroskopisches Bild von Exosomen mit Wnt3a an deren Oberfläche

Nach der Exosomenisolierung sowie nachfolgender Fixierung erfolgte eine Immunogold-Färbung mit antiWnt3a-Antikörpern (R\&D Systems, Klon \# 217804) und anschließender elektronenmikroskopischer Darstellung. Wnt3a wurde mittels der Gold-Partikel (schwarze Punkte) an der Oberfläche der Exosomenmembran nachgewiesen.

\subsubsection{Vorkommen von SFRP4 und Wnt3a in Mikrovesikel- und Exosomenfraktion}

Ein Vorkommen von SFRP4 in der Exosomenfraktion konnte bereits für mesenchymale Stammzellen gezeigt werden (Lai et al. 2010). Insbesondere durch den Nachweis von Wnt3a auf der Exosomenoberfläche von DLBCL-Zellen war es von Interesse, auch SFRP4 in diesem Zusammenhang zu analysieren. Bei beiden Proteinen handelt es sich um sekretorische Proteine, mit dem Unterschied, dass bei Wnt3a aufgrund der hydrophoben Eigenschaften ein Transport im Extrazellulärraum mittels Carrier-Proteinen oder Vesikeln angenommen wird, während SFRP4 als frei Iösliches Protein gilt (vgl. 1.2.2 Secreted frizzled-related protein 4 (SFRP4)).

Daher wurde eine vergleichende Untersuchung durchgeführt, die neben vesikulären Strukturen auch den Überstand einbezog. Der Versuchsablauf folgte dabei der Beschreibung auf S. 42 (2.2.13 Isolation von Mikrovesikeln und Exosomen) und wurde mit OCl-Ly3-Zellen durchgeführt. Betrachtet wurden dabei sowohl Gesamtzelllysate, Mikrovesikel und Exosomen als auch zu verschiedenen Zeitpunkten entnommene Überstände. Die Mikrovesikel- und Exosomenisolierung erfolgte dabei aus der gleichen Probe, so dass ein quantitativer Vergleich der beiden Fraktionen zulässig war. Die gewonnenen Proben wurden schließlich mittels SDSPage aufgetrennt und im Western Blot analysiert (Abbildung 29). 
(a)

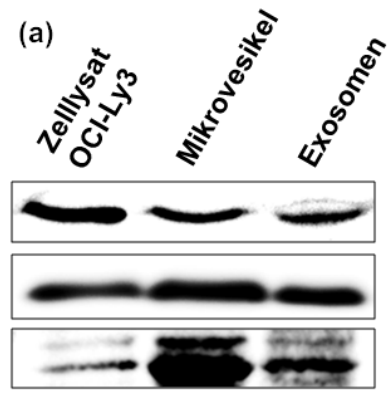

(b)

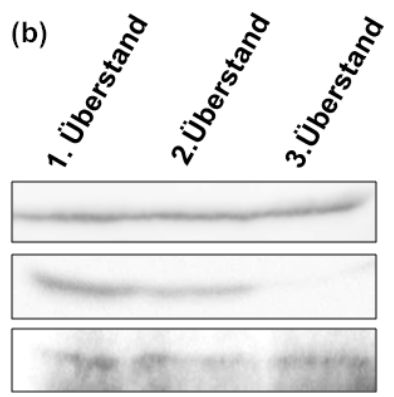

Abbildung 29 SFRP4 und Wnt3a in der Mikrovesikel- und Exosomenfraktion sowie in den Überständen von OCI-Ly3-Zellen

Aus $180 \mathrm{ml}$ Panserin-Überstand von OCI-Ly3-Zellen nach 72-stündiger Kultivierung ohne Mediumwechsel wurden Exosomen und Mikrovesikel mittels Ultrazentrifuge isoliert. Gleichzeitig wurden jeweils $3 \mathrm{ml}$ vom Überstand nach der 1., 2. und 3. Zentrifugation entnommen und mittels Amicon Ultra-Filtern eingeengt. (a) zeigt das Gesamtzelllysat der OCl-Ly3-Zellen neben der Mikrovesikel- und Exosomenfraktion nach Analyse mittels Western Blot. Sowohl SFRP4 als auch Wnt3a waren in den Proben des Gesamtzellysats, der Mikrovesikel und der Exosomen zu finden. In (b) wurden die Überstände aus den verschiedenen Aufreinigungsschritten mittels Western Blot analysiert. SFRP4 und Wnt3a befanden sich in allen Überständen, Wnt3a jedoch nur sehr geringfügig. Flotillin-2 war in Zellysat, Mikrovesikel- und Exosmenfraktion sowie 1. und 2. Überstand zu finden, nicht aber im 3. Überstand.

Sowohl SFRP4 als auch Wnt3a waren in den Proben des Gesamtzelllysats, der Mikrovesikel und der Exosomen zu finden. Für Wnt3a bestätigte sich hierdurch zum einen der zuvor durchgeführte Nachweis von Wnt3a in der Exosomenfraktion. Zum anderen machte der Versuch deutlich, dass Wnt3a im Extrazellulärraum nicht auf die Exosomenfraktion beschränkt ist, sondern mindestens noch im Zusammenhang mit Mikrovesikeln zu finden ist. Dabei zeigte sich ein sehr starkes Wnt3a-Signal in der Mikrovesikelfraktion. SFRP4 wurde ebenso wie Wnt3a im Zusammenhang mit Exosomen und Mikrovesikeln nachgewiesen, wobei aus diesem Versuch nicht hervorging, ob SFRP4 sich innerhalb der vesikulären Strukturen befindet, in die Membran integriert vorliegt oder von außen an das exponierte Wnt3a bindet.

Für die zu verschiedenen Zeitpunkten der Isolierung entnommenen Überstände zeigte sich ein ähnliches Bild. SFRP4 ist in allen Überständen zu finden und dementsprechend auch noch nach Entfernung von Exosomen und Mikrovesikeln im Überstand vorhanden. Für Wnt3a gilt das Gleiche, doch waren die Signale weniger stark ausgeprägt.

Flotillin-2 diente in diesem Versuch als Vesikelmarker zur Abgrenzung von Vesikelfreiem Medium. In allen Proben bis auf den letzten Überstand konnte es nachgewiesen werden. Dieses Ergebnis implizierte, dass nach Isolierung von Exosomen und Mikrovesikeln aus dem entsprechenden Medium das Medium nahezu frei von Vesikeln ist, so dass kein Flotillin-2 mehr nachzuweisen war. 


\subsubsection{Stimulation mit Exosomen vergrößert Side Population}

Der Nachweis von Wnt3a auf Exosomen legte nahe, den Einfluss von Exosomen auf die Regulation der Side Population von Lymphomzelllinien zu untersuchen.

Analog zu den Versuchen mit rhSFRP4 und den SFRP-expressionsreduzierten Zellen wurden hier OCl-Ly3-Zellen, die zuvor mit Exosomen inkubiert worden waren, bezüglich ihrer Ausprägung einer Side Population analysiert. Die isolierten Exosomen wurden hierzu für 24 Stunden auf 1 x $10^{6} \mathrm{OCl}$-Ly3-Zellen in Exosomen-freiem Medium (Panserin) gegeben; als Kontrolle dienten 1 × $10^{6}$ unbehandelte OCl-Ly3Zellen in Exosomen-freiem Medium. Die durchflusszytometrische Analyse nach Hoechst-Färbung der beiden Proben ergab eine signifikant vergrößerte Side Population bei den mit Exosomen stimulierten OCl-Ly3-Zellen (Abbildung 30).

(a)

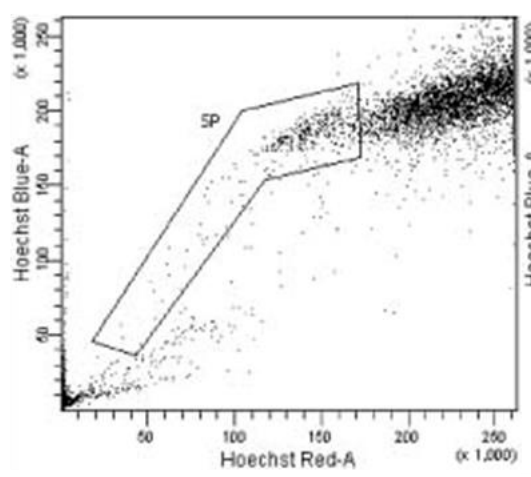

(b)

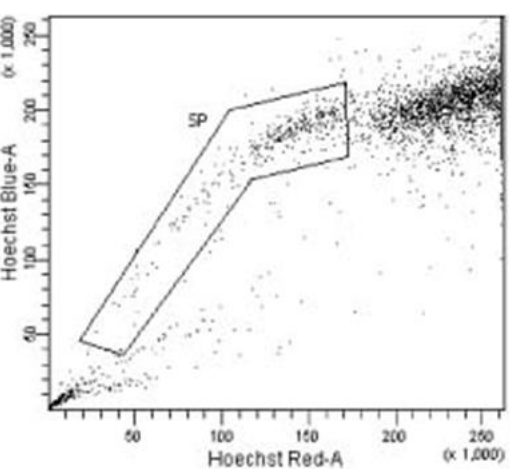

(c)

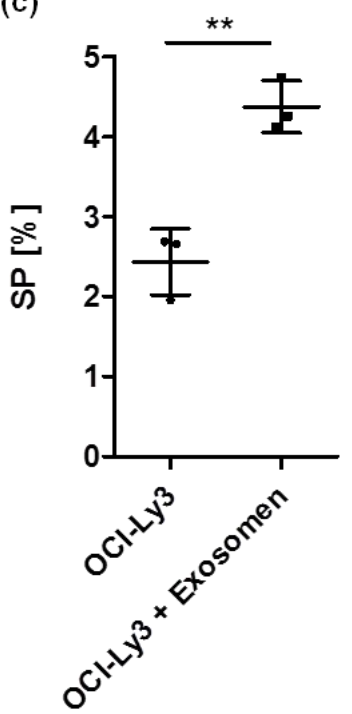

\section{Abbildung 30 Vergrößerte Side Population bei Exosomen-stimulierten OCl-Ly3-Zellen}

Durchflusszytometrische Analyse nach Hoechst-Färbung (a) von unbehandelten OCI-Ly3-Zellen und (b) von OCI-Ly3-Zellen, die für 24 Stunden mit autologen Exosomen stimuliert worden waren. Im Gate SP befindet sich jeweils die Side Population. (c) zeigt die SP von unbehandelten OCI-Ly3-Zellen im Vergleich zur SP von Exosomen-stimulierten OCI-Ly3-Zellen für $n=3$. Die SP der Exosomen-stimulierten OCI-Ly3-Zellen war vergrößert im Vergleich zur SP der unbehandelten OCI-Ly3-Zellen. Unpaired two-sided t-test; ** $p<0,01 ; n=3$; Fehlerbalken repräsentieren die Standardabweichung. 


\section{Diskussion}

Die heterogene Biologie der diffusen großzelligen B-Zell-Lymphome und die daraus resultierenden Differenzen in Therapieansprechen und Prognose stellen ein wesentliches Problem in der aktuellen Therapie von DLBCL dar. Ein besseres Verständnis dieser Heterogenität kann die Grundlage für individualisierte Therapieregime mit besserem Ansprechen bilden.

Anomalien im kanonischen Wnt-Signalweg und seinen natürlichen Antagonisten wie SFRPs sind für verschiedene solide und hämatologische Malignome als wichtiger Bestandteil der Tumorgenese und Tumorprogression identifiziert worden (McMahon und Bradley 1990; Bellei et al. 2004). Für DLBCL liegen aktuell nur wenige Erkenntnisse zur Rolle des kanonischen Wnt-Signalwegs und der SFRPs, im Speziellen SFRP4, vor.

Vorarbeiten unserer Arbeitsgruppe lieferten Hinweise für die Bedeutung von Wnt3a und SFRP4 in der Regulation von DLBCL (Koch et al. 2014). Daher sollte im Rahmen dieser Arbeit untersucht werden, welche Rolle SFRP4 bei der Wachstumsregulation von DLBCL zukommt.

\subsection{Vorkommen von SFRP4 in diffusen großzelligen B-Zell- Lymphomen}

Grundlage für weitere Überlegungen zur Bedeutung von SFRP4 in DLBCL war der Nachweis des zu untersuchenden Proteins in verschiedenen DLBCL-Zelllinien. Dabei konnte sowohl mittels Western Blot als auch in der Immunfluoreszenz gezeigt werden, dass SFRP4 in allen getesteten DLBCL-Zelllinien exprimiert wurde. Deutliche Expressionsunterschiede zwischen den ABC-DLBCL-Zelllinien OCI-Ly3 und U2932 und den GCB-DLBCL-Zelllinien Karpas 422, OCI-Ly1 und SUDHL4 ließen sich nicht nachweisen. Tendenziell zeigten die beiden getesteten ABC-DLBCL-Zelllinien nach Analyse im Western Blot eine höhere Expression von SFRP4 und gleichzeitig auch von $\beta$-Catenin, dem Mediator des kanonischen Wnt-Signalwegs. Für die weiteren Versuche wurden vorzugsweise OCI-Ly3- und OCI-Ly1-Zellen verwendet, um sowohl eine ABC- als auch eine GCB-DLBCL-Zelllinie als Modellzellinien zu analysieren. 


\subsection{Hemmung des Wachstums von DLBCL durch SFRP4}

Wie bereits für andere Malignome nachgewiesen (Horvath et al. 2007; Carmon und Loose 2008), konnte hier gezeigt werden, dass SFRP4 das Wachstum von DLBCLZellinien hemmte. Die Effekte von SFRP4 auf das Wachstumsverhalten wurden in der Suspensionskultur durch Analysen der Zellvermehrung, in Kolonie-Versuchen durch Bestimmung des klonogenen Potenzials, in der durchflusszytometrischen Analyse der Side Population und durch in ovo-Passage von Lymphomen deutlich. Sowohl Versuche unter Verwendung von rekombinantem humanen SFRP4 als auch die Analyse von Zellen, die nach lentiviraler Transduktion eine reduzierte SFRP4Expression aufwiesen, belegten die expansionshemmende Wirkung von SFRP4.

\subsubsection{Hemmung der Expansionskapazität durch SFRP4}

Untersuchungen an OCI-Ly1-Zellen, die eine reduzierte Expression von SFRP4 nach lentiviraler Transduktion aufwiesen, zeigten eine im Vergleich zur Kontrolle verstärkte Zunahme der Zellzahl in der Suspensionskultur, während bei Behandlung mit rekombinantem humanen SFRP4 für OCI-Ly1-Zellen und für OCl-Ly3-Zellen eine verminderte Zunahme der Zellzahl gezeigt werden konnte. Über die Untersuchungen in der Suspensionskultur hinaus konnte für in ovo-passagierte Lymphome der gleiche Effekt für die SFRP4-expressionsreduzierten Zellen belegt werden. Lymphome der SFRP4-Expressionsreduktion hatten eine signifikant größere Masse als jene der Kontrolle.

Zwar lässt sich aus diesem Versuch nicht die Übertragbarkeit auf die in vivo-Situation sichern, dennoch sind die Ergebnisse der in ovo-passagierten Lymphome in Übereinstimmung mit den zuvor in der Suspensionskultur gewonnenen Daten ein Indiz für eine ähnliche in vivo-Situation.

\subsubsection{Reduzierte Klonogenität durch SFRP4}

Kolonie-Versuche mit den SFRP4-expressionsreduzierten OCI-Ly1-Zellen sowie mit nicht modifizierten OCI-Ly1- und OCI-Ly3-Zellen, die mit gegen SFRP4 gerichteten Antikörpern behandelt wurden, zeigten ein erhöhtes klonogenes Potenzial im Vergleich zur Kontrolle. Gemeinsam ist diesen Versuchen, dass eine Reduktion des freien SFRP4 zu einer erhöhten Klonogenität führte. Zu den entscheidenden Eigenschaften von Malignomen gehören ihre Expansionskapazität, im engeren Sinne Zellvermehrung, Zellwachstum und Viabilität der Zellen, sowie die Fähigkeit einzelner 
Zellen, klonal zu expandieren. In dieser Fähigkeit einzelner Tumorzellen klonal zu expandieren, liegt ein zentrales Problem der Behandlung von Tumoren, da diese bei Überleben der Chemotherapie zu einem Rezidiv der Erkrankung führen können (Hirschmann-Jax et al. 2005).

Diese Fähigkeit einzelner Zellen wird ebenso wie die Expansionskapazität durch SFRP4 in DLBCL-Zelllinien und mutmaßlich ebenso in diffusen großzelligen B-ZellLymphomen in vivo eingeschränkt.

\subsubsection{Beeinflussung des zellulären $\beta$-Catenins durch SFRP4}

$\beta$-Catenin als Mediator des kanonischen Wnt-Signalwegs ist an der Proliferationsregulation von Lymphomen maßgeblich beteiligt (Bellei et al. 2004; Groen et al. 2008). Für die SFRP4-Expressionsreduktion konnte neben der erhöhten Expansionskapazität ein erhöhter zellulärer $\beta$-Catenin-Spiegel nachgewiesen werden, der zugleich eine Erklärung für die erhöhte Expansionskapazität bietet. Der erhöhte $\beta$ Catenin-Gehalt der SFRP4-Expressionsreduktion resultiert mutmaßlich aus einer verminderten Bindung von Wnt-Proteinen im Extrazellulärraum durch SFRP4, so dass vermehrt Wnt-Proteine über Frizzled-Rezeptoren den kanonischen Wnt-Signalweg aktivieren können. Somit konnte als eine Ursache für die Effekte des SFRP4 in DLBCL die Veränderung im zellulären $\beta$-Catenin-Gehalt identifiziert werden. Darüber hinaus können auch andere Signalkaskaden durch Veränderungen des zellulären und extrazellulären SFRP4-Gehalts beeinflusst werden, was weiterer Untersuchungen bedarf.

Entgegen den Erwartungen konnte für OCI-Ly1- und OCI-Ly3-Zellen, die mit rhSFRP4 behandelt wurden, keine Veränderung des zellulären $\beta$-Catenin-Gehalts festgestellt werden. Da es sich bei SFRP4 um einen Wnt-Antagonisten handelt, besagte die Hypothese, dass es über eine vermehrte extrazelluläre Bindung von Wnt-Liganden durch SFRP4 zu einer reduzierten Aktivität des Wnt-Signalwegs und somit zu einer Abnahme des aktiven, zellulären $\beta$-Catenin kommen würde. Bei der Suche nach Erklärungen für den konstanten $\beta$-Catenin-Gehalt muss berücksichtigt werden, dass $\beta$-Catenin-Antikörper verwendet wurden, die das gesamte zelluläre $\beta$-Catenin detektieren und nicht ausschließlich das nicht-phosphorylierte, aktive $\beta$-Catenin. Für $\beta$-Catenin wurde in anderen Arbeiten beschrieben, dass es nach der Degradierung dem Abbau in Lysosomen zugeführt wird oder sich als inaktive Ablagerung in Aggresomen befindet (Sukhdeo et al. 2012). Dieses $\beta$-Catenin ist nicht mehr in der 
Lage, nukleäre Transkriptionsfaktoren zu aktivieren, wird aber noch von den verwendeten $\beta$-Catenin-Antikörpern detektiert.

Folgende diskutierbare Erklärungsansätze der unter rhSFRP4-Behandlung konstanten $\beta$-Catenin-Level stehen unter Einbeziehung dieser Kenntnisse im Vordergrund: 1) Das verwendete rhSFRP4 hatte keinen Effekt auf das zelluläre $\beta$ Catenin. 2) Das $\beta$-Catenin wurde degradiert und lag in inaktivem Zustand vor, wurde aber noch von den verwendeten Antikörpern detektiert.

Die erste Variante erscheint jedoch aufgrund des Effektes der alleinigen rhSFRP4Behandlung auf das Expansionsverhalten sowie der Wirkungen der Co-Stimulation mit rhSFRP4 und rhWnt3a unwahrscheinlich. Insbesondere die Beeinflussung des zellulären $\beta$-Catenins durch die Expressionsreduktion mittels lentiviraler Transduktion spricht für die Annahme, dass SFRP4 einen reduzierenden Effekt auf $\beta$-Catenin hat. Bei dieser Versuchsanordnung konnten die oben angenommenen Fehler durch die Wahl der Antikörper nicht entstehen, da die Expressionsreduktion zu einer Zunahme im Sinne einer vermehrten Bereitstellung von $\beta$-Catenin führte. Für eine endgültige Klärung bedarf es der Wiederholung des Versuchs unter Verwendung spezifischer gegen aktives, nicht-phosphoryliertes $\beta$-Catenin gerichteter Antikörper.

\subsubsection{Veränderung der Proliferationseigenschaften durch Expressionsreduktion von SFRP4}

Als biologische Grundlage der gesteigerten Expansionskapazität der SFRP4Expressionsreduktion konnte ein beschleunigter Zellzyklus mit vermehrtem Anteil der Zellen in der G2- bzw. M-Phase nachgewiesen werden. Es kann vermutet werden, dass umgekehrt eine Überexpression bzw. ein vermehrtes Vorhandensein von SFRP4 mit einer verlangsamten Zellvermehrung assoziiert ist.

Da der kanonische Wnt-Signalweg maßgeblich an der Proliferationsregulation von Malignomen beteiligt ist (Groen et al. 2008), lag die Vermutung nahe, dass SFRP4 mittels Beeinflussung des kanonischen Wnt-Signalwegs zu einem veränderten Proliferationsverhalten führt. Diese Vermutung bestätigte sich durch den Nachweis, dass SFRP4 Einfluss auf die Progression des Zellzyklus hat.

\subsection{Interaktion von Wnt3a und SFRP4 in DLBCL}

Aufgrund der Vorbefunde unserer Arbeitsgruppe zur Bedeutung von Wnt3a in der Regulation von DLBCL war es von Interesse, die Interaktion zwischen diesen beiden für DLBCL bedeutenden Proteinen, die in die Wnt-Signalkaskaden involviert sind, 
besser zu verstehen. Über die physikalische Interaktion von Wnt3a und SFRP4 liegen kontroverse Daten vor. Während von Constantinou et al. 2008 eine hohe Affinität der beiden Proteine postuliert wurde, zeigten Carmon und Loose 2010 eine sehr geringe Affinität von SFRP4 und Wnt3a zueinander.

Im Rahmen dieser Arbeit konnte in verschiedenen Untersuchungen gezeigt werden, dass die Behandlung von Zellen mit rhSFRP4 die Effekte von rhWnt3a inhibieren kann. Während die Behandlung von OCI-Ly3- und OCl-Ly1-Zellen mit rhWnt3a zu einem Anstieg des zellulären $\beta$-Catenins führte, reduzierte die gleichzeitige Gabe von rhSFRP4 den Anstieg des zellulären $\beta$-Catenins. Analoges galt für die Effekte auf das Expansionsverhalten: Während rhWnt3a zu einer signifikant gesteigerten Zellvermehrung führte, war zwischen der unbehandelten Kontrolle und einer costimulierten, d.h. zeitgleich mit rhSFRP4 und rhWnt3a behandelten, OCI-Ly3-Probe kein Unterschied hinsichtlich der Zellzahl feststellbar.

Ein Summationseffekt der beiden rekombinanten humanen Proteine ist nahezu ausgeschlossen, da die alleinige rhSFRP4-Gabe in der angegebenen Versuchsanordnung zu keiner Veränderung des zellulären $\beta$-Catenin-Gehalts führte. Mutmaßlich hat das rhSFRP4 das im Extrazellulärraum befindliche rhWnt3a gebunden und verhinderte so die Aktivierung des kanonischen Wnt-Signalwegs. Die verminderte Aktivierung führte wiederum zu dem reduzierten $\beta$-Catenin-Anstieg im Vergleich zur rhWnt3a-behandelten Probe. Da $\beta$-Catenin als Mediator des kanonischen Wnt-Signalwegs an der Proliferationsregulation von Lymphomen beteiligt ist (Groen et al. 2008), kann über den veränderten zellulären $\beta$-Catenin-Gehalt auch das veränderte Proliferationsverhalten unter Stimulation mit rhWnt3a im Vergleich zur co-stimulierten Probe erklärt werden.

Gemäß diesen Überlegungen wurde parallel auch eine Wnt3a-Expressionsreduktion hinsichtlich ihrer Expansionskapazität untersucht. Den Erwartungen entsprechend, dass weniger vorhandenes Wnt3a zu einer reduzierten Aktivierung des kanonischen Wnt-Signalwegs führen könnte, zeigte die Wnt3a-Expressionsreduktion eine reduzierte Expansionskapazität.

Die im Rahmen dieser Arbeit durchgeführten Versuche belegen nicht die physikalische Interaktion wie eine Immunpräzipitation sie demonstrieren könnte, durch die funktionelle Relevanz sind sie dennoch ein starkes Indiz für eine physikalische Assoziation zwischen SFRP4 und Wnt3a. 


\subsection{Die SFRP4-abhängige Regulation der Side Population in DLBCL}

Wie zuvor beschrieben wurde für zahlreiche Malignome eine Side Population nachgewiesen, die entsprechend ihrer erhöhten Exportfähigkeit von Hoechst 33342 mithilfe durchflusszytometrischer Analysen identifiziert werden kann. Vorarbeiten unserer Arbeitsgruppe zeigten für verschiedene DLBCL-Zelllinien die Existenz der Side Population. Eine Besonderheit der Side Population in DLBCL besteht darin, dass DLBCL, die aus Keimzentrums-B-Zellen oder post-Keimzentrumszellen entstehen und somit aus reifen B-Zellen hervorgehen, keinem Stammzellpool angehören. Bisher wurde die Side Population vornehmlich mit Stammzellen und Stammzelleigenschaften in Verbindung gebracht.

\subsubsection{Die exogene und endogene SFRP4-abhängige Beeinfluss- barkeit des SP-Phänotyps}

Die Beeinflussbarkeit des SP-Phänotyps bei OCI-Ly3-Zellen durch rhSFRP4 sowie durch Exosomen belegte dessen exogene Regulierbarkeit. Mutmaßlich haben die Exosomen über den Transport von Wnt-Liganden, z.B. Wnt3a, zu einer Stimulation von Frizzled-Rezeptoren geführt und konnten so über Signalwege, deren Details aktuell unbekannt sind, den SP-Phänotyp induzieren. Ähnliche Überlegungen gelten für die beobachteten Veränderungen bei Stimulation mit rhSFRP4. Möglicherweise hemmte die Zugabe von rhSFRP4 den oben beschrieben Vorgang über extrazelluläre Bindung von Wnt-Liganden, bevor diese ihre Zielrezeptoren erreichen konnten, und die Reduktion der Side Population folgte. Diese Versuche weisen stark darauf hin, dass der SP-nonSP-Switch einer exogenen Regulierbarkeit unterliegt, so dass hier ein möglicher Angriffspunkt für Therapien besteht, die darauf abzielen die besonders chemoresistenten und klonogenen SP-Zellen zu reduzieren.

Dieses Modell der Beeinflussbarkeit des SP-Phänotyps durch Modifikationen im kanonischen Wnt-Signalweg wird weiter bekräftigt durch die Auswirkungen der SFRP4-Expressionsreduktion auf den SP-Phänotyp. Dabei zeigte die SFRP4Expressionsreduktion eine vergrößerte Side Population im Vergleich zur unbehandelten Zelllinie, die sich im Gegensatz zu den zuvor beschriebenen Versuchen als permanent vergrößert präsentierte. Die Erklärung für die permanente Vergrößerung ist am ehesten in der Tatsache zu suchen, dass die Zellen nicht kurz zuvor mit einer Substanz behandelt wurden, sondern eine langfristige Situation nach lentiviraler Transduktion vorlag. Die Bedeutung von SFRP4 und dem kanonischen 
Wnt-Signalweg für die Regulation des SP-Phänotyps wurde hier besonders deutlich, da es sich um einen dauerhaften Zustand durch Expressionsreduktion von SFRP4 handelte.

Wie einleitend beschrieben zeichnen sich die SP-Zellen von DLBCL durch ein hohes klonogenes und repopulatives Potenzial aus. Bei erneuter Betrachtung der Expansionskapazität der SFRP4-Expressionsreduktion und der mit rhSFRP4behandelten Zellen wird deutlich, dass die Ergebnisse der durchflusszytometrischen Analysen konkordant mit dem Expansionsverhalten sind. Die reduzierte Side Population nach rhSFRP4-Behandlung kann zur verminderten Expansionsfähigkeit der Zellen beitragen, während die verstärkte Side Population der SFRP4Expressionsreduktion als eine Ursache der erhöhten Expansionskapazität aufgefasst werden kann.

\subsubsection{Die differentielle Expression und Promotormethylierung von SFRP4 in Side Population und non-Side Population}

Die rein deskriptiven Analysen zur variablen Größe der Side Population wurden durch Untersuchungen ergänzt, die die SFRP4-Genexpression und die SFRP4Promotormethylierung in den SP- und den nonSP-Zellen auf Differenzen prüften.

Für verschiedene DLBCL-Zellinien zeigte sich eine verminderte SFRP4-Expression in Zellen der Side Population. Die Mitwirkung epigenetischer Mechanismen an der Regulation des SP-Phänotyps wurde durch die differentielle DNA-Methylierung in Side Population und non-Side Population von OCI-Ly3-Zellen belegt. Bei kombinierter Betrachtung dieser beiden Analysen zeigten die Side Population-Zellen eine hypermethylierte SFRP4-Promotorregion und geringe SFRP4-Expression, während die non-Side Population-Zellen eine hypomethylierte SFRP4-Promotorregion und hohe SFRP4-Expression aufwiesen.

Schlussfolgernd ergab sich ein klarer Hinweis für die Bedeutung von SFRP4 in der Regulation des SP-Phänotyps. Sowohl die deutlichen Differenzen zwischen Side Population- und non-Side Population-Zellen in Genexpression und Promotormethylierung als auch die Beeinflussbarkeit der Side Population durch Veränderungen im SFRP4-Haushalt der Zelle zeigten die Bedeutsamkeit. 


\subsection{Einsatz des demethylierenden Medikamentes 5-Azacytidine bei DLBCL}

Das Medikament 5-Azacytdine kommt aktuell vor allem in der Behandlung von Patienten mit myelodysplastischem Syndrom und AML klinisch zum Einsatz. Aufgrund seiner DNMT1-inhibierenden Eigenschaft sollte dieses Medikament bei DLBCL evaluiert werden, da bei diesem aggressiven $\mathrm{NHL}$ in $48 \%$ eine Überexpression von DNMT1 beobachtet wurde (Amara et al. 2010). Im Rahmen dieser Arbeit war zudem die differentielle Promotormethylierung von SFRP4 in SPund nonSP-Zellen Anlass für die Testung des demethylierenden Medikamentes 5Azacytidine an DLBCL-Zellen.

Entscheidend für den Einsatz eines Chemotherapeutikums in der Therapie ist seine Fähigkeit, die Expansionskapazität eines Malignoms zu hemmen sowie das klonogene Potenzial zu reduzieren. An der ABC-DLBCL-Zelllinie OCl-Ly3 und der GCB-DLBCL-Zelllinie OCI-Ly1 ließ sich nachweisen, dass 5-Azacytidine in der Lage ist, bereits ab einer Konzentration von $1 \mu \mathrm{M}$ im Zellkulturmedium bzw. in Methylzellulose signifikant die Expansion sowie die Klonogenität der Lymphomzellen zu reduzieren.

Wie zuvor bereits beschrieben wurden die Wnt-Signalwege in einigen Malignomen als epigenetisch auffällig charakterisiert (Suzuki et al. 2004; Ying und Tao 2009). Eine Behandlung mit 5-Azacytidine steigerte bei verschiedenen hämatologischen Neoplasien die Expression von SFRPs im Sinne einer Re-Expression, die zu einer besseren Prognose führen kann (Moskalev et al. 2012).

Die Behandlung mit 5-Azacytidine erhöhte in der DLBCL-Zelllinie OCl-Ly3 konzentrationsabhängig die Menge an zellulärem SFRP4 und Wnt3a, während der zelluläre $\beta$-Catenin-Spiegel fiel. Ob diese Effekte primär auf der demethylierenden oder der zytotoxischen Wirkung von 5-Azacytidine beruhten, konnte nicht identifiziert werden. Da die Veränderungen in den Wnt-Komponenten mit zunehmender Konzentration von 5-Azacytidine zunahmen, während DNMT1 bereits bei $1 \mu \mathrm{M}$ vollständig supprimiert war, ist anzunehmen, dass ein Teil der Effekte auf der zytotoxischen Wirkung des Medikaments beruht oder andere DNAMethyltransferasen, die unberücksichtigt blieben, mitwirkten.

Eine mögliche Erklärung für die Zunahme des zellulären SFRP4 und Wnt3a unter 5Azacytidine-Behandlung liegt in der DNA-Methylierung ihrer Promotoren. Wie gezeigt, 
waren beide Promotorregionen in einer der Subpopulationen verstärkt methyliert, so dass eine Demethylierung zu einem Anstieg der Expression führen kann.

Darüber hinaus könnten zahlreiche Signalwege, die bei der Versuchsanordnung keine Beachtung fanden, über komplexe Interaktionen die verschiedenen WntKomponenten beeinflussen. Hinzu kommen die zytotoxische Wirkung des 5Azacytidine und der resultierende Zellstress, die Einfluss auf die WntSignalwegkaskade nehmen könnten.

Der Abfall des zellulären $\beta$-Catenins in DLBCL-Zellen unter 5-Azacytidine-Behandlung passt gut zu dem im myelodysplastischen Syndrom beobachteten Phänomen, wo $\beta$ Catenin ebenfalls unter 5-Azacytidine abfiel (Wang et al. 2013). Da 5-Azacytidine beim MDS sehr erfolgreich zur Anwendung kommt, ist dies ein vielversprechendes Zeichen für den Einsatz von demethylierenden Medikamenten bei DLBCL.

Letztlich blieb zwar die Ursache der hier gezeigten Wirkungen von 5-Azacytidine unklar, doch die Relevanz der Ergebnisse ist eindeutig: 5-Azacytidine führte zu einer Hemmung der Expansion, einer Reduktion der Klonogenität sowie einer Supprimierung des kanonischen Wnt-Signalwegs.

\subsection{Interzelluläre Kommunikation zwischen DLBCL-Zellen mittels SFRP4, Wnt3a und Exosomen}

Exosomen erlangen aktuell zunehmende Bedeutung in der onkologischen Forschung, insbesondere auch im Zusammenhang mit den Wnt-Signalwegen. Verschiedene Malignomzellen, unter anderem DLBCL-Zellen, sind in der Lage, Exosomen zu produzieren (Aung et al. 2011; Raposo und Stoorvogel 2013). Zudem konnte nachgewiesen werden, dass Exosomen Wnt-Proteine transportieren und über diese Wnt-Signalwege aktivieren können (Gross et al. 2012).

Mittels Sucrose-Gradienten-Sedimentierung und Elektronenmikroskopie konnte im Rahmen dieser Arbeit gezeigt werden, dass Wnt3a sich an der Oberfläche von Exosomen der DLBCL-Zellen befindet. Wie es bereits für mesenchymale Stammzellen gezeigt wurde (Lai et al. 2010), konnte SFRP4 ebenfalls in der Exosomenfraktion von DLBCL-Zellen nachgewiesen werden. Darüber hinaus befanden sich SFRP4 sowie Wnt3a in der Mikrovesikelfraktion und den Überständen. Dabei war eine deutliche Anreicherung von Wnt3a in der Mikrovesikelfraktion festzustellen. 
Sowohl bei Wnt3a als auch bei SFRP4 handelt es sich um sekretorische Proteine, mit dem Unterschied, dass für Wnt3a aufgrund der hydrophoben Eigenschaften ein Transport im Extrazellulärraum mittels Carrier-Proteinen oder Vesikeln angenommen wird, während SFRP4 am ehesten als frei lösliches Protein vorliegt (vgl. 1.2.2 Secreted frizzled-related protein 4 (SFRP4)). Dass Wnt3a sich außerhalb der vesikulären Strukturen auch in den Überständen nachweisen ließ, legte daher die Vermutung nahe, dass es im Extrazellulärraum auch mittels Carrier-Proteinen transportiert wird. In der Konsequenz würde dies bedeuten, dass Wnt3a in der interzellulären Kommunikation von DLBCL über verschiedene Wege seine Zielzellen erreichen kann.

Da eine Aussage über die exakte Lokalisation von SFRP4 in der Exosomenfraktion anhand der durchgeführten Versuche nicht möglich ist, lassen sich über die Zusammenhänge nur Vermutungen anstellen. Weil es sich bei SFRP4 um ein lösliches Protein handelt, könnte dieses beispielsweise das exponierte Wnt3a an der Exosomenoberfläche binden und so transienter Bestandteil der Exosomenfraktion sein. Unter dieser Annahme könnte SFRP4 über die Bindung des Wnt-Liganden zu einer Inhibition des durch die Exosomen übertragenen Signals führen. Zur endgültigen Klärung bedarf es einer elektronenmikroskopischen Aufnahme, die die Lokalisation von Wnt3a und SFRP4 zueinander und im Bezug zur Exosomenmembran darstellt.

Funktionell waren die Exosomen der DLBCL-Zellen in der Lage, eine Aktivierung des kanonischen Wnt-Signalwegs an den Zielzellen auszulösen (Koch et al. 2014) sowie eine Vergrößerung der Side Population hervorzurufen. Im Weiteren wird zu klären sein, inwiefern die Exosomen bei DLBCL zu einer Tumorprogression beitragen. 


\section{Zusammenfassung}

Die heterogene Biologie der diffusen großzelligen B-Zell-Lymphome und die daraus resultierenden Unterschiede in Therapieansprechen und Prognose stellen ein wesentliches Problem in der aktuellen Therapie von DLBCL dar. Anomalien im kanonischen Wnt-Signalweg und seinen natürlichen Antagonisten wie SFRPs sind für verschiedene solide und hämatologische Malignome als wichtige Bestandteile der Tumorgenese und Tumorprogression identifiziert worden (McMahon und Bradley 1990; Bellei et al. 2004). Vorarbeiten unserer Arbeitsgruppe lieferten Hinweise für die Bedeutung von Wnt3a und SFRP4 in der Regulation von DLBCL (Koch et al. 2014). Im Rahmen dieser Arbeit wurde untersucht, welche Rolle dem Protein SFRP4 in der Wachstumsregulation von diffusen großzelligen B-Zell-Lymphomen zukommt.

Die Synthese von SFRP4 wurde in den als Modellzellinien genutzten DLBCLZelllinien nachgewiesen. Unter Verwendung von rekombinantem humanen SFRP4 sowie einer mittels lentiviraler shRNA erzeugten Expressionsreduktion von SFRP4 konnte gezeigt werden, dass SFRP4 zu einer Expansionshemmung sowie zu einer reduzierten Klonogenität bei DLBCL-Zellen führt. Als Ursache für diese Effekte konnte die Inhibition des kanonischen Wnt-Signalwegs durch SFRP4 identifiziert werden.

SFRP4 wurde hinsichtlich seiner Bedeutung für die Ausprägung der Side Population, einer Tumorzellsubpopulation mit repopulativem Potenzial, in DLBCL-Zellen untersucht. Dabei wurde sowohl durch exogene Zugabe als auch durch Reduktion von SFRP4 auf Transkriptebene die Bedeutsamkeit von SFRP4 für die SP-Regulation gezeigt. Untersuchungen zur differentiellen SFRP4-Expression sowie SFRP4Promotormethylierung in Side Population versus non-Side Population wiesen epigenetische Mechanismen in der Regulation des SP-Phänotyps nach. Das DNAdemethylierende Medikament 5-Azacytidine reduzierte in DLBCL-Zelllinien Expansion sowie Klonogenität. Darüber hinaus beeinflusste 5-Azacytidine den kanonischen WntSignalweg und den SFRP4-Gehalt der DLBCL-Zellen.

Die Bedeutung von Exosomen als interzelluläre Kommunikatoren, die Wnt-Proteine transportieren, wurde unter besonderer Berücksichtigung von SFRP4 evaluiert. Sowohl SFRP4 als auch Wnt3a waren in der Exosomen- und der Mikrovesikelfraktion von DLBCL-Zellen nachweisbar. Die Exosomen waren in der Lage, den kanonischen 
Wnt-Signalweg an den Zielzellen zu aktivieren und Einfluss auf die Side Population zu nehmen.

Insgesamt wurde für SFRP4 erstmalig eine hemmende Wirkung auf das Wachstum von DLBCL-Zellen demonstriert. Weiterführende Studien können adressieren, inwiefern die aufgezeigten Mechanismen der Wachstumsmodulation von DLBCLZellen durch SFRP4 in therapeutischen Anwendungen genutzt werden können. 


\section{Literaturverzeichnis}

Admyre C, Johansson SM, Qazi KR, Filen JJ, Lahesmaa R, Norman M, Neve EP, Scheynius A, Gabrielsson S (2007): Exosomes with immune modulatory features are present in human breast milk. J Immunol $\underline{179}$, 1969-1978

Aguilera O, Fraga MF, Ballestar E, Paz MF, Herranz M, Espada J, Garcia JM, Munoz A, Esteller M, Gonzalez-Sancho JM (2006): Epigenetic inactivation of the Wnt antagonist DICKKOPF-1 (DKK-1) gene in human colorectal cancer. Oncogene $\underline{25}$, 4116-4121

Akyurek N, Uner A, Benekli M, Barista I (2012): Prognostic significance of MYC, BCL2, and BCL6 rearrangements in patients with diffuse large B-cell lymphoma treated with cyclophosphamide, doxorubicin, vincristine, and prednisone plus rituximab. Cancer $\underline{118}$, 4173-4183

Alizadeh AA, Eisen MB, Davis RE, Ma C, Lossos IS, Rosenwald A, Boldrick JC, Sabet H, Tran T, Yu X (2000): Distinct types of diffuse large B-cell lymphoma identified by gene expression profiling. Nature $\underline{403}, 503-511$

Amara K, Trimeche M, Ziadi S, Laatiri A, Hachana M, Korbi S (2008): Prognostic significance of aberrant promoter hypermethylation of $\mathrm{CpG}$ islands in patients with diffuse large B-cell lymphomas. Ann Oncol $\underline{19}$, 1774-1786

Amara K, Ziadi S, Hachana M, Soltani N, Korbi S, Trimeche M (2010): DNA methyltransferase DNMT3b protein overexpression as a prognostic factor in patients with diffuse large B-cell lymphomas. Cancer Sci 101, 1722-1730

Amini RM, Berglund $M$, Rosenquist $R$, Von Heideman $A$, Lagercrantz $S$, Thunberg $U$, Bergh J, Sundstrom C, Glimelius B, Enblad G (2002): A novel B-cell line (U-2932) established from a patient with diffuse large B-cell lymphoma following Hodgkin lymphoma. Leuk Lymphoma $\underline{43}$, 2179-2189

Arzneimittelkommission der deutschen Ärzteschaft (2009): Vidaza® (Azacitidin). Zugriff am 3. August 2013 unter https://www.kvwl.de/arzt/verordnung/arzneimittel/info/na/vidaza_ na.pdf.

Aung T, Chapuy B, Vogel D, Wenzel D, Oppermann M, Lahmann M, Weinhage T, Menck K, Hupfeld T, Koch R (2011): Exosomal evasion of humoral immunotherapy in aggressive B-cell lymphoma modulated by ATP-binding cassette transporter A3. Proc Natl Acad Sci U S A $\underline{108}, 15336-15341$

Bafico A, Gazit A, Pramila T, Finch PW, Yaniv A, Aaronson SA (1999): Interaction of frizzled related protein (FRP) with Wnt ligands and the frizzled receptor suggests alternative mechanisms for FRP inhibition of Wnt signaling. J Biol Chem 274, 1618016187

Bakhoum SF, Danilova OV, Kaur P, Levy NB, Compton DA (2011): Chromosomal instability substantiates poor prognosis in patients with diffuse large B-cell lymphoma. Clin Cancer Res $\underline{17}$, 7704-7711

Bard MP, Hegmans JP, Hemmes A, Luider TM, Willemsen R, Severijnen LA, van Meerbeeck JP, Burgers SA, Hoogsteden HC, Lambrecht BN (2004): Proteomic analysis of 
exosomes isolated from human malignant pleural effusions. Am J Respir Cell Mol Biol $\underline{31}$, 114-121

Baumgarten A, Marks R, Denz U, Finke J: Hochmaligne Non-Hodgkin-Lymphome. In: Das Rote Buch - Hämatologie und internistische Onkologie; hrsg. v. Berger DP, Engelhardt R, Mertelsmann R u.a.; Ecomed Medizin, Landsberg/Lech 2013, 695-698

Bavi P, Uddin S, Bu R, Ahmed M, Abubaker J, Balde V, Qadri Z, Ajarim D, Al-Dayel F, Hussain AR (2011): The biological and clinical impact of inhibition of NF-kappaB-initiated apoptosis in diffuse large B cell lymphoma (DLBCL). J Pathol 224, 355-366

Bellei B, Pacchiarotti A, Perez M, Faraggiana T (2004): Frequent beta-catenin overexpression without exon 3 mutation in cutaneous lymphomas. Mod Pathol $\underline{17}$, 12751281

Bhagwat AS, Roberts RJ (1987): Genetic analysis of the 5-azacytidine sensitivity of Escherichia coli K-12. J Bacteriol 169, 1537-1546

Botchkina G (2012): Colon cancer stem cells - From basic to clinical application. Cancer Lett $\underline{338}, 127-140$

Brock A, Chang $\mathrm{H}$, Huang S (2009): Non-genetic heterogeneity--a mutation-independent driving force for the somatic evolution of tumours. Nat Rev Genet 10, 336-342

Carmon KS, Loose DS (2008): Secreted frizzled-related protein 4 regulates two Wnt7a signaling pathways and inhibits proliferation in endometrial cancer cells. Mol Cancer Res 6, $1017-1028$

Carmon KS, Loose DS (2010): Development of a bioassay for detection of Wnt-binding affinities for individual frizzled receptors. Anal Biochem 401, 288-294

Cazzola M, Malcovati L (2005): Myelodysplastic syndromes--coping with ineffective hematopoiesis. N Engl J Med 352, 536-538

Chaffer CL, Brueckmann I, Scheel C, Kaestli AJ, Wiggins PA, Rodrigues LO, Brooks M, Reinhardt F, Su Y, Polyak K (2011): Normal and neoplastic nonstem cells can spontaneously convert to a stem-like state. Proc Natl Acad Sci U S A $\underline{108}, 7950-7955$

Chang H, Blondal JA, Benchimol S, Minden MD, Messner HA (1995): p53 mutations, cmyc and bcl-2 rearrangements in human non-Hodgkin's lymphoma cell lines. Leuk Lymphoma $\underline{19}$, 165-171

Christman JK (2002): 5-Azacytidine and 5-aza-2'-deoxycytidine as inhibitors of DNA methylation: mechanistic studies and their implications for cancer therapy. Oncogene 21, 5483-5495

Cihak A (1974): Biological effects of 5-azacytidine in eukaryotes. Oncology $\underline{30}$, 405-422

Cihak A, Vesely J (1978): Effects of 5-aza-2'-deoxycytidine on DNA synthesis in mouse lymphatic tissues. Neoplasma $\underline{25}, 385-393$

Constantinides PG, Jones PA, Gevers W (1977): Functional striated muscle cells from non-myoblast precursors following 5-azacytidine treatment. Nature 267, 364-366 
Constantinou T, Baumann F, Lacher MD, Saurer S, Friis R, Dharmarajan A (2008): SFRP4 abrogates Wnt-3a-induced beta-catenin and Akt/PKB signalling and reverses a Wnt-3aimposed inhibition of in vitro mammary differentiation. J Mol Signal $\underline{3}, 10$

Dave BJ, Nelson M, Pickering DL, Chan WC, Greiner TC, Weisenburger DD, Armitage JO, Sanger WG (2002): Cytogenetic characterization of diffuse large cell lymphoma using multi-color fluorescence in situ hybridization. Cancer Genet Cytogenet 132, 125-132

Davis RE, Ngo VN, Lenz G, Tolar P, Young RM, Romesser PB, Kohlhammer H, Lamy L, Zhao H, Yang $Y$ (2010): Chronic active B-cell-receptor signalling in diffuse large B-cell lymphoma. Nature $\underline{463}, 88-92$

Denzer K, Kleijmeer MJ, Heijnen HF, Stoorvogel W, Geuze HJ (2000): Exosome: from internal vesicle of the multivesicular body to intercellular signaling device. J Cell Sci 113 3365-3374

Deutsche Gesellschaft für Hämatologie und Medizinische Onkologie e.V. (2012): Onkopedia Leitlinie DLBCL. Zugriff am 21. Juli 2014 unter https://www.dghoonkopedia.de/de/onkopedia/leitlinien/diffuses-grosszelliges-b-zell-lymphom.

Deutsche Gesellschaft für Hämatologie und Medizinische Onkologie e.V. (2013): Onkopedia Leitlinie Myelodysplastisches Syndrom. Zugriff am 9. September 2013 unter https://www.dgho-onkopedia.de/de/onkopedia/leitlinien/mds.

Dick JE, Lapidot T (2005): Biology of normal and acute myeloid leukemia stem cells. Int J Hematol 82, 389-396

Dyer MJ, Fischer P, Nacheva E, Labastide W, Karpas A (1990): A new human B-cell nonHodgkin's lymphoma cell line (Karpas 422) exhibiting both $t(14 ; 18)$ and $t(4 ; 11)$ chromosomal translocations. Blood $\underline{75}, 709-714$

Epstein AL, Herman MM, Kim H, Dorfman RF, Kaplan HS (1976): Biology of the human malignant lymphomas. III. Intracranial heterotransplantation in the nude, athymic mouse. Cancer $\underline{37}, 2158-2176$

Fenaux P, Mufti GJ, Hellstrom-Lindberg E, Santini V, Gattermann N, Germing U, Sanz G, List AF, Gore S, Seymour JF (2010): Azacitidine prolongs overall survival compared with conventional care regimens in elderly patients with low bone marrow blast count acute myeloid leukemia. J Clin Oncol 28, 562-569

Ford CE, Jary E, Ma SS, Nixdorf S, Heinzelmann-Schwarz VA, Ward RL (2013): The Wnt gatekeeper SFRP4 modulates EMT, cell migration and downstream Wnt signalling in serous ovarian cancer cells. PLoS One $\underline{8}$, e54362

Freedman AS, Aster JC (2012): Epidemiology, clinical manifestations, pathologic features, and diagnosis of diffuse large B cell lymphoma. Zugriff am 23. Juli 2013 unter http://www.uptodate.com/contents/epidemiology-clinical-manifestations-pathologicfeatures-and-diagnosis-of-diffuse-large-b-cell-lymphoma.

Gardiner-Garden M, Frommer M (1987): CpG islands in vertebrate genomes. J Mol Biol $\underline{196}, 261-282$

Ge X, Lv X, Feng L, Liu X, Wang X (2012): High expression and nuclear localization of beta-catenin in diffuse large B-cell lymphoma. Mol Med Rep $\underline{5}, 1433-1437$ 
Goodell MA, Rosenzweig M, Kim H, Marks DF, DeMaria M, Paradis G, Grupp SA, Sieff CA, Mulligan RC, Johnson RP (1997): Dye efflux studies suggest that hematopoietic stem cells expressing low or undetectable levels of CD34 antigen exist in multiple species. Nat Med $\underline{3}, 1337-1345$

Green TM, Young KH, Visco C, Xu-Monette ZY, Orazi A, Go RS, Nielsen O, Gadeberg OV, Mourits-Andersen T, Frederiksen M (2012): Immunohistochemical double-hit score is a strong predictor of outcome in patients with diffuse large B-cell lymphoma treated with rituximab plus cyclophosphamide, doxorubicin, vincristine, and prednisone. J Clin Oncol $\underline{30}, 3460-3467$

Groen RW, Oud ME, Schilder-Tol EJ, Overdijk MB, ten Berge D, Nusse R, Spaargaren M, Pals ST (2008): Illegitimate WNT pathway activation by beta-catenin mutation or autocrine stimulation in T-cell malignancies. Cancer Res $\underline{68}, 6969-6977$

Gross JC, Boutros M (2013): Secretion and extracellular space travel of Wnt proteins. Curr Opin Genet Dev 23, 385-390

Gross JC, Chaudhary V, Bartscherer K, Boutros M (2012): Active Wnt proteins are secreted on exosomes. Nat Cell Biol 14, 1036-1045

He X, Semenov M, Tamai K, Zeng X (2004): LDL receptor-related proteins 5 and 6 in Wnt/beta-catenin signaling: arrows point the way. Development 131, 1663-1677

Hirschmann-Jax C, Foster AE, Wulf GG, Goodell MA, Brenner MK (2005): A distinct "side population" of cells in human tumor cells: implications for tumor biology and therapy. Cell Cycle 4, 203-205

Hood JL, San RS, Wickline SA (2011): Exosomes released by melanoma cells prepare sentinel lymph nodes for tumor metastasis. Cancer Res $\underline{71}$, 3792-3801

Horning SJ, Rosenberg SA (1984): The natural history of initially untreated low-grade nonHodgkin's lymphomas. N Engl J Med $\underline{311}$, 1471-1475

Horvath LG, Lelliott JE, Kench JG, Lee CS, Williams ED, Saunders DN, Grygiel JJ, Sutherland RL, Henshall SM (2007): Secreted frizzled-related protein 4 inhibits proliferation and metastatic potential in prostate cancer. Prostate $\underline{67}, 1081-1090$

Howe LR, Brown AM (2004): Wnt signaling and breast cancer. Cancer Biol Ther $\underline{3}$, 36-41

Hrzenjak A, Tippl M, Kremser ML, Strohmeier B, Guelly C, Neumeister D, Lax S, Moinfar F, Tabrizi AD, Isadi-Moud N (2004): Inverse correlation of secreted frizzled-related protein 4 and beta-catenin expression in endometrial stromal sarcomas. J Pathol 204, 19-27

Hsieh JC, Rattner A, Smallwood PM, Nathans J (1999): Biochemical characterization of Wnt-frizzled interactions using a soluble, biologically active vertebrate Wnt protein. Proc Natl Acad Sci U S A 96, 3546-3551

Jackson-Grusby L, Laird PW, Magge SN, Moeller BJ, Jaenisch R (1997): Mutagenicity of 5-aza-2'-deoxycytidine is mediated by the mammalian DNA methyltransferase. Proc Natl Acad Sci U S A $\underline{94}, 4681-4685$

Jair KW, Bachman KE, Suzuki H, Ting AH, Rhee I, Yen RW, Baylin SB, Schuebel KE (2006): De novo CpG island methylation in human cancer cells. Cancer Res $\underline{66}, 682-692$ 
Jehan Z, Siraj AK, Abubaker J, Ruiz C, Simon R, Sultana M, Uddin S, Bavi P, Hussain A, Razack S (2008): Distinct gene expression profiles: nodal versus extranodal diffuse large B-cell lymphoma. Oncology $\underline{75}, 71-80$

Jeltsch A (2006): Molecular enzymology of mammalian DNA methyltransferases. Curr Top Microbiol Immunol $\underline{301}$, 203-225

Jho EH, Zhang T, Domon C, Joo CK, Freund JN, Costantini F (2002): Wnt/betacatenin/Tcf signaling induces the transcription of Axin2, a negative regulator of the signaling pathway. Mol Cell Biol 22, 1172-1183

Jin J, Morse M, Frey C, Petko J, Levenson R (2010): Expression of GPR177 (Wntless/Evi/Sprinter), a highly conserved Wnt-transport protein, in rat tissues, zebrafish embryos, and cultured human cells. Dev Dyn 239, 2426-2434

Jones PL, Veenstra GJ, Wade PA, Vermaak D, Kass SU, Landsberger N, Strouboulis J, Wolffe AP (1998): Methylated DNA and MeCP2 recruit histone deacetylase to repress transcription. Nat Genet $\underline{19}$, 187-191

Jones SE, Jomary C (2002): Secreted Frizzled-related proteins: searching for relationships and patterns. Bioessays $\underline{24}, 811-820$

Kalac M, Scotto L, Marchi E, Amengual J, Seshan VE, Bhagat G, Ulahannan N, Leshchenko VV, Temkin AM, Parekh S (2011): HDAC inhibitors and decitabine are highly synergistic and associated with unique gene-expression and epigenetic profiles in models of DLBCL. Blood 118, 5506-5516

Kaplan LD (2012): HIV-associated lymphoma. Best Pract Res Clin Haematol 25, 101-117

Kim W, Kim M, Jho EH (2013): Wnt/beta-catenin signalling: from plasma membrane to nucleus. Biochem J $\underline{450}, 9-21$

Kinzler KW, Vogelstein B (1996): Lessons from hereditary colorectal cancer. Cell $\underline{87}, 159-$ 170

Knippers R: Molekulare Genetik. 9. Auflage; Thieme, Stuttgart 2006

Koch R, Demant M, Aung T, Diering N, Cicholas A, Chapuy B, Wenzel D, Lahmann M, Guntsch A, Kiecke C (2014): Populational equilibrium through exosome-mediated Wnt signaling in tumor progression of diffuse large B-cell lymphoma. Blood $\underline{123}$, 2189-2198

Koivula S, Valo E, Raunio A, Hautaniemi S, Leppa S (2011): Rituximab regulates signaling pathways and alters gene expression associated with cell death and survival in diffuse large B-cell lymphoma. Oncol Rep 25, 1183-1190

Lai RC, Arslan F, Lee MM, Sze NS, Choo A, Chen TS, Salto-Tellez M, Timmers L, Lee CN, El Oakley RM (2010): Exosome secreted by MSC reduces myocardial ischemia/reperfusion injury. Stem Cell Res $\underline{4}, 214-222$

Lee SM, Lee EJ, Ko YH, Lee SH, Maeng L, Kim KM (2009): Prognostic significance of O6-methylguanine DNA methyltransferase and p57 methylation in patients with diffuse large B-cell lymphomas. Apmis $\underline{117}, 87-94$

Lee TT, Karon MR (1976): Inhibition of protein synthesis in 5-azacytidine-treated HeLa cells. Biochem Pharmacol 25, 1737-1742 
Lenz G, Wright G, Dave SS, Xiao W, Powell J, Zhao H, Xu W, Tan B, Goldschmidt N, lqbal J (2008): Stromal gene signatures in large-B-cell lymphomas. N Engl J Med $\underline{359}$, 2313-2323

Linderoth J, Eden P, Ehinger M, Valcich J, Jerkeman M, Bendahl PO, Berglund M, Enblad G, Erlanson M, Roos G (2008): Genes associated with the tumour microenvironment are differentially expressed in cured versus primary chemotherapy-refractory diffuse large Bcell lymphoma. Br J Haematol 141, 423-432

Lu LJ, Chiang GH, Randerath K (1980): Effects of 5-azacytidine on transfer RNA modification: comparative study on normal and malignant tissues. Life Sci 27, 577-584

Maganga R, Giles N, Adcroft K, Unni A, Keeney D, Wood F, Fear M, Dharmarajan A (2008): Secreted Frizzled related protein-4 (sFRP4) promotes epidermal differentiation and apoptosis. Biochem Biophys Res Commun $\underline{377}$, 606-611

Mahdi T, Hanzelmann S, Salehi A, Muhammed SJ, Reinbothe TM, Tang Y, Axelsson AS, Zhou Y, Jing X, Almgren P (2012): Secreted frizzled-related protein 4 reduces insulin secretion and is overexpressed in type 2 diabetes. Cell Metab $\underline{16}, 625-633$

Martelli M, Ferreri AJ, Agostinelli C, Di Rocco A, Pfreundschuh M, Pileri SA (2013): Diffuse large B-cell lymphoma. Crit Rev Oncol Hematol 87, 146-171

Marusyk A, Polyak K (2010): Tumor heterogeneity: causes and consequences. Biochim Biophys Acta $\underline{1805}, 105-117$

McMahon AP, Bradley A (1990): The Wnt-1 (int-1) proto-oncogene is required for development of a large region of the mouse brain. Cell $\underline{62}, 1073-1085$

Montecalvo A, Larregina AT, Shufesky WJ, Stolz DB, Sullivan ML, Karlsson JM, Baty CJ, Gibson GA, Erdos G, Wang Z (2012): Mechanism of transfer of functional microRNAs between mouse dendritic cells via exosomes. Blood $\underline{119}$, 756-766

Moskalev EA, Luckert K, Vorobjev IA, Mastitsky SE, Gladkikh AA, Stephan A, Schrenk M, Kaplanov KD, Kalashnikova OB, Potz O (2012): Concurrent epigenetic silencing of wnt/beta-catenin pathway inhibitor genes in B cell chronic lymphocytic leukaemia. BMC Cancer $\underline{12}, 213$

Muley A, Majumder S, Kolluru GK, Parkinson S, Viola H, Hool L, Arfuso F, Ganss R, Dharmarajan A, Chatterjee S (2010): Secreted frizzled-related protein 4: an angiogenesis inhibitor. Am J Pathol 176, 1505-1516

Nakamura N, Abe M (2003): Richter syndrome in B-cell chronic lymphocytic leukemia. Pathol Int $\underline{53}, 195-203$

Nakanishi R, Akiyama H, Kimura H, Otsuki B, Shimizu M, Tsuboyama T, Nakamura T (2008): Osteoblast-targeted expression of Sfrp4 in mice results in low bone mass. J Bone Miner Res $\underline{23}$, 271-277

Niehrs C (2012): The complex world of WNT receptor signalling. Nat Rev Mol Cell Biol $\underline{13}$, 767-779

Nusse R, Varmus H (2012): Three decades of Wnts: a personal perspective on how a scientific field developed. Embo J $\underline{31}, 2670-2684$ 
Ok CY, Papathomas TG, Medeiros LJ, Young KH (2013): EBV-positive diffuse large B-cell lymphoma of the elderly. Blood 122, 328-340

Peveling-Oberhag J, Arcaini L, Hansmann ML, Zeuzem S (2013): Hepatitis C-associated B-cell non-Hodgkin lymphomas. Epidemiology, molecular signature and clinical management. J Hepatol $\underline{59}, 169-177$

Pinson KI, Brennan J, Monkley S, Avery BJ, Skarnes WC (2000): An LDL-receptor-related protein mediates Wnt signalling in mice. Nature $\underline{407}, 535-538$

Polakis P (2012): Wnt signaling in cancer. Cold Spring Harb Perspect Biol $\underline{4}$, ohne Seitenangabe

Ponce RA, Gelzleichter T, Haggerty HG, Heidel S, Holdren MS, Lebrec H, Mellon RD, Pallardy M (2013): Immunomodulation and lymphoma in humans. J Immunotoxicol 11, 112

Prokhortchouk E, Hendrich B (2002): Methyl-CpG binding proteins and cancer: are MeCpGs more important than MBDs? Oncogene 21, 5394-5399

Ranheim EA, Kwan HC, Reya T, Wang YK, Weissman IL, Francke U (2005): Frizzled 9 knock-out mice have abnormal B-cell development. Blood 105, 2487-2494

Raposo G, Stoorvogel W (2013): Extracellular vesicles: exosomes, microvesicles, and friends. J Cell Biol 200, 373-383

Reya T, O'Riordan M, Okamura R, Devaney E, Willert K, Nusse R, Grosschedl R (2000): Wnt signaling regulates $B$ lymphocyte proliferation through a LEF-1 dependent mechanism. Immunity $\underline{13}, 15-24$

Saran U, Arfuso F, Zeps N, Dharmarajan A (2012): Secreted frizzled-related protein 4 expression is positively associated with responsiveness to cisplatin of ovarian cancer cell lines in vitro and with lower tumour grade in mucinous ovarian cancers. BMC Cell Biol $\underline{13}$, 25

Savina A, Fader CM, Damiani MT, Colombo MI (2005): Rab11 promotes docking and fusion of multivesicular bodies in a calcium-dependent manner. Traffic $\underline{6}, 131-143$

Schilham MW, Wilson A, Moerer P, Benaissa-Trouw BJ, Cumano A, Clevers HC (1998): Critical involvement of Tcf-1 in expansion of thymocytes. J Immunol $\underline{161}$, 3984-3991

Schumann H, Holtz J, Zerkowski HR, Hatzfeld M (2000): Expression of secreted frizzled related proteins 3 and 4 in human ventricular myocardium correlates with apoptosis related gene expression. Cardiovasc Res $\underline{45}, 720-728$

Sena-Esteves M, Saeki Y, Camp SM, Chiocca EA, Breakefield XO (1999): Single-step conversion of cells to retrovirus vector producers with herpes simplex virus-Epstein-Barr virus hybrid amplicons. J Virol $\underline{73}, 10426-10439$

Sheldahl LC, Slusarski DC, Pandur P, Miller JR, Kuhl M, Moon RT (2003): Dishevelled activates Ca2+ flux, PKC, and CamKII in vertebrate embryos. J Cell Biol 161, 769-777

Smith A, Howell D, Patmore R, Jack A, Roman E (2011): Incidence of haematological malignancy by sub-type: a report from the Haematological Malignancy Research Network. Br J Cancer 105, 1684-1692 
Staudt LM, Dent AL, Shaffer AL, Yu X (1999): Regulation of lymphocyte cell fate decisions and lymphomagenesis by BCL-6. Int Rev Immunol $\underline{18}$, 381-403

Sukhdeo K, Mani M, Hideshima T, Takada K, Pena-Cruz V, Mendez G, Ito S, Anderson KC, Carrasco DR (2012): beta-catenin is dynamically stored and cleared in multiple myeloma by the proteasome-aggresome-autophagosome-lysosome pathway. Leukemia $\underline{26}, 1116-1119$

Suzuki H, Watkins DN, Jair KW, Schuebel KE, Markowitz SD, Chen WD, Pretlow TP, Yang B, Akiyama Y, Van Engeland M (2004): Epigenetic inactivation of SFRP genes allows constitutive WNT signaling in colorectal cancer. Nat Genet $\underline{36}, 417-422$

Taylor KH, Briley A, Wang Z, Cheng J, Shi H, Caldwell CW (2013): Aberrant epigenetic gene regulation in lymphoid malignancies. Semin Hematol $\underline{50}, 38-47$

Teshima K, Nara M, Watanabe A, Ito M, Ikeda S, Hatano Y, Oshima K, Seto M, Sawada K, Tagawa H (2013): Dysregulation of BMI1 and microRNA-16 collaborate to enhance an anti-apoptotic potential in the side population of refractory mantle cell lymphoma. Oncogene $\underline{33}, 2191-2203$

Ting AH, Jair KW, Schuebel KE, Baylin SB (2006): Differential requirement for DNA methyltransferase 1 in maintaining human cancer cell gene promoter hypermethylation. Cancer Res $\underline{66}, 729-735$

Tweeddale M, Jamal N, Nguyen A, Wang XH, Minden MD, Messner HA (1989): Production of growth factors by malignant lymphoma cell lines. Blood $\underline{74}, 572-578$

Wang H, Fan R, Wang XQ, Wu DP, Lin GW, Xu Y, Li WY (2013): Methylation of Wnt antagonist genes: a useful prognostic marker for myelodysplastic syndrome. Ann Hematol 92, 199-209

Wawrzak D, Metioui M, Willems E, Hendrickx M, de Genst E, Leyns L (2007): Wnt3a binds to several sFRPs in the nanomolar range. Biochem Biophys Res Commun 357 , $1119-1123$

Willert K, Brown JD, Danenberg E, Duncan AW, Weissman IL, Reya T, Yates JR, 3rd, Nusse R (2003): Wnt proteins are lipid-modified and can act as stem cell growth factors. Nature $\underline{423}, 448-452$

Wong SC, Lo SF, Lee KC, Yam JW, Chan JK, Wendy Hsiao WL (2002): Expression of frizzled-related protein and Wnt-signalling molecules in invasive human breast tumours. $\mathrm{J}$ Pathol $\underline{196}, 145-153$

Wu CH, Nusse R (2002): Ligand receptor interactions in the Wnt signaling pathway in Drosophila. J Biol Chem 277, 41762-41769

Wulf GG, Wang RY, Kuehnle I, Weidner D, Marini F, Brenner MK, Andreeff M, Goodell MA (2001): A leukemic stem cell with intrinsic drug efflux capacity in acute myeloid leukemia. Blood $\underline{98}, 1166-1173$

Xu Y, Banerjee D, Huelsken J, Birchmeier W, Sen JM (2003): Deletion of beta-catenin impairs T cell development. Nat Immunol $\underline{4}, 1177-1182$

Yang SH, Li SL, Dong ZM, Kan QC (2012): Epigenetic inactivation of Wnt inhibitory factor1 in human esophageal squamous cell carcinoma. Oncol Res $\underline{20}, 123-130$ 
Ying Y, Tao Q (2009): Epigenetic disruption of the WNT/beta-catenin signaling pathway in human cancers. Epigenetics 4, 307-312

Yoo CB, Jones PA (2006): Epigenetic therapy of cancer: past, present and future. Nat Rev Drug Discov $\underline{5}, 37-50$

Zitvogel L, Regnault A, Lozier A, Wolfers J, Flament C, Tenza D, Ricciardi-Castagnoli P, Raposo G, Amigorena S (1998): Eradication of established murine tumors using a novel cell-free vaccine: dendritic cell-derived exosomes. Nat Med $\underline{4}, 594-600$

Die Ergebnisse der vorliegenden Arbeit wurden bis zum jetzigen Zeitpunkt publiziert in:

Koch R, Demant M, Aung T, Diering N, Cicholas A, Chapuy B, Wenzel D, Lahmann M, Guntsch A, Kiecke C (2014): Populational equilibrium through exosome-mediated Wnt signaling in tumor progression of diffuse large B-cell lymphoma. Blood $\underline{123}, 2189-$ 2198 


\section{Danksagung}

Mein herzlicher Dank gilt meinem Doktorvater Prof. Dr. med. G. G. Wulf und meinem Betreuer Dr. Raphael Koch für die Bereitstellung des Themas und die hervorragende Betreuung, ohne die mir die Fertigstellung der vorliegenden Arbeit nicht möglich gewesen wäre. Ich bedanke mich für die anregenden Diskussionen und unterstützenden Denkanstöße. Insbesondere hervorheben möchte ich auch die umfangreiche methodische Ausbildung durch Dr. Raphael Koch, durch die ich ein breites Spektrum zell- und molekularbiologischer Methoden erlernen konnte.

Ich bedanke mich bei Prof. Dr. med. L. Trümper für die Integration in die Klinik für Hämatologie und Medizinische Onkologie.

Ebenfalls möchte ich mich bei den MTAs Sabrina Becker, Doris Krause, Christina Kiecke und Ursula Sinzig sowie bei den Doktoranden Daniel Vogel, Thiha Aung und Martin Demant bedanken, die wesentlich zu meiner Grundausbildung im Labor beigetragen haben und mich allzeit freundlich und kollegial unterstützten.

Ich bedanke mich herzlich bei Herrn Dr. rer. nat. Dirk Wenzel für die Herstellung der elektronenmikroskopischen Bilder. 